NILSON TAZAWA

\title{
Modelagem da dor utilizando-se redes neurais artificiais
}




\section{Modelagem da dor utilizando-se redes neurais artificiais}

Dissertação apresentada à Escola Politécnica da Universidade de São Paulo para a obtenção do título de Mestre em Engenharia Elétrica.

Área de concentração: Microeletrônica

Orientador: Prof. Dr. João Francisco Justo Filho

São Paulo

2006 


\section{FICHA CATALOGRÁFICA}

Tazawa, Nilson

Modelagem da dor utilizando-se redes neurais artificiais / $\mathrm{N}$. Tazawa. -- São Paulo, 2006.

$110 \mathrm{p}$.

Dissertação (Mestrado) - Escola Politécnica da Universidade de São Paulo. Departamento de Engenharia de Sistemas Eletrônicos.

1.Dor 2.Redes neurais 3.Modelagem matemática I.Universidade de São Paulo. Escola Politécnica. Departamento de Engenharia de Sistemas Eletrônicos II.t. 
Aos meus amigos e familiares, pelo grande apoio dado durante a realização deste trabalho. 


\section{AGRADECIMENTOS}

Ao professor Dr. João Francisco Justo Filho, meu orientador, pela atenção e apoio durante todo o processo de definição e orientação, contribuindo para o desenvolvimento deste trabalho e conseqüentemente para o meu progresso científico e intelectual.

Ao professor Dr. Francisco Javier Ramirez Fernandez, pelo conhecimento, incentivo e sugestões oferecidas que contribuíram em muito no refinamento deste trabalho.

Ao professor Javier Ropero Pelaéz, pela motivação inicial dada sobre o tema durante a disciplina PTC5713.

À Escola Politécnica da Universidade de São Paulo, pela oportunidade de realização do curso de mestrado.

À minha família, aos meus amigos e à minha namorada, pelo apoio incondicional proporcionado durante a realização deste trabalho. 


\section{RESUMO}

TAZAWA, N. Modelagem da dor utilizando-se redes neurais artificiais. 2006. Dissertação (Mestrado) - Escola Politécnica, Universidade de São Paulo, São Paulo, 2006.

Este trabalho apresenta os resultados obtidos na elaboração de dois modelos para o fenômeno da dor utilizando-se redes neurais artificiais, de forma a simular computacionalmente as prováveis respostas de um indivíduo na presença de dor. Os modelos são fundamentados na Teoria de Controle da Comporta de dor, onde são analisados os principais componentes envolvidos na percepção/inibição da dor, bem como o funcionamento dos mecanismos biológicos e cognitivos participantes do processo. A escolha do tipo de rede neural é feita a partir das observações realizadas, considerando-se também o número de fatores envolvidos e o comportamento esperado frente a cada conjunto de entrada. O método de treinamento das redes neurais baseia-se no algoritmo de retropropagação. $O$ foco do processamento da rede é responder adequadamente, considerando-se a influência das entradas envolvidas, a eventos posteriores à ocorrência de uma lesão gerando um sinal de alerta a ser utilizado como uma resposta natural do organismo a este dano tecidual. $\mathrm{O}$ desempenho de cada modelo é avaliado comparando-se as saídas obtidas com aquelas esperadas para cada padrão de entrada. 


\begin{abstract}
TAZAWA, N. Modelling of Pain Using Artificial Neural Networks.

This work presents the results of two models that were developed to describe the phenomenon of pain using Artificial Neural Networks, with the final goal to simulate computationally possible answers of an individual in the presence of pain. The models are based on The Gate Control Theory, where the main components involved in the perception/inhibition of pain were analysed, as well as the operation of the biological and cognitive mechanisms involved in the process. The type of neural network was chosen based on accumulated knowledge, considering also the number of involved factors and the expected behaviour response to each set of patterns. The neural networks were trained based on the backpropagation algorithm. The major focus of the network processing was to answer adequately to the occurrence of an injury, considering the role of the involved inputs, and generating an alert signal to this tecidual damage, which could replace the natural reply of the organism. The performance of each model is evaluated comparing the outputs obtained with those expected for each pattern.
\end{abstract}




\section{SUMÁRIO}

LISTA DE FIGURAS

LISTA DE TABELAS

LISTA DE ABREVIATURAS E NOTAÇÕES UTILIZADAS

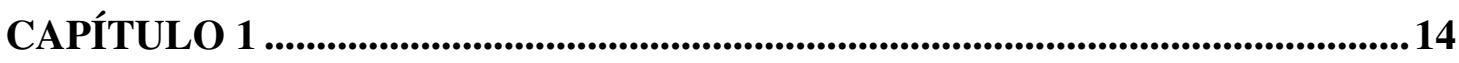

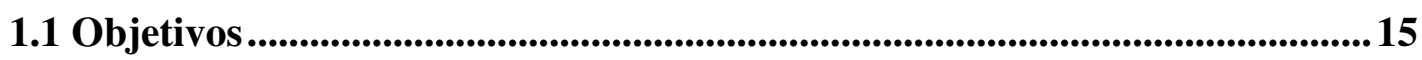

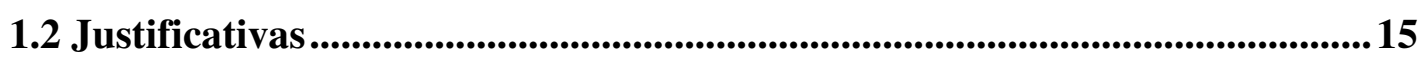

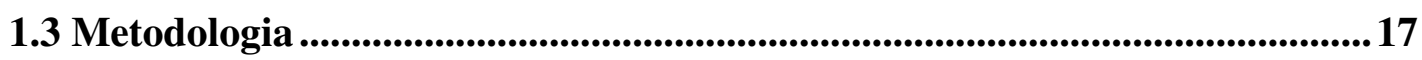

1.4 Teoria da dor ................................................................................................. 17

1.5 Estrutura do Texto ............................................................................................................. 18

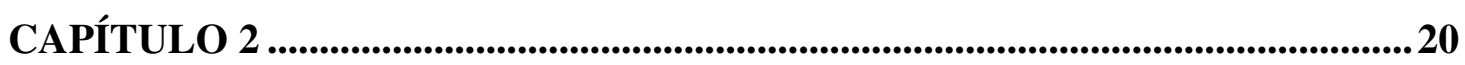

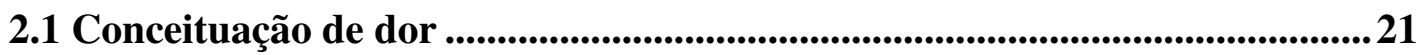

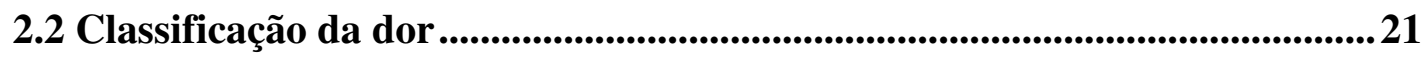

2.3 Fatores que influenciam na sensação dolorosa ....................................................22

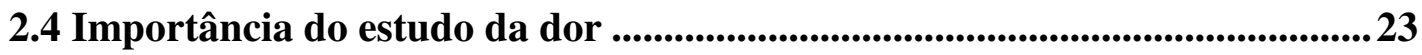

2.5 Mecanismos envolvidos na percepção da dor .............................................25

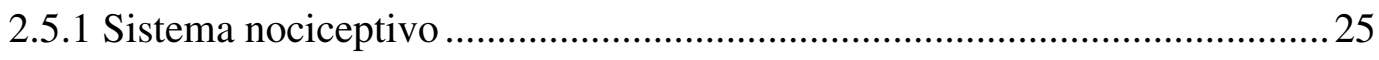

2.5.2 Classificação das fibras nervosas sensoriais .............................................226

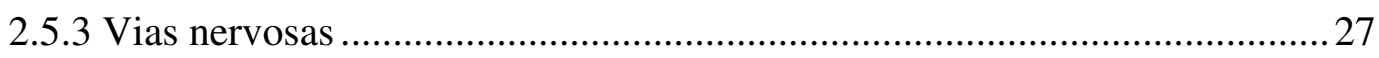

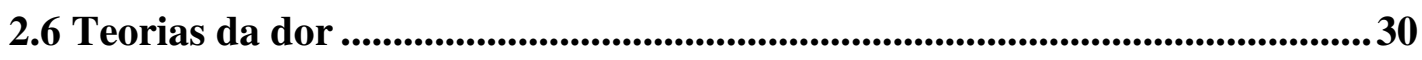

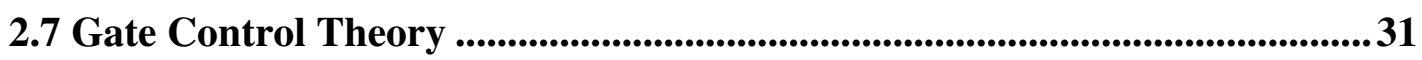

2.7.1 Hipóteses da Teoria de Controle da Comporta........................................... 33

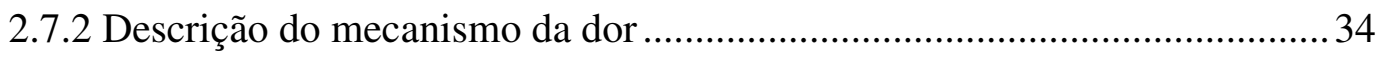

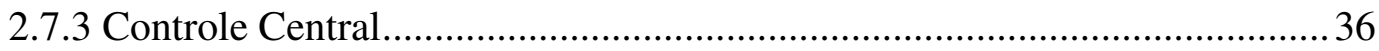

2.7.4 Algumas reconsiderações da Teoria de Controle da Comporta.................... 37

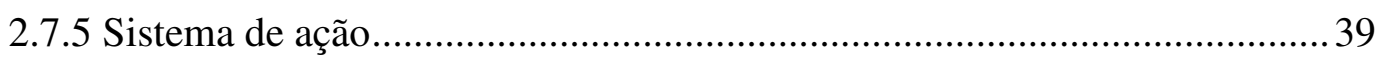


3.1 Definiç̧̃̃o .................................................................................................................................41

3.2 O neurônio biológico....................................................................................42

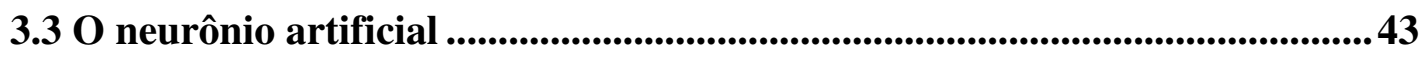

3.4 Funções de ativação ....................................................................................................45

3.5 Arquiteturas de Redes Neurais.................................................................46

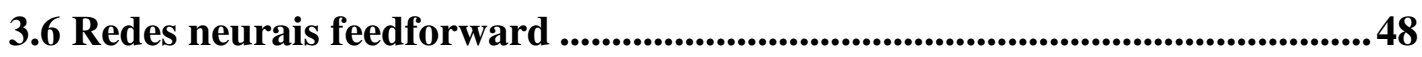

3.7 Tipos de aprendizado .......................................................................................... 48

3.8 Etapas de desenvolvimento de uma RNA .................................................50

3.8.1 Coleta de dados correspondentes a fatores cognitivos e emocionais............51

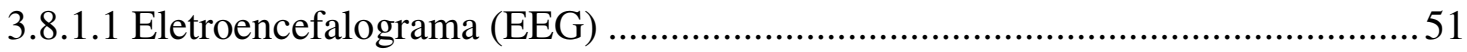

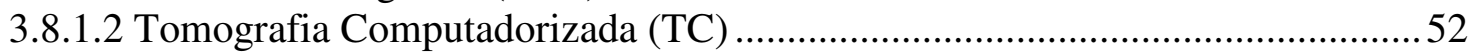

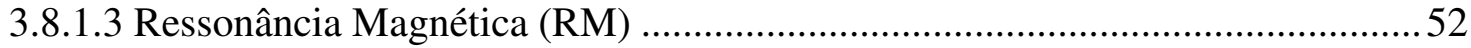

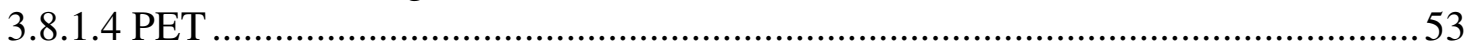

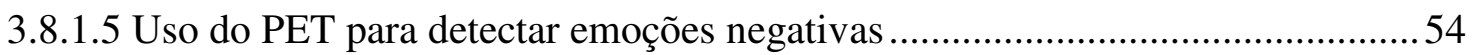

3.8.1.6 Tratamento das informações cognitivas coletadas ..........................................54

3.9 Por que utilizar Redes Neurais Artificiais? ...............................................55

3.10 Aplicações de Redes Neurais Artificiais ......................................................56

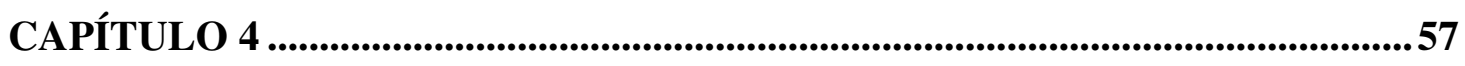

4.1 Procedimento para ajustes dos parâmetros da rede neural .........................59

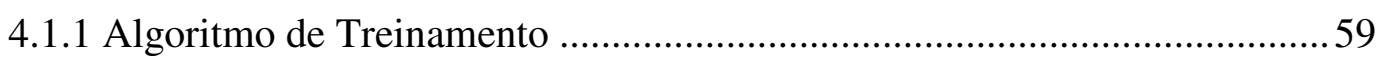

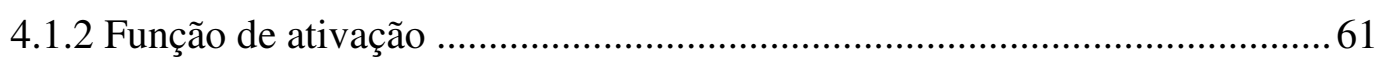

4.1.3 Ajuste da inclinação e do deslocamento da sigmóide ................................6 62

4.2 Uso do MatLab para o desenvolvimento de RNA......................................68

4.3 Modelo Neural com duas entradas....................................................................69

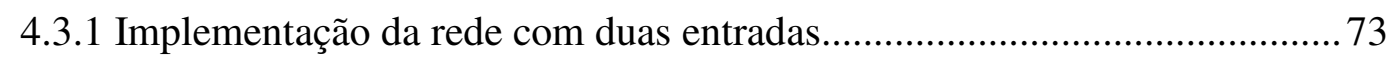

4.3.2 Treinamento da rede com duas entradas............................................. 75

4.4 Modelo Neural com três entradas ................................................................77

4.4.1 Implementação da rede com três entradas ................................................ 85

4.4.3 Treinamento da rede com três entradas ...................................................... 87 
5.1 Resultados obtidos: rede neural com duas entradas 90

5.1.1 Teste geral da rede de duas entradas...... 91

5.2 Resultados obtidos: rede neural com três entradas......................................91

5.2.1 Teste geral da rede de três entradas ......................................................... 93

5.3 Importância da mensuração da dor .....................................................................94

5.3.1 Escala de Categoria Numérica .................................................................. 95

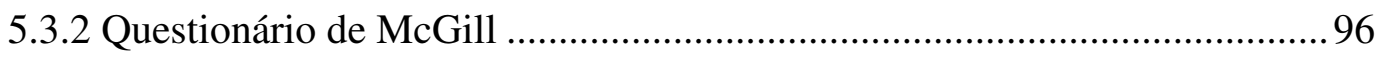

5.4 Uso do modelo neural de três entradas na mensuração da dor.....................98

5.4.1 Modelo Neural de três entradas e Questionário de McGill de Dor ............. 99

5.5 Conclusão e Perspectivas Futuras ..............................................................104

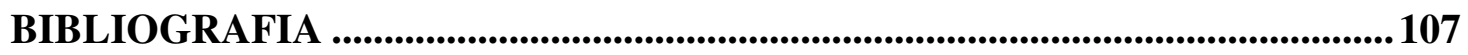




\section{LISTA DE FIGURAS}

Figura 2.1 - A medula espinhal. 28

Figura 2. 2 - Terminais das fibras nervosas aferentes nas seis lâminas do corno dorsal da medula espinhal. 30

Figura 2. 3 - Principais componentes do sistema aferente cutâneo no corno dorsal superior. 35

Figura 2. 4 - Diagrama esquemático da Teoria do Controle da Comporta. 36

Figura 2. 5 - Diagrama da Teoria de Controle da Comporta considerando a influência do cérebro no processo de modulação da dor. 38

Figura 3. 1 - Componentes do Neurônio 42

Figura 3. 2 - Representação gráfica de um neurônio artificial. ..................................43

Figura 3. 3 - Representação gráfica de algumas funções de ativação.......................46

Figura 3. 4 - Processo de aprendizado supervisionado, ou com professor, de uma rede neural artificial.

Figura 3. 5 - Aprendizado não supervisionado, ou sem professor, de uma rede neural artificial. 49

Figura 4. 1 - Curva sigmoidal para função de transferência. 62

Figura 4. 2 - Ajuste do parâmetro de deslocamento da função sigmoidal. ................64

Figura 4. 3 - Ajuste do parâmetro de inclinação da função sigmoidal. .....................64

Figura 4. 4 - Modelo Neural para o Mecanismo da porta com duas entradas. ........69

Figura 4. 5- Modelo Neural com duas entradas vista em detalhes............................ 74

Figura 4. 6 - Modelo Neural para o Mecanismo da porta com três entradas........... 77

Figura 4. 7 - Modelo Neural com três entradas.......................................................86

Figura 5. 1 -Questionário de McGill da dor. 96 


\section{LISTA DE TABELAS}

Tabela 3. 1 - Tipos de Funções de ativação. 45

Tabela 4. 1 - Tabela da verdade para o modelo de duas entradas. ........................... 71

Tabela 4. 2 - Valores obtidos para os pesos sinápticos da rede. ............................... 75

Tabela 4. 3 - Valores obtidos para a inclinação ...........................................................76

Tabela 4. 4 - Valores obtidos para o deslocamento ................................................. 76

Tabela 4. 5 - Tabela para ilustrar o Mecanismo da porta para a rede com três entradas.79

Tabela 4. 6 - Valores obtidos para os pesos sinápticos da rede.

Tabela 4.7 - Valores obtidos para a inclinação de cada função de transferência da rede.

Tabela 4. 8 - Valores obtidos para o deslocamento de cada função de transferência da rede.

Tabela 5. 1 - Tabela comparativa das saídas fornecidas pela rede (duas entradas) com as esperadas. 90

Tabela 5. 2 - Tabela comparativa das saídas fornecidas pela rede (duas entradas) com as esperadas (teste geral).

Tabela 5. 3 - Tabela comparativa das saídas fornecidas pela rede (três entradas) com aquelas esperadas.

Tabela 5. 4 - Tabela comparativa das saídas fornecidas pela rede (três entradas) com aquelas esperadas (teste geral).

Tabela 5. 5 - Tabela contendo de forma resumida alguns resultados obtidos a partir de estudo utilizando o Questionário de McGill. 101

Tabela 5. 6 - Tabela normalização dados de entrada da rede. 102

Tabela 5. 7 - Tabela de normalização dos dados de saída da rede. 103

Tabela 5. 8 - Resultados obtidos com dados do Questionário. 103 


\section{LISTA DE ABREVIATURAS E NOTAÇÕES UTILIZADAS}

$\rho \quad$ Parâmetro de translação da curva sigmoidal

$\lambda \quad$ Parâmetro de inclinação da curva sigmoidal

RNA Rede Neural Artificial

IASP International Association for the Study of Pain ou Associação Internacional para o Estudo da dor.

EEG Eletroencefalograma

TC Tomografia Computadorizada

RM Ressonância Magnética

PET Tomografia por emissão de posítron

MPQ McGill Pain Questionnaire ou Questionário McGill de dor

NRS Numeric Rating Scale ou Escala de Categoria Numérica

PRI Pain Rating Index ou Índice de Avaliação da Dor

PPI Present Pain Intensity ou Intensidade de Dor Presente 


\section{CAPÍTULO 1}

\section{INTRODUÇÃO}

Este capítulo apresenta uma proposta para a construção de um modelo artificial dos mecanismos envolvidos com a percepção da dor. O capítulo descreve as justificativas e motivações para a realização deste trabalho. Adicionalmente, o capítulo apresenta como o trabalho está organizado e uma descrição sucinta dos capítulos subseqüentes. 


\subsection{Objetivos}

O principal objetivo deste trabalho é desenvolver um modelo para simular artificialmente os comportamentos relacionados ao fenômeno da percepção da dor. O modelo foi elaborado usando redes neurais artificiais (RNA) para simular as possíveis respostas de um indivíduo à dor após sofrer uma determinada lesão. O modelo aqui proposto, se implementado fisicamente, pode, por exemplo, auxiliar indivíduos que sofrem de uma síndrome que os torna insensíveis à dor. Neste caso, o modelo pode desempenhar o papel de agente de envio de sinais de alerta ao cérebro quando estes indivíduos sofressem algum tipo de lesão tecidual.

Dentre os resultados esperados com o desenvolvimento deste sistema, destacam-se:

- Convergência no treinamento de uma rede quando submetida a entradas que representam fatores que influenciam no processo de percepção de dor.

- Respostas da rede neural artificial, consistentes com aquelas observadas em seres humanos, quando estes são submetidos à sensação de dor.

\subsection{Justificativas}

Consideráveis recursos são atualmente gastos com pacientes que sofrem algum tipo de dor, sejam dores agudas ou crônicas. De acordo com a Associação Internacional para o Estudo da dor (IASP), aproximadamente 90 milhões de pessoas sofrem de dor crônica e cefaléias nos Estados Unidos, representando custos anuais da ordem de 125 bilhões de dólares somente com o tratamento desses pacientes. Como consequiência desses problemas, um grande número de trabalhadores acaba por se aposentar prematuramente, o que implica em grande gasto para o sistema de seguros social e privado. No Brasil, a dor crônica atinge quase 
$30 \%$ da população, sendo uma das principais causas de absenteísmo, afastamentos e incapacidades no trabalho. É neste contexto que surge a necessidade de se entender os mecanismos envolvidos com a percepção da dor. Desta forma, a construção de um modelo para a dor pode eventualmente contribuir no estudo desse fenômeno.

Na literatura científica, as pesquisas na construção de modelos representativos de comportamentos complexos inerentes ao ser humano, como a dor, ainda são incipientes. Dessa forma, procura-se aqui modelar os mecanismos de percepção da dor considerando-se alguns dos principais fatores envolvidos segundo a Teoria de Controle da Comporta de dor. A percepção da dor é um evento importante para a sobrevivência de qualquer ser humano, principalmente por funcionar como um sinalizador de algum desequilíbrio no organismo. Por outro lado, existem casos raros em que a percepção da dor está ausente. Por exemplo, existem crianças que são portadoras da síndrome de "insensibilidade congênita à dor", e que são incapazes de perceber sensações dolorosas. Sem o alarme da dor, essas crianças não reagem, por exemplo, a eventos de queimaduras ou cortes, aumentando a gravidade dos ferimentos resultantes. Pessoas insensíveis à dor requerem cuidados especiais, que podem restringir o número de atividades que essas pessoas podem exercer. Um dispositivo baseado em mecanismos artificiais de percepção de dor poderia auxiliar tais pessoas a terem uma vida normal. Neste caso, pode-se implementar artificialmente, combinando dispositivos de hardware (circuitos integrados combinando sensores, processadores e atuadores) com elementos de software (baseado em redes neurais artificiais), compreendendo um sistema auto-consistente que substitua ou ajude a desempenhar as atividades dos processos biológicos e/ou fisiológicos de dor que não estejam funcionando em sua plenitude. 
Além disso, este trabalho mostra como a multidisciplinaridade pode ser empregada no desenvolvimento de modelos consistentes, considerando-se para isto os conceitos presentes em diferentes campos científicos desde a fisiologia, passando pela biologia e a neurociência, alinhadas às técnicas matemáticas e computacionais das redes neurais artificiais.

\subsection{Metodologia}

O mecanismo de percepção da dor pode ser representado pela Teoria de Controle da Comporta. A partir daí pode-se conhecer quais são os principais fatores que influenciam no processo de percepção de dor e os respectivos comportamentos esperados para cada combinação de entradas. Considerando que é possível conhecer as entradas e saídas, todo o procedimento de tomada de decisão frente a cada comportamento pode ser realizado de maneira rápida e eficaz com uma rede neural artificial. O desenvolvimento, treinamento e validação das redes neurais são realizados com o auxílio do software Matlab.

\subsection{Teoria da dor}

Em meados da década de 60, dois pesquisadores, Melzack e Wall (1965), propuseram a Teoria de Controle da Comporta (Gate Control Theory) de dor. Embora desenvolvida há aproximadamente quarenta anos, esta teoria ainda é considerada a mais completa para explicar o fenômeno de percepção de dor. Essa teoria, que pode ser considerada como um marco na compreensão do fenômeno de percepção de dor, se baseia em dois aspectos: primeiro em termos dos mecanismos de transmissão e modulação dos sinais nociceptivos, e segundo em termos da percepção de dor como um fenômeno resultante de interações entre eventos fisiológicos e psicológicos. 
O objetivo deste trabalho é desenvolver um modelo dos mecanismos da dor, baseado inicialmente na Teoria da Comporta, e implementado usando redes neurais artificiais. Desta forma, inicialmente deve-se analisar qual o tipo e a arquitetura de rede neural mais adequada para tal propósito. Este procedimento envolve ainda a escolha de entradas e saídas da rede e o tipo de processamento do sinal a ser realizado pelos neurônios.

As Redes Neurais Artificiais são técnicas computacionais que representam um modelo matemático inspirado na estrutura neural de organismos inteligentes e que adquirem conhecimento através da experiência. Uma rede neural artificial pode conter desde algumas até milhares de unidades de processamento (neurônios). Essas unidades de processamento são geralmente conectadas por canais de comunicação, que levam em conta alguns elementos locais para a determinação de um peso do fluxo de informação entre dois neurônios. As unidades fazem operações apenas sobre seus dados locais, que são as entradas recebidas pelas suas conexões. A chamada inteligência de uma Rede Neural Artificial (RNA) está associada às interações entre as unidades de processamento da rede, que acumulam conhecimento com o uso da rede.

\subsection{Estrutura do Texto}

Este trabalho está dividido em cinco capítulos. Este primeiro capítulo apresenta uma descrição da proposta e dos objetivos de se realizar uma modelagem da dor, e as justificativas que levaram à realização deste trabalho. $\mathrm{O}$ capítulo 2 descreve os elementos da fenomenologia da dor, os mecanismos biológicos e psicológicos envolvidos, e a sua contextualização na vida cotidiana. Este capítulo também introduz a teoria da dor mais aceita atualmente, a Teoria de Controle da Comporta de Dor. O capítulo 3 apresenta os elementos 
principais da metodologia utilizada. O capítulo descreve os fundamentos teóricos sobre as redes neurais artificiais, apresentando uma caracterização de seus principais parâmetros, bem como, suas principais vantagens e aplicações frente a outros métodos de reconhecimento e classificação existentes. O capítulo 4 trata da metodologia utilizada no desenvolvimento dos modelos, incluindo desde a escolha do tipo da rede e arquitetura até o processo de treinamento da mesma. O capítulo discute ainda alguns testes dos modelos neurais construídos. O capítulo 5 discute os resultados obtidos com os modelos propostos neste trabalho, comparando o desempenho de cada um frente ao que se esperava obter ao se ter um determinado padrão de entrada na rede. Além disso, são apresentadas as conclusões obtidas a partir desta pesquisa, avaliando pontos positivos e negativos dos modelos propostos e discutindo um conjunto de novos elementos que possam enriquecer ou melhorar os pontos discutidos neste trabalho. 


\section{CAPÍTULO 2}

A DOR

O principal componente de estudo deste trabalho pode ser resumido em uma única palavra: dor. Desta forma, é fundamental se familiarizar com alguns dos conceitos que permeiam este fenômeno, bem como os componentes que contribuem para a sua manifestação. Este capítulo apresenta uma definição para o fenômeno da dor, ressaltando a importância de seu estudo e caracterizando-a em termos da duração de sua manifestação. Além disso, são descritos todos os mecanismos biológicos e cognitivos envolvidos na percepção ou inibição da dor no contexto de uma das teorias de dor mais usadas atualmente. 


\subsection{Conceituação de dor}

Segundo a Associação Internacional para o Estudo da Dor (IASP), a dor é uma experiência sensorial e emocional desagradável, associada a uma lesão tecidual atual ou potencial, ou descrita em termos de tal lesão. Essa definição é extremamente subjetiva, carecendo de elementos precisos que permitiriam entender e modelar com exatidão a dor dentro de parâmetros científicos, que pudessem combinar elementos biológicos e matemáticos. Embora a dor seja um fenômeno, ou experiência, difícil de se definir de maneira exata, sua ocorrência é de fácil identificação. Ela é tipicamente uma resposta direta a um evento desfavorável, associado a algum dano tecidual, como lesão, inflamação ou doença. Por outro lado, a dor pode surgir independentemente de qualquer causa aparente e pode persistir por longos períodos, mesmo após a lesão inicial ter sido curada, como ocorre, por exemplo, com o fenômeno da dor do membro fantasma (RANG et al., 2004).

\subsection{Classificação da dor}

De acordo com a literatura, a dor pode ser classificada em três tipos (CARVALHO et al., 1999), considerando a duração da sua manifestação:

- Dor Aguda - dor que se manifesta durante um período relativamente curto, e está geralmente associada às lesões em tecidos ou órgãos ocasionadas por inflamação, infecção, traumatismo, dentre outros. Essa dor normalmente desaparece quando a sua causa é eliminada, ou quando, após ter sido diagnosticada, o paciente segue as recomendações e tratamentos recomendados por um especialista.

- Dor Crônica - Dor que possui duração prolongada, podendo se estender por vários anos, e está geralmente relacionada a uma doença crônica. A dor crônica pode também 
ser conseqüência de seqüelas de lesões tratadas anteriormente. Como exemplos relacionados a este tipo de dor podem ser citadas: dores ocasionadas pela inflamação das articulações, dores em pacientes com câncer, dores relacionadas a esforços repetitivos durante o trabalho.

- Dor Recorrente - Dor que apresenta períodos de curta duração que, no entanto, se repetem frequientemente, podendo ocorrer durante toda a vida de um indivíduo, mesmo sem estar associada a um processo ou mecanismo específico. A chamada enxaqueca é um exemplo comum deste tipo de dor.

\subsection{Fatores que influenciam na sensação dolorosa}

Existem diversos fatores que podem de alguma forma contribuir para a percepção da dor, ou para a intensificação ou redução dessa percepção. A experiência dolorosa geralmente vem acompanhada de componentes físicos, dependendo da extensão da lesão e da medicação, e emocionais, como depressão e ansiedade. Um indivíduo num estado de depressão, centrado em si mesmo e afastado do convívio social e das suas atividades do cotidiano, está susceptível a ter sensações dolorosas amplificadas, sensações que em outras situações teriam magnitudes consideravelmente menores (CARVALHO et al., 1999).

Os elementos primordialmente subjetivos da percepção da dor, observados geralmente em adultos, também podem ser identificados entre crianças. Neste último caso, os efeitos cognitivos são geralmente mais visíveis. Por exemplo, uma criança pequena freqüentemente se machuca durante uma brincadeira, mas ignora os ferimentos e continua brincando sem maiores queixas. Por outro lado, a mesma criança pode externar uma percepção de dor amplificada resultante de uma vacina rotineira de pequena intensidade de dor. A percepção da 
dor na criança não depende somente do grau de lesão ou da doença, mas também de fatores emocionais (a ansiedade pode aumentar a dor e esta, por sua vez, pode levar ao medo, à frustração e à depressão), comportamentais (resposta da criança aos pais e à equipe médica) e situacionais (relacionadas com as características da criança, suas experiências prévias, personalidade, idade, aprendizado prévio, entre outros).

\subsection{Importância do estudo da dor}

Nas últimas décadas, o interesse em entender e modelar os mecanismos neurais associados à dor aumentou substancialmente, conforme descrito em (MÁRQUEZ, 2004). Entre os motivos que levaram a este crescente interesse destacam-se:

- Maior sobrevida em geral da população. Por exemplo, no Brasil, em 1940 a expectativa de vida era de 38,5 anos, aumentando sistematicamente com o passar das décadas, com estimativa de atingir 71 anos em 2010. Como conseqüência, aumentou a incidência dos três tipos de dor na população, principalmente naquelas faixas etárias mais avançadas.

- Maior sobrevida em relação aos traumas.

- Maior sobrevida em relação às doenças (descoberta de novos tratamentos, vacinas, medicamentos). A manifestação da dor durante os processos de recuperação de enfermidades também vem recebendo grande atenção.

Esses três fatores são determinantes para que as pessoas, tendo maior sobrevida, estejam mais sujeitas às doenças e traumas, ficando, portanto, mais expostas às causas de dores. 
Embora a dor cause uma sensação desagradável e estressante, ela é essencial para a sobrevivência. A dor exerce uma função protetora para o organismo, dando um sinal de alerta quando algum órgão do corpo não está funcionando corretamente. Ou seja, ela surge como um mecanismo de aviso de algum processo de desequilíbrio do organismo. Como exemplo, podemos citar o papel relevante da dor referente a queimaduras. Nesta situação, uma criança ao se queimar poderia reagir menos ao estímulo doloroso se ela nunca tivesse passado por essa experiência anteriormente. Por outro lado, a intensidade e a freqüência da dor também extrapolam de suas funções indicadoras e interferem negativamente na qualidade de vida do indivíduo com dor, comprometendo suas atividades cotidianas. Em (HEATH; AMARTEY, 2005) mostra-se que aproximadamente 10 milhões de britânicos, ou seja, mais de $10 \%$ da população, sofrem de algum tipo de dor periodicamente, o que prejudica sua qualidade de vida e contribui para o crescimento estatístico do número de dias não trabalhados.

A dor pode servir a diversos propósitos. Primeiro, a dor desempenha um papel de alerta para algum evento externo. Por exemplo, quando um objeto quente ou cortante entra em contato com um indivíduo, a dor gera uma resposta imediata do indivíduo, prevenindo uma lesão mais grave. Segundo, os eventos de dor servem como um banco de dados para o treinamento do indivíduo, por exemplo, para identificar, e desta forma evitar, situações de potencial causa de dor. Terceiro, a dor proveniente de contusões, infecções abdominais ou lesões musculares impõem um limite na atividade física do indivíduo, prevenindo assim o excesso de atividades e, portanto podendo garantir a sua sobrevida. A percepção da dor força um descanso, que é freqüentemente essencial para a recuperação natural da dor e para os mecanismos de defesa do organismo, que muitas vezes evitam danos irreversíveis ao organismo. 
Em (MÁRQUEZ, 2004) se reporta que em 2000 havia cerca de 86 milhões de norteamericanos com dores crônicas (mais de $31 \%$ da população), dos quais 65 milhões estavam incapacitados total ou parcialmente $(75 \%$ desses 86 milhões). Como resultado, aproximadamente 70 bilhões de dólares são necessários somente para cobrir as despesas médicas, além das perdas de dias trabalhados e gastos com compensações trabalhistas.

A dor possui um papel relevante na vida cotidiana de cada ser humano, e ainda mais, tem implicações em aspectos sociais e econômicos. Desta forma, é fundamental o seu estudo em diversos níveis, desde a sua conceituação até o desenvolvimento de mecanismos para prevenir ou suprimir a dor. Como resultado, é desejável compreender os mecanismos neurais envolvidos com a dor, e conseqüentemente mapear e/ou modelar cada fator que contribua para a sua aparição.

\subsection{Mecanismos envolvidos na percepção da dor}

\subsubsection{Sistema nociceptivo}

A nocicepção é a atividade específica do sistema nervoso que viabiliza a percepção de dor. Os sinais do sistema nervoso são captados e conduzidos por nervos periféricos primários, os nociceptores, que sucessivamente se conectam pelas sinapses a outras classes de neurônios, e seguem até o cérebro, onde a percepção de dor ocorre. 


\subsubsection{Classificação das fibras nervosas sensoriais}

As fibras nervosas sensoriais são divididas em dois tipos: A e C, sendo as do tipo A subdivididas em alfa, beta, gama e delta. As fibras do tipo A são típicas dos nervos espinhais, enquanto que as fibras do tipo $\mathrm{C}$ (pequeno diâmetro e não mielínicas) caracterizam-se pela condução de impulsos com baixa velocidade (TRIBIOLI, 2003).

Os dois tipos de fibras nervosas citadas no parágrafo anterior podem ser agrupados, de acordo com suas características e funcionalidades, em cinco sub-grupos de fibras sensoriais:

- Grupo Ia - refere-se às terminações de fusos musculares correspondendo, na classificação geral, às fibras do tipo $A \alpha$;

- Grupo $\mathrm{Ib}$ - são fibras dos órgãos tendinosos de Golgi, correspondendo também às fibras $\mathrm{A} \alpha$;

- Grupo II - são fibras dos receptores táteis cutâneos e dos fusos musculares, com um diâmetro médio de 8 micrômetros, correspondendo às fibras dos tipos $\mathrm{A} \beta$ e $\mathrm{A} \gamma$;

- Grupo III - são fibras que conduzem o tato, a temperatura e a dor aguda, tendo um diâmetro médio de 3 micrômetros, sendo do tipo A $\delta$ na classificação geral;

- Grupo IV - fibras não mielínicas que conduzem a dor crônica, a temperatura e o tato, com um diâmetro médio de 0,5 a 2 micrômetros, sendo na classificação geral chamadas do tipo C.

As fibras nervosas que transmitem a informação dolorosa são as do grupo III e as do grupo IV. Assim, quando ocorre uma lesão tecidual, três tipos de fibras nervosas são ativados: as fibras $\mathrm{A} \beta$ (com velocidade de condução em torno de 30 a $100 \mathrm{~m} / \mathrm{s}$ ) são fibras grandes e 
mielínicas que são ativadas pela estimulação elétrica de baixo nível, produzindo sensações não dolorosas. Além disso, essas fibras são capazes de inibir a resposta das fibras nervosas relacionadas aos estímulos nociceptivos e reduzir a intensidade da dor. A fibra $A \delta$, por sua vez, são fibras mielínicas e pequenas que respondem aos estímulos nociceptivos com disparos longos e intensos. Este tipo de fibra conduz impulsos nervosos com certa rapidez (velocidade em torno de 6 a $30 \mathrm{~m} / \mathrm{s}$ ). Finalmente, as fibras C são pequenas e não-mielínicas, para as quais a condução do estímulo nociceptivo é a principal função. Elas operam de forma semelhante à das fibras $\mathrm{A} \delta$, mas sua velocidade de condução é menor, situando-se na faixa de 0.25 a 1.25 m/s (BRITTON; SKEVINGTON, 1989).

\subsubsection{Vias nervosas}

O trajeto dos impulsos nervosos que originam a dor inclui: o sistema nervoso periférico, a medula espinhal, o tronco cerebral, o tálamo e o córtex cerebral. Do gânglio espinhal, as fibras se dirigem para o corno posterior da medula espinhal, o qual representa uma organização laminar (Lâminas de Rexed), numerada de I a X, cada lâmina com características morfofuncionais e de recepção das fibras advindas da periferia, distintas (MÁRQUEZ, 2004).

Os corpos celulares das fibras $\mathrm{A} \delta$ e $\mathrm{C}$ são encontrados nos gânglios da raiz dorsal e suas conexões centrais entram na medula espinhal através das raízes dorsais, onde elas fazem sinapse com a célula de transmissão central. As células específicas da nocicepção se localizam principalmente na lâmina I da substância gelatinosa e respondem apenas aos nociceptores. Contudo, células com amplas faixas dinâmicas se encontram na lâmina V, recebendo impulsos de nociceptores e fibras $A \beta$ de grande diâmetro. A partir dessas 
estruturas, a informação é transmitida pela via direta até o tálamo, ou indiretamente, pelo trato espino-retículo-talâmico, sendo que, a partir do tálamo, a informação é, então, transmitida para o córtex somatossensorial e outras regiões corticais.

O corno dorsal, também conhecido como corno posterior, refere-se à coluna cinzenta na porção posterior da medula espinhal vista numa seção em corte transversal. Pode ser visto um nítido "H" maiúsculo, em cinza, sobre um fundo esbranquiçado. O "H" é formado por corpos de células nervosas, juntamente com parte de seus prolongamentos. Esses corpos representam o ponto de partida e chegada dos estímulos nervosos de todo o corpo.

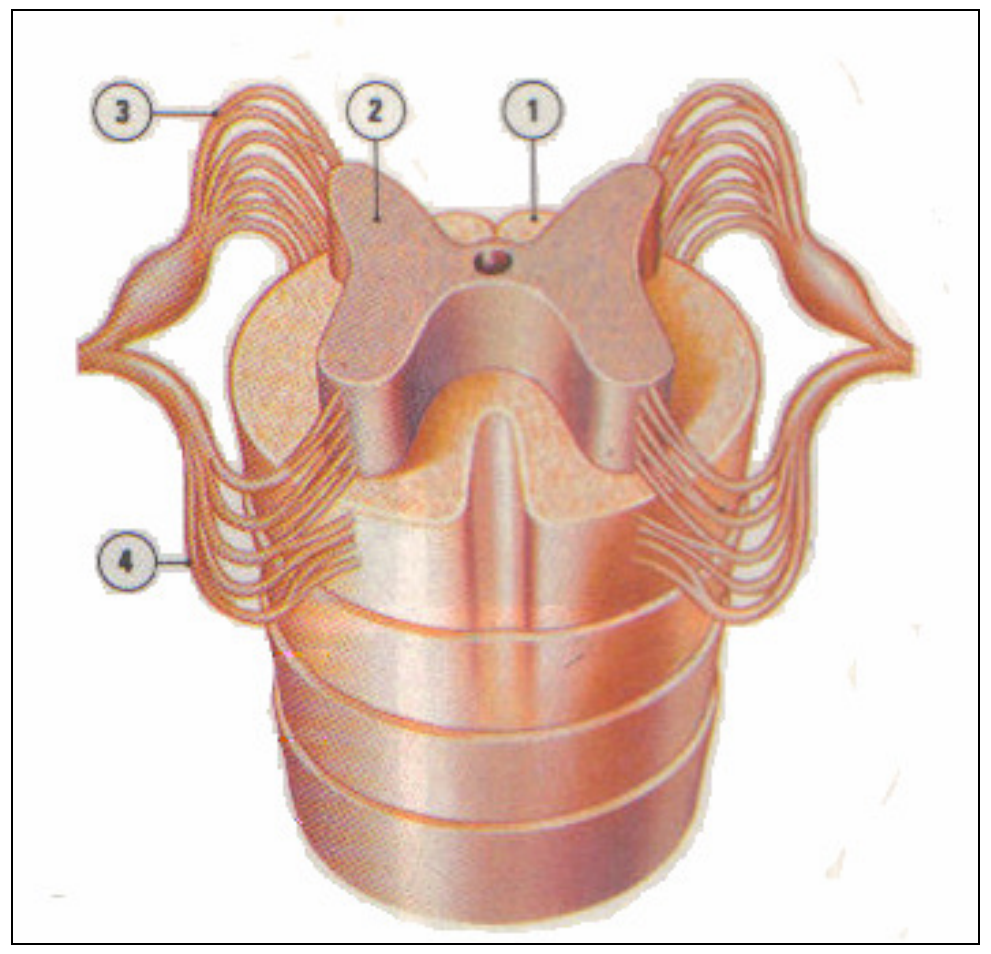

Figura 2.1 - A medula espinhal.

A medula corresponde à região mais inferior do sistema nervoso central (SNC) e funciona como um condutor de impulsos (sinais) entre o cérebro e o corpo. É formada por substância branca (1) e cinzenta (2). Desta última se originam as raízes dorsal (3) e ventral (4), que se unem para formar os nervos espinhais.

Fonte: (ENCICLOPÉDIA MIRADOR INTERNACIONAL, 1987). 
A medula espinhal consiste em uma estrutura segmentada e colunar de tecido neural que se estende ao longo da espinha dorsal. Em cada um dos 30 segmentos que formam a medula, existem quatro raízes: raízes dorsais direita/esquerda e raízes ventrais direita/esquerda. Destas raízes emergem os troncos nervosos periféricos: nervos exclusivamente sensoriais ou aferentes, das raízes dorsais e nervos exclusivamente motores, ou eferentes, das raízes ventrais. A seção transversal da medula, representada na figura 2.1, revela uma massa cinzenta central, densamente preenchida por células nervosas, envolvidas por um feixe de fibras nervosas ascendentes e descendentes que constituem a chamada substância branca (KOVÁCS, 1997).

Nas hastes inferiores da substância cinzenta, os chamados cornos anteriores da medula, localizam-se os neurônios que originam as fibras nervosas motoras, que por sua vez formam os nervos espinhais. Nas hastes superiores (cornos posteriores), situam-se os neurônios que estão ligados com os gânglios sensitivos, localizados junto aos nervos, fora da medula. Dos gânglios provêm as fibras nervosas que conduzem impulsos sensitivos da periferia até a medula, de onde são retransmitidos até o cérebro. A figura 2.2 mostra a localização das Lâminas de Rexed (de I a VI) no corno posterior. 


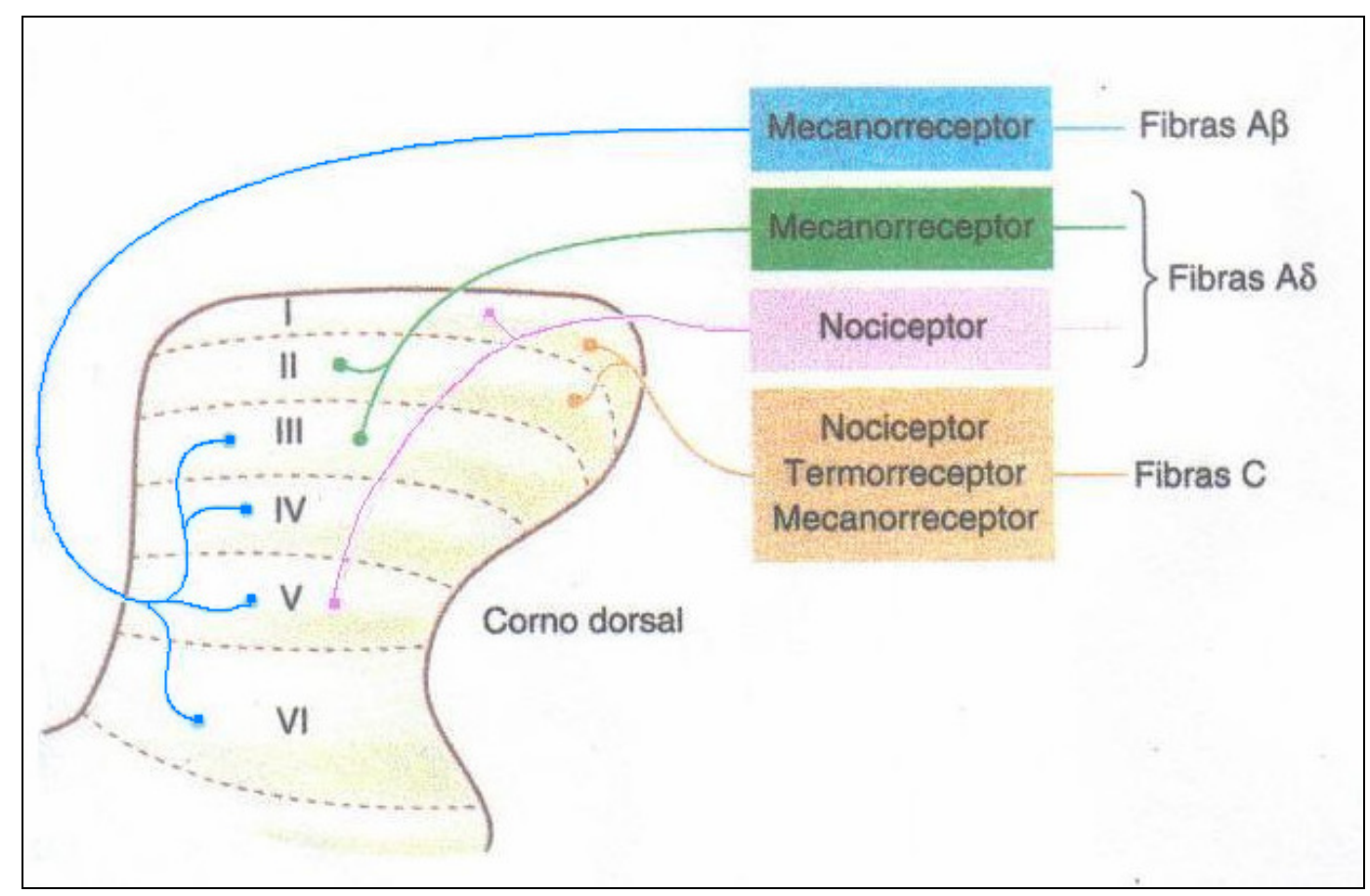

Figura 2. 2 - Terminais das fibras nervosas aferentes nas seis lâminas do corno dorsal da medula espinhal. Fonte: (RANG, H. P.; DALE, M. M.; RITTER, J. M.; MOORE, P. K., 2004).

\subsection{Teorias da dor}

Diversas teorias foram propostas na tentativa de explicar o fenômeno de percepção da dor. A Teoria da Especificidade e a Teoria Padrão são consideradas as pioneiras (MELZACK; WALL, 1982).

A Teoria da Especificidade defende que a dor é comunicada ao cérebro por um sistema sensorial exclusivo (daí o nome "especificidade"), como os da audição e da visão. Assim, se uma pessoa sofre um ferimento num determinado órgão, esta percepção dolorosa é captada por receptores nociceptivos presentes na pele e esta mensagem é carregada por um sistema específico de vias nervosas para um centro de processamento de dor no cérebro. 
A Teoria Padrão está em contraposição à Teoria da Especificidade, defendendo que a intensidade do estímulo e a natureza do somatório central dos estímulos sensoriais são os principais determinantes da dor. Esta teoria reconhece a regularidade (padrão) espaçotemporal do estímulo nervoso, que é essencial para explicar o mecanismo de dor. Por outro lado, essa teoria ignora a especialização fisiológica dos receptores de dor, considerando todos os terminais sensoriais igualmente enervados, de modo que a dor é compreendida como o resultado de uma intensa estimulação de receptores (MELZACK; WALL, 1982).

Tanto a Teoria da Especificidade como a Teoria Padrão explicam a dor pela quantidade, grau ou natureza do estímulo sensorial ou da lesão tecidual adquirida. Apesar disso, apenas estas condições não são suficientes para que uma dessas teorias fosse aceita como uma teoria geral da dor, principalmente no que se refere aos aspectos psicológicos que não são possíveis de serem explicados utilizando isoladamente os conceitos abordados em cada teoria (CARVALHO et al., 1999). É neste contexto é que a Teoria de Controle da Comporta de dor (Gate Control Theory) foi desenvolvida.

\subsection{Gate Control Theory}

A Teoria da Comporta, também denominada de Teoria do Controle da Comporta, foi desenvolvida por Ronald Melzack e Patrick D. Wall e apresentada na literatura em 1965 (MELZACK; WALL, 1965). Essa teoria propunha um novo modelo para descrever os mecanismos da dor, sugerindo que os sinais oriundos do cérebro podem ativar portas neurais na medula espinhal e bloquear sinais de dor. Segundo esta teoria, há fibras nervosas de diferentes diâmetros relacionadas à percepção de dor que se projetam para a substância gelatinosa (uma área da medula espinhal que é associada com a modulação de dor). Há outras 
fibras que partem da substância gelatinosa para o sistema nervoso central, onde os sinais são integrados. As fibras de largo diâmetro podem produzir, por meio da substância gelatinosa, um estímulo inibitório para as células de transmissão, que por sua vez, projetam para o sistema nervoso central. Isto explicaria a razão de se sentir alívio na dor ao massagear o local lesionado. Os estímulos da massagem viajariam na fibra nervosa de largo diâmetro e inibiriam o trabalho das células de transmissão. Uma vez que as células de transmissão são inibidas, a mensagem de dor não seguiria adiante. Neste caso, as portas de dor se fechariam. A ação de fibras nociceptivas usualmente excitaria as células de transmissão para converter a mensagem de dor, mas isto não poderia ser feito quando as células de transmissão fossem inibidas. Por outro lado, quando há uma lesão grave, a ação de fibras nervosas de pequeno diâmetro é mais intensa fazendo com que a porta se abra e a dor seja sentida. Neste caso, a massagem na área lesionada não desempenharia o papel de inibir o estímulo de dor, podendo ter um efeito inverso, ou seja, amplificando a sensação de dor. Esta teoria defende ainda que existe um componente cognitivo ou motivacional-afetivo de percepção de dor, que pode também afetar o estado da porta. Este elemento cognitivo tenta incorporar no modelo, diversas situações, como por exemplo, quando um esportista lesionado não se incomoda com a extensão da lesão até a conclusão de uma partida, permanecendo focado com a disputa da partida.

Diversos experimentos foram realizados com o objetivo de comprovar a validade dos mecanismos envolvidos na percepção da dor conforme descrito pela Teoria de Controle da Comporta. Em (BARNHILL et al., 1996) mostra-se que a dor associada pela aplicação de uma injeção intramuscular pode ser consideravelmente reduzida se for exercida uma pressão naquele local durante dez segundos antes da injeção. Neste caso, ao pressionar o local da injeção, fibras de largo diâmetro mielínicas $(\mathrm{A} \beta)$ estariam sendo estimuladas, contribuindo para o fechamento da comporta. 


\subsubsection{Hipóteses da Teoria de Controle da Comporta}

A Teoria de Controle da Comporta é baseada nas seguintes hipóteses ou proposições (MELZACK, 1993):

- A transmissão de impulsos nervosos de fibras aferentes para as células de transmissão da medula espinhal é modulada pelo mecanismo de controle espinhal presente no corno dorsal;

- O mecanismo de controle espinhal é influenciado pela quantidade relativa de atividade nas fibras de largo diâmetro e pequeno diâmetro: as atividades nas fibras largas tendem a inibir (fechar a comporta) enquanto as atividades em fibras de pequeno diâmetro tendem a facilitar a transmissão (abrir a comporta).

- O mecanismo de bloqueio espinhal é influenciado por impulsos nervosos centrais, ou descendentes do cérebro. Um sistema especializado de fibras largas, de rápida condução (Central Control Trigger) ativa os processos cognitivos (emoções, memórias, experiências), que por meio dessas fibras descendentes influenciam as propriedades moduladoras do mecanismo de controle da dor.

- Quando as saídas das células de transmissão excedem um limiar crítico, ativa-se o sistema de ação - a área neural que forma a base para a complexa seqüência de experiências e comportamentos característicos da dor. 


\subsubsection{Descrição do mecanismo da dor}

A incidência de estímulos cutâneos provoca impulsos nervosos que são transmitidos a três componentes da medula espinhal (figura 2.3): às células da substância gelatinosa no corno dorsal, às fibras dorsais que se projetam para o cérebro, e às células de transmissão. A Teoria do Controle da Comporta propõe que o fenômeno de percepção de dor é determinado pela interação entre estes três componentes (MELZACK; WALL, 1965).

Na figura 2.3, as fibras grossas periféricas são representadas pela linha contínua saindo da raiz dorsal e terminando na região da substância gelatinosa; uma delas, conforme a figura, envia uma ramificação de volta ao cérebro. As fibras periféricas finas são representadas por linhas tracejadas indo diretamente para a substância gelatinosa. As células maiores, onde os nervos cutâneos aferentes terminam, são mostradas como grandes esferas de cor preta com seus dendritos se estendendo para a substância gelatinosa e seus axônios se projetando profundamente para o corno dorsal. Os círculos abertos representam as células da substância gelatinosa.

A figura 2.3 mostra ainda uma região conhecida como Trato de Lissauer (LT), que consiste num conjunto de fibras localizadas no corno dorsal superior e, que interconectam as células da substância gelatinosa. Através deste conjunto de fibras, sinais provenientes tanto de fibras largas como de fibras de pequeno diâmetro podem influenciar as diferentes células da substância gelatinosa. 


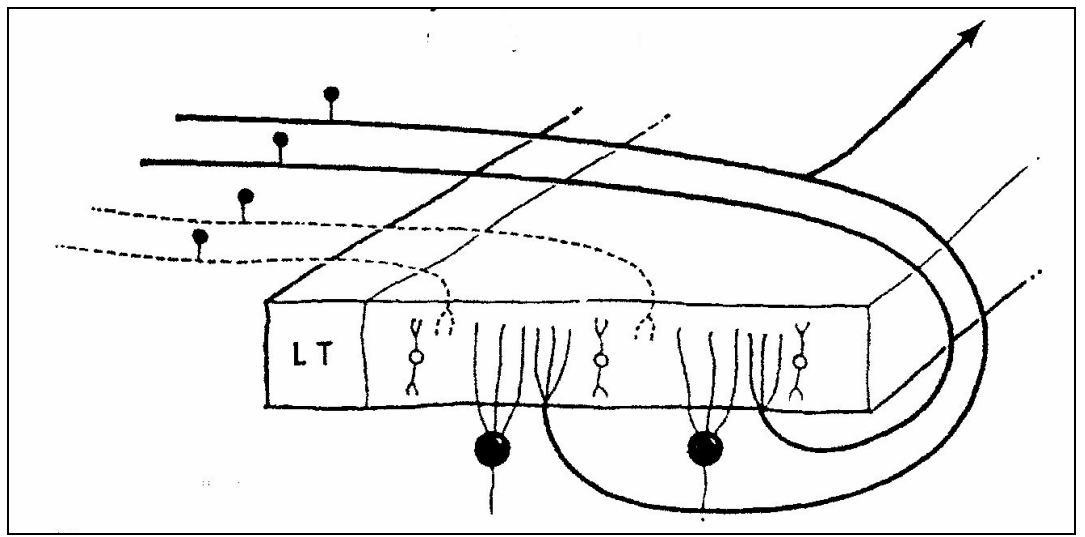

Figura 2. 3 - Principais componentes do sistema aferente cutâneo no corno dorsal superior.

Fonte: (MELZACK; WALL, 1965).

Melzack e Wall (1965) propuseram que a substância gelatinosa funcionaria como um sistema de controle de comporta que modularia os padrões de sinais trazidos pelas fibras nervosas aferentes antes que eles pudessem ativar as células de transmissão T. A figura 2.4 mostra os mecanismos envolvidos na transmissão de impulsos nervosos periféricos para células de transmissão T.

Nesta situação, os efeitos do controle da dor são determinados pelos seguintes fatores: pelo número total de fibras nervosas ativas, pela freqüência dos impulsos nervosos, e pelo balanço da atividade entre fibras grossas e finas. Se este balanço é tal que a atividade de fibras pequenas predomina, haverá um aumento na atividade da célula T resultando no fenômeno da dor (porta aberta). O inverso também é válido se houver um aumento na atividade das fibras largas (porta fechada). 


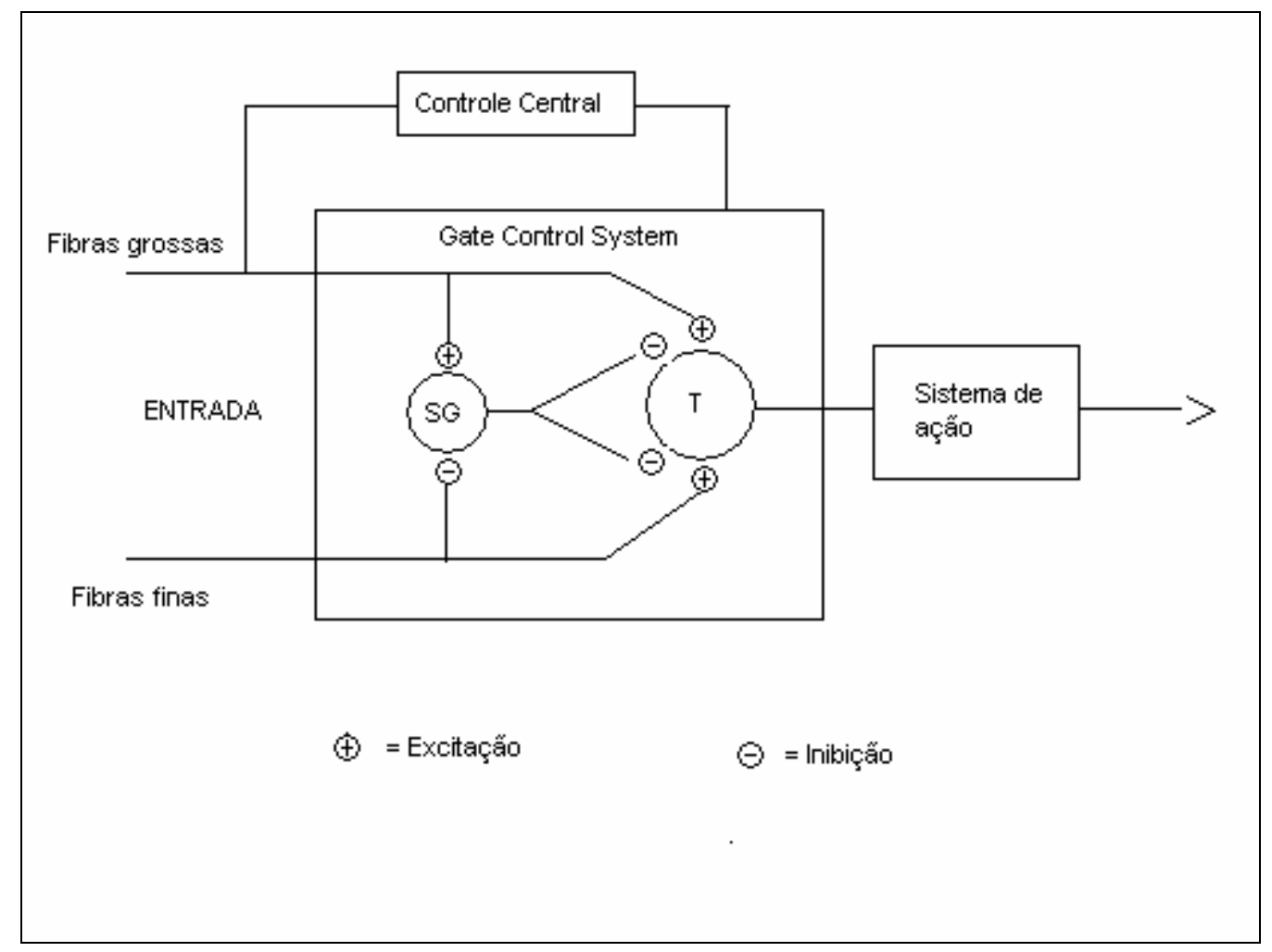

Figura 2. 4 - Diagrama esquemático da Teoria do Controle da Comporta.

Neste diagrama, $L$ representa as fibras grossas ( $L$ do inglês larger); enquanto $S$, as fibras finas ( $\mathrm{S}$ do inglês small). As fibras se projetam para a substância gelatinosa (SG) e para as células de transmissão (T). Fonte: (MELZACK; WALL, 1965).

\subsubsection{Controle Central}

O modo como as atividades do sistema nervoso central provocam determinadas ações é importante de ser analisado. Enquanto algumas dessas atividades, tais como a ansiedade ou a excitação pode abrir ou fechar a porta para todas as entradas em qualquer parte do corpo, outras envolvem atividades de controle cerebrais localizadas e seletivas. Por exemplo, experimentos mostraram que cães que repetidamente recebem comida após terem sua pele lesionada respondem a esses estímulos como um sinal para comida e salivam sem mostrar quaisquer sinais de dor. Situações como esta devem ser identificadas, avaliadas em termos de condições anteriores, localizadas e inibidas antes que o sistema de ação seja ativado. A teoria de controle da comporta propõe que existe no sistema nervoso um mecanismo, conhecido como controle central (central control trigger) que ativa os processos cognitivos do cérebro, e 
que exercem controle sobre as entradas sensoriais, influenciando no mecanismo de bloqueio da dor. A informação que chega a este controle central é trazida por fibras largas mielínicas que conduzem rapidamente a informação, permitindo ao cérebro identificar, avaliar e modular as entradas antes que o sistema de ação seja ativado por células T.

\subsubsection{Algumas reconsiderações da Teoria de Controle da Comporta}

A teoria original de Melzack e Wall foi modificada pelos próprios autores alguns anos depois (WALL, 1978), introduzindo novos elementos na teoria. O diagrama mostrado na figura 2.4 tinha como ênfase a substância gelatinosa e o balanço de atividades das fibras nervosas. No entanto, diversas descobertas e avanços científicos desde 1965, fizeram com que a teoria fosse revista. Na teoria de 1965, houve uma tentativa de considerar todos os tipos de dor e suas variações e sugerir uma maneira em que os fatos então conhecidos sobre fisiologia e anatomia pudessem juntos produzir uma estrutura consistente para o mecanismo da dor. No entanto, (BRITTON; SKEVINGTON, 1989) discutem que uma teoria plausível descritiva do fenômeno da dor deve ser capaz de explicar de forma consistente, além da parte relacionada à atividade das fibras de diferente calibre, algumas das seguintes observações:

(a) Situações em que uma mesma lesão normalmente pode causar grande, pequena ou até nenhuma dor, ou que o início da sensação de dor é atrasado (por exemplo, lesões adquiridas por soldados em batalhas);

(b) Situações em que a expectativa de dor é suficiente para aumentar o nível de ansiedade e, portanto, a intensidade de dor percebida. 
Em 1982, Melzack e Wall revisaram a teoria inicialmente proposta em 1965, de modo a ressaltar a contribuição de sinais provenientes do cérebro no processo de dor. A figura 2.5 mostra um diagrama do modelo revisado. A presença do controle descendente do cérebro, juntamente com o controle cognitivo, torna possível explicar as observações (a) e (b) citadas no parágrafo anterior, por permitir que o cérebro possa conscientemente ou automaticamente inibir ou promover a transmissão de impulsos nociceptivos para a medula espinhal e assim controlar a percepção da dor.

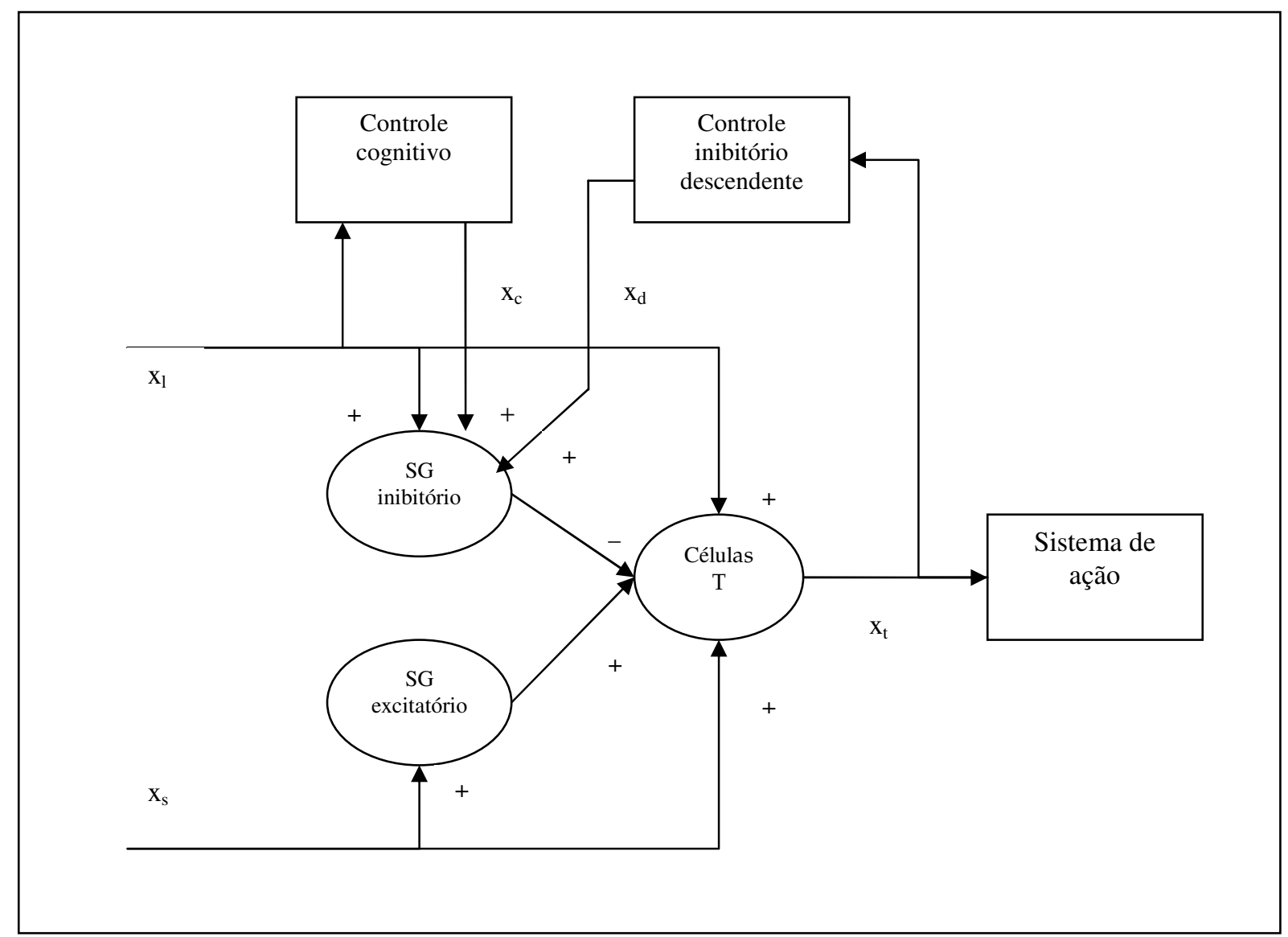

Figura 2. 5 - Diagrama da Teoria de Controle da Comporta considerando a influência do cérebro no processo de modulação da dor.

Fonte: (BRITTON; SKEVINGTON, 1989). 
De acordo com a figura, o controle inibitório descendente refere-se a sinais provenientes de uma região no cérebro conhecida como mesencéfalo (midbrain). A inclusão de tal controle pode ainda auxiliar na explicação do alívio da dor para o caso de existir uma estimulação elétrica artificial nesta área (BRITTON; SKEVINGTON, 1989).

\subsubsection{Sistema de ação}

Uma vez excedido o limiar crítico nas células T, o "disparo" destas células ativaria uma sucessão de respostas por um sistema de ação. Desse modo, uma lesão inesperada na pele é seguida por:

- Resposta de alarme;

- Reflexo de flexão;

- Mudança na postura;

- Vocalização;

- Direcionamento do sistema de visão para examinar a área afetada;

- Evocação de experiências passadas em situações semelhantes e predições das conseqüências da estimulação;

- Vários outros padrões de comportamento como, por exemplo, esfregar a área danificada, evitar realizar determinadas ações, dentre outros. 


\section{CAPÍTULO 3}

\section{REDES NEURAIS ARTIFICIAIS}

Este trabalho tem por objetivo desenvolver um modelo matemático para a dor. A dor envolve experiências fisiológicas e psicológicas, que por sua vez estão associadas a processos complexos, conforme descrito em (PRINCE et al. 2005). É provavelmente devido a estas complexidades inerentes que, apesar de intensivas pesquisas, o fenômeno da dor ainda não possui um modelo matemático satisfatório. Em (HAERI; ASEMANI; GHARIBZADEH, 2003) discute-se que devido à complexidade dos mecanismos neurais da sensação de dor, métodos não-lineares se tornam fundamentais para uma apropriada modelagem desse fenômeno. Nesse contexto, as redes neurais artificiais representam uma alternativa extremamente viável para esta modelagem, uma vez que possibilitam a implementação de comportamentos não-lineares e complexos. 
Adicionalmente, como a dor é um evento tipicamente neural, é natural que o modelo proposto seja baseado em modelos matemáticos de sistemas neurais, como as redes neurais artificiais. Este capítulo descreve os conceitos ligados às redes neurais artificiais, apresentando as definições empregadas na área, e fazendo uma comparação funcional entre o neurônio biológico e o neurônio artificial. Além disso, são apresentados os tipos de rede existentes e as principais funções de ativação utilizadas. O capítulo ressalta ainda a importância da escolha correta dos parâmetros de uma rede neural, descrevendo as etapas que devem ser seguidas para sua confecção. Seguir estas etapas é fundamental e visa garantir que a rede neural construída seja consistente e possua graus de liberdade na sua arquitetura que permitam uma otimização.

\subsection{Definição}

Redes Neurais Artificiais (RNAs) podem ser definidas de diversas formas. Em (HAYKIN, 1999), uma rede neural é definida como um processador paralelamente distribuído constituído de unidades de processamento simples, que têm a propensão natural para armazenar conhecimento experimental e posteriormente torná-lo disponível para o uso. Uma rede neural artificial se assemelha ao cérebro em dois aspectos: o conhecimento é adquirido pela rede através de um processo de aprendizagem; e forças de conexão entre neurônios, conhecidas como pesos sinápticos, são utilizadas para armazenar o conhecimento adquirido.

De acordo com (LOESCH; SARI, 1996), as redes neurais artificiais consistem em sistemas computacionais, implementadas em hardware ou software, que imitam as habilidades computacionais do sistema nervoso biológico, usando um grande número de neurônios artificiais interconectados. A maioria das definições existentes procura conceituar 
RNAs como sistemas computacionais constituídos por unidades de processamento (neurônios), dispostas em uma ou mais camadas e interligadas por um grande número de conexões (pesos).

\subsection{O neurônio biológico}

As Redes Neurais Artificiais são compostas por unidades de processamento semelhantes, em funcionalidade, aos neurônios do cérebro humano. O neurônio biológico é uma célula dividida em três partes: o corpo da célula (soma), os dendritos e o axônio, cada um com funções específicas, porém complementares. A figura 3.1 ilustra de forma simplificada os componentes do neurônio.

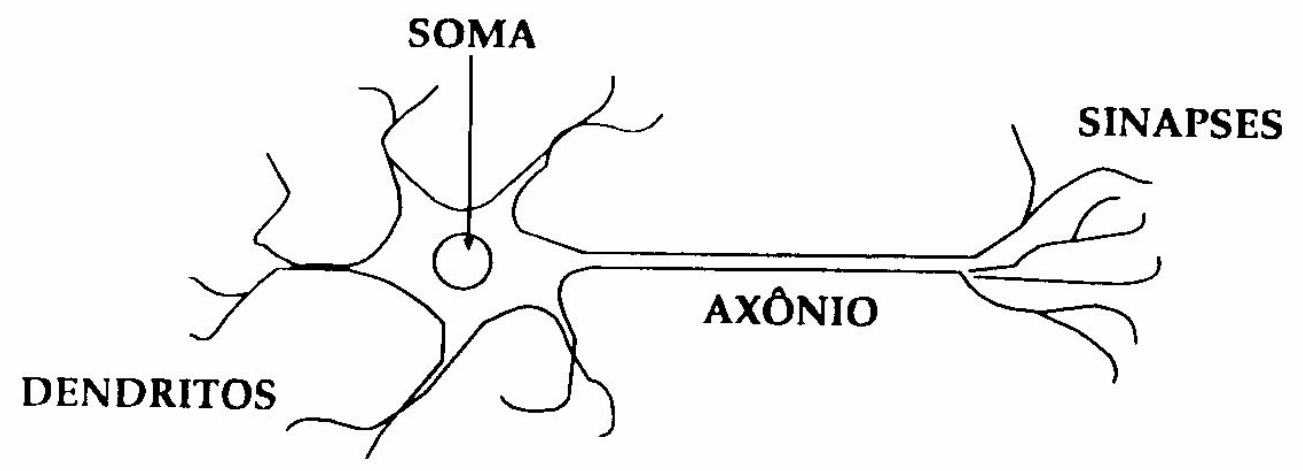

Figura 3. 1 - Componentes do Neurônio.

Fonte: (TAFNER, M. A; XEREZ, M.; I.W. RODRIGUES FILHO, 1999).

Os dendritos têm como função receber os impulsos nervosos oriundos de outros neurônios, e conduzi-los até o corpo celular. Este, por sua vez, processa a informação e gera novos impulsos que são transmitidos a outros neurônios (nodos), passando pelo axônio e atingindo os dendritos do neurônio seguinte (KÓVACS, 1996). Quando os estímulos de entrada, trazidos pelos dendritos, chegam ao corpo da célula, ocorre um processo de 
integração (soma), e como resultado pode ser gerado um impulso elétrico que se propaga até os terminais do axônio. O processo de controle da produção do impulso elétrico é normalmente uma função de limiar que produz uma saída, caso a soma das entradas seja maior ou igual a um dado limiar. A região de contato entre a terminação axônica do neurônio pré-sináptico com o dendrito do neurônio pós-sináptico é denominada de sinapse. É nas sinapses onde os neurônios se conectam funcionalmente formando as redes neurais. As sinapses são capazes de controlar o fluxo de informação entre os neurônios da rede e, sendo seu comportamento variável, permitem ao neurônio se adaptar a diferentes situações.

Há dois tipos de sinapses: as excitatórias, cujo efeito é despolarizar o potencial póssináptico, e as inibitórias, que hiperpolarizam este potencial. As primeiras permitem a passagem de informação entre neurônios, enquanto as segundas envolvem o bloqueio da atividade de uma célula para outra, impedindo ou dificultando a transmissão da informação.

\subsection{O neurônio artificial}

Uma representação típica de um neurônio artificial pode ser visto na figura 3.2. De acordo com a figura, as conexões entre os neurônios procuram simular as conexões biológicas fazendo-se uso dos chamados pesos sinápticos.

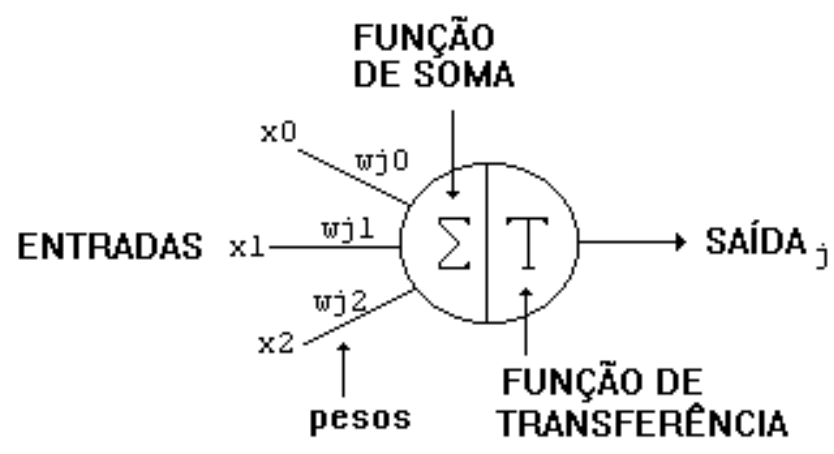

Figura 3. 2 - Representação gráfica de um neurônio artificial.

Fonte: (TAFNER, M. A; XEREZ, M.; I.W. RODRIGUES FILHO, 1999). 
$\mathrm{O}$ valor de um determinado peso, representado por $w$ (do inglês weight), pondera a relevância de uma entrada em relação às outras entradas, para um determinado neurônio. Em outras palavras, isto significa que, quando uma entrada é bastante estimulada, acaba estimulando também os pesos correspondentes à sua conexão. À medida que um peso for demasiadamente estimulado, terá cada vez mais influência no resultado do sinal de saída. A saída do i-ésimo neurônio é a combinação linear das entradas $x_{j}$ dos elementos que são conectados ao elemento i através dos pesos $w_{i j}$.

$$
s_{i}=\sum_{j} w_{i j} \cdot x_{j}
$$

A saída linear $s_{i}$ poderá ser convertida em uma resposta não-linear do neurônio através da função de transferência ou ativação utilizada (degrau, tangente hiperbólica, sigmóide, dentre outras). 


\subsection{Funções de ativação}

As funções de ativação utilizadas nas redes neurais artificiais são apresentadas na tabela 3.1 e as respectivas representações gráficas na figura 3.3.

\begin{tabular}{ll}
\hline Nome da função & Equação \\
\hline Linear & $f(s)=\alpha . s$, onde $\alpha$ é uma constante. \\
\hline Sinal & $f(s)=\left\{\begin{array}{lll}+1 & \text { se } & s \geq 0 \\
-1 & \text { se } & s<0\end{array}\right.$ \\
\hline Degrau & $f(s)=\left\{\begin{array}{lll}+1 & \text { se } & s \geq 0 \\
0 & \text { se } & s<0\end{array}\right.$ \\
\hline Rampa & $f(s)=\left\{\begin{array}{lll}-k & \text { se } & s \leq k \\
k & \text { se } & -k<s<k \\
\text { Logística } & s \geq k\end{array}\right.$ \\
\hline Hiperbólica & $f(s)=\frac{1}{1+e^{-\lambda .(s-\rho)},}$ onde $\lambda$ é o parâmetro de inclinação da \\
\hline & curva sigmoidal e $\rho$ refere-se à translação \\
&
\end{tabular}

Tabela 3. 1 - Tipos de Funções de ativação. 


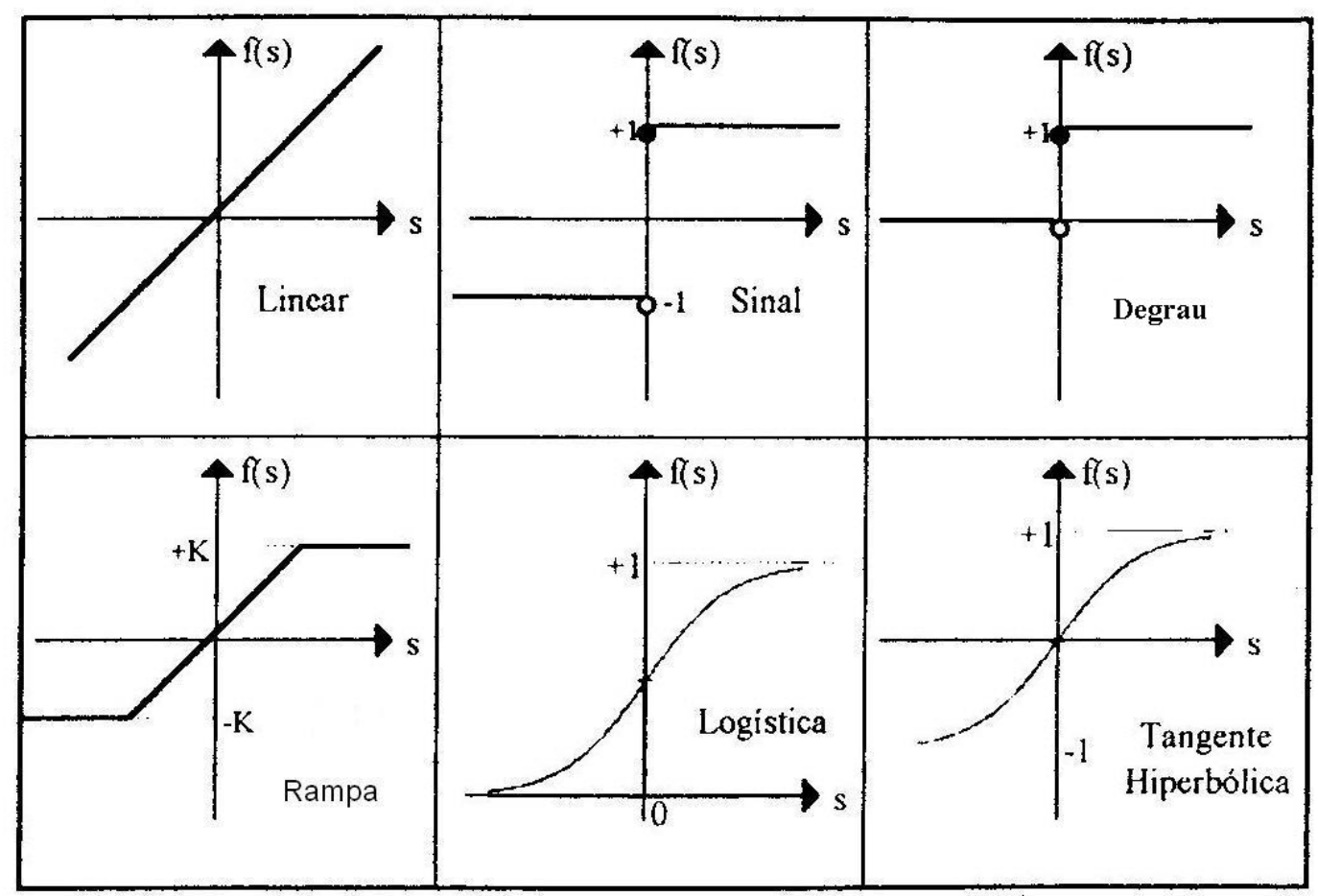

Figura 3. 3 - Representação gráfica de algumas funções de ativação.

Fonte: (LOESCH, C.; SARI, S. T., 1996)

Redes multicamadas geralmente utilizam funções de ativação não-lineares. Caso seja utilizada uma função linear, o desempenho computacional da rede multicamadas será equivalente a de uma rede de uma única camada e tal rede não terá a capacidade de aprender mapeamentos não-lineares.

\subsection{Arquiteturas de Redes Neurais}

Os seguintes componentes fazem parte da definição da arquitetura de uma rede (BRAGA; PONCE; LUDERMIR, 2000):

- Quanto ao número de camadas: uma rede é classificada como rede de camada única quando só há uma camada de neurônios entre qualquer entrada e qualquer saída da 
rede e em rede de múltiplas camadas quando existem no mínimo duas camadas de neurônios entre alguma entrada e alguma saída da rede;

- Quanto ao número de neurônios em cada camada;

- Quanto ao tipo de conexão entre os neurônios: feedforward ou acíclica (a saída de um neurônio na i-ésima camada da rede não pode ser usada como entrada de neurônio em camadas de índice menor ou igual a i) e feedback ou cíclica (a saída de algum neurônio na i-ésima camada da rede é usada como entrada de neurônios em camadas de índice menor ou igual a i);

- Quanto à conectividade: uma rede pode ser classificada como fraca (ou parcial) quando nem todos os neurônios de uma camada i são interconectados a todos os outros neurônios da camada i +1 , ou completamente interconectada.

Outra característica importante a ser considerada no desenvolvimento de uma rede neural refere-se ao número de neurônios na(s) camada(s) intermediária(s). Esse número geralmente é definido de forma empírica e depende fortemente da distribuição dos dados de treinamento e validação da rede (BRAGA; PONCE; LUDERMIR, 2000). Alguns dos métodos mais utilizados consideram o número de neurônios na camada escondida em função do número de entradas e saídas, ou ainda em função da dimensão de conexões com relação ao número de exemplos. Este último procedimento tem como único objetivo reduzir a incidência de overfitting, em que a quantidade de conexões é muito maior que o número de exemplos. Por outro lado, pode ocorrer o underfitting, fenômeno em que a rede pode até convergir, mas apresentando valores grandes para a função de erro ou simplesmente não havendo convergência da rede durante seu treinamento. 


\subsection{Redes neurais feedforward}

$\mathrm{Na}$ operação de uma rede neural feedforward, todas as informações seguem para frente, partindo dos neurônios da camada de entrada para os neurônios das camadas intermediárias ou escondidas (ocultas), e daí para os neurônios da camada de saída. A informação não é retropropagada durante a operação da rede.

\subsection{Tipos de aprendizado}

Há dois métodos principais para o treinamento de redes neurais: o aprendizado supervisionado e o aprendizado não-supervisionado (BRAGA; PONCE; LUDERMIR, 2000). No método de aprendizado supervisionado a entrada e saída desejadas para a rede são fornecidas por um supervisor (professor) externo. O objetivo é ajustar os parâmetros da rede de modo a encontrar uma relação entre as entradas e saídas desejadas. A figura 3.4 ilustra o mecanismo de aprendizado supervisionado. O supervisor indica explicitamente um comportamento certo ou errado para a rede, visando a direcionar o processo de treinamento. A cada padrão de entrada fornecida, compara-se a resposta obtida pela rede com a resposta desejada, ajustando-se os parâmetros da rede de tal forma que esta diferença ou erro seja minimizado. 


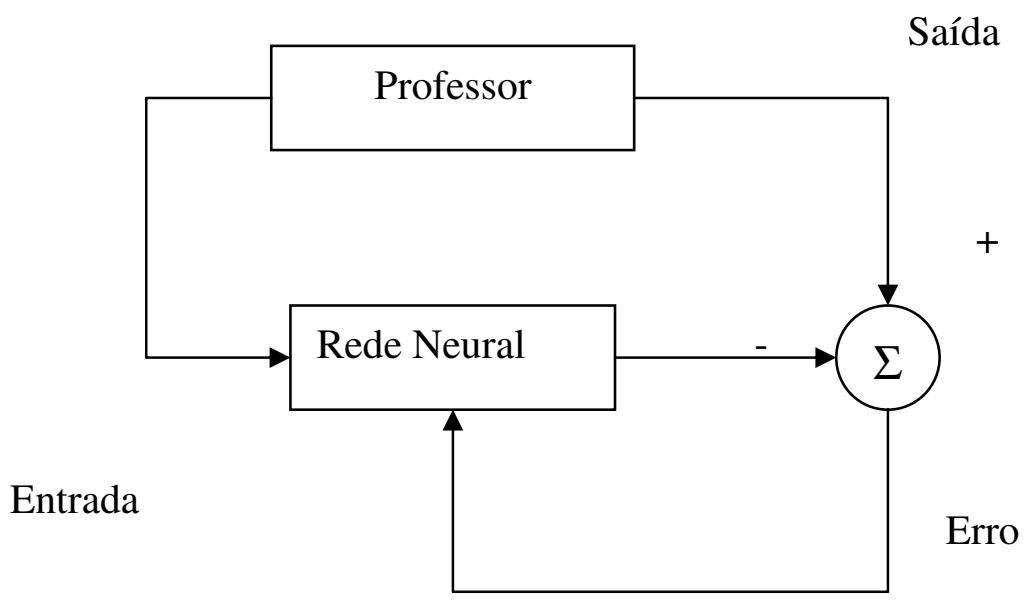

Figura 3. 4 - Processo de aprendizado supervisionado, ou com professor, de uma rede neural artificial.

No método de aprendizado não-supervisionado, ilustrado na figura 3.5, não há um supervisor (professor) para acompanhar o processo de treinamento da rede. Ao contrário do aprendizado supervisionado, neste método não é fornecido um valor de saída desejado para cada padrão de entrada, cabendo à rede neural criar uma classe ou grupo representativo das características relevantes da entrada que é fornecida.

Estímulo

Resposta

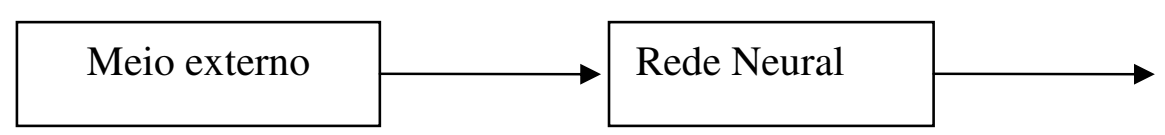

Figura 3. 5 - Aprendizado não supervisionado, ou sem professor, de uma rede neural artificial. 


\subsection{Etapas de desenvolvimento de uma RNA}

O processo de desenvolvimento de uma rede neural segue os seguintes passos (TAFNER; XEREZ; RODRIGUES FILHO, 1995):

I) Coleta e pré-processamento dos dados de entrada e saída para a rede de interesse. Nesta etapa será necessário conferir se há informações suficientes e se elas são relevantes, ou seja, informações redundantes devem ser eliminadas para não prejudicar o desempenho da rede;

II) Preparo dos dados para a rede neural. A rede neural pode manipular somente dados numéricos. Assim, será necessário utilizar esquemas de codificação de dados para tratar dados categóricos de uma forma que a rede possa identificá-los. As redes neurais também trabalham melhor quando os dados são razoavelmente distribuídos. Desta forma, é freqüentemente necessário transformar os dados numéricos para melhorar sua distribuição.

III) Criar a rede. Isso inclui a seleção de uma arquitetura de rede que é apropriada para o problema (selecionar o número de camadas escondidas, o número de neurônios em cada camada, as características de cada neurônio e a função de ativação).

IV) Treinar a rede com um conjunto de dados coletados.

V) Testar a rede treinada com os dados restantes. 


\subsubsection{Coleta de dados correspondentes a fatores cognitivos e emocionais}

Conforme discutido no capítulo anterior, o processo de percepção de dor é influenciado por fatores cognitivos e emocionais. Este tipo de informação pode ser fornecido a um modelo neural através do uso de algumas técnicas de exame ou mapeamento cerebrais. Desta forma, o estado emocional de uma pessoa que estivesse com depressão, por exemplo, poderia ser indicado através do emprego destas técnicas. Esta seção discute algumas das técnicas experimentais que poderiam ser usadas na construção de um banco de dados da atividade cerebral relacionada ao comportamento da dor.

\subsubsection{Eletroencefalograma (EEG)}

O Eletroencefalograma (EEG) é uma técnica de exame cerebral que é realizado por meio de sinais elétricos captados a partir de eletrodos colocados na cabeça do paciente. No EEG, as oscilações da corrente elétrica medida são desenhadas em uma folha sob a forma de ondas. As características das ondas elétricas cerebrais captadas variam conforme o funcionamento (situação funcional) do cérebro.

A evolução da informática, com o desenvolvimento de softwares capacitados a efetuar cálculos matemáticos complexos, aliados à técnica convencional do EEG (Qualitativo), permitiram realizar mapeamentos cerebrais detalhados. Este tipo de exame recebe o nome de EEG Quantitativo e visa proporcionar uma avaliação mais precisa, fornecendo uma visão gráfica mais detalhada na localização das atividades cerebrais (BALLONE, 2005). Em psiquiatria, o EEG Quantitativo tem sido utilizado em diagnósticos envolvendo distúrbios de atenção em crianças, esquizofrenia e depressão. 


\subsubsection{Tomografia Computadorizada (TC)}

A técnica conhecida como tomografia computadorizada é constituída por um tubo de emissão de raios-X que gira em volta do corpo do paciente $\left(360^{\circ}\right)$ e por um conjunto de detectores que vai simultaneamente recolhendo os raios do lado oposto ao tubo de emissão girando também em $360^{\circ}$. Os raios-X recolhidos pelos detectores são variavelmente atenuados pelo corpo do paciente cuja alteração na densidade dos diversos tecidos corpóreos determina o fluxo dos raios transmitidos. Estes raios detectados são convertidos em sinais digitais e processados por computadores de modo a compor as imagens em alta resolução e de aspecto tridimensional. Esta técnica permite uma visualização espacial dos órgãos em geral e, em particular, do cérebro. As imagens do cérebro poderiam ser utilizadas, por exemplo, para a caracterização e localização de tumores.

\subsubsection{Ressonância Magnética (RM)}

A ressonância magnética é uma técnica de mapeamento que aproveita as propriedades naturais dos átomos de hidrogênio existentes no corpo humano para criar uma imagem de diagnóstico. Os átomos de hidrogênio podem ser considerados como pequenos dipolos magnéticos e, quando o corpo do paciente é colocado sob a influência de um forte campo magnético, esses átomos irão se alinhar na direção das linhas de força deste campo. Eles também irão girar em torno dessas linhas de força com uma freqüência $f_{l}$ e no caso de existir uma incidência de ondas eletromagnéticas na mesma frequiência $f_{1}$, eles absorverão energia. Depois que esse campo magnético é desligado, os prótons do hidrogênio voltam à posição anterior devolvendo a energia que ganharam sob a forma de ondas eletromagnéticas. A energia dessas ondas é captada pelo aparelho, que as amplifica e as usa para gerar as imagens. 
A ressonância magnética se distingue dos demais métodos pela não utilização de radiação e tem sido um dos exames mais empregados no campo da neurociência e neurocirurgia.

\subsubsection{PET}

Pela técnica de PET (Positron Emission Tomography ou Tomografia de Emissão Positrônica), átomos de flúor radioativo são incorporados às moléculas de glicose, que é o único alimento das células nervosas. As células nervosas mais ativas absorverão mais essa substância, pois terão um metabolismo mais acelerado e, conseqüentemente, necessitarão de mais energia (KOVÁCS, 1997). Nessas circunstâncias, o átomo de flúor, por ser radioativo, emite um pósitron, que é uma partícula subatômica com carga elétrica positiva. Quando este pósitron colide com um elétron, ocorre a liberação de raios gama, que são captados pelo aparelho de PET. Este exame difere da tomografia computadorizada e da ressonância magnética pelo fato de mostrar a função cerebral ao invés da anatomia, possibilitando avaliar como as diferentes regiões do cérebro funcionam ao se desempenhar as mais diversas atividades mentais. O mapa cerebral fornecido pelo PET corresponde fielmente à função do cérebro, com a vantagem de ser possível obter imagens em tempo real, ou seja, simultaneamente à função cerebral.

Atualmente, o PET tem sido adotado para a coleta de informações valiosas sobre muitas doenças neurológicas e psiquiátricas, notadamente em relação à esquizofrenia, depressão, transtorno obsessivo-compulsivo dentre outras desordens. Além disso, este tipo de exame tem se mostrado útil para a investigação das chamadas funções cognitivas, como por exemplo, a consciência, o aprendizado, a sensibilidade e a memória. 


\subsubsection{Uso do PET para detectar emoções negativas}

Experimentos realizaram uma comparação de imagens PET do fluxo sangüíneo do cérebro entre um grupo de pacientes com depressão e um grupo de pacientes normais (de controle) da mesma idade (POSNER; RAICHLE, 1994). O experimento selecionou esse último grupo, evitando pacientes com doenças psiquiátricas, o que poderia interferir na análise. As imagens PET de cada grupo foram avaliadas conjuntamente para produzir uma imagem composta e representativa de pacientes normais e uma outra imagem correspondendo a pacientes com depressão. A imagem representativa do grupo de controle foi então subtraída da imagem correspondendo ao grupo de pacientes deprimidos para revelar as mudanças funcionais no cérebro associadas à depressão. A imagem resultante desta análise, conforme demonstrado em (POSNER; RAICHLE, 1994), imediatamente revela um aumento no fluxo sangüíneo no córtex frontal em pacientes deprimidos, especialmente no lado esquerdo. Além disso, há uma diminuição do fluxo sangüíneo nos lóbulos parietal e posterior temporal.

\subsubsection{Tratamento das informações cognitivas coletadas}

As técnicas apresentadas anteriormente podem ser combinadas de modo a fornecer dados sobre as atividades cerebrais com grande riqueza de detalhes. Pode-se, por exemplo, combinar o método de EEG, que fornece características sobre o processamento temporal e a intensidade dos impulsos elétricos das células nervosas envolvidas, com o PET, que fornece informações a respeito da localização das áreas funcionais cerebrais. Os dados fornecidos pelos exames devem ser tratados de forma a adequá-los como entradas de uma rede neural, ou seja, é preciso transformá-los em resultados quantitativos para o processamento da rede. Este tratamento pode ser feito tomando uma amostragem de vários pacientes, de forma a definir 
qual o estado ou imagem que pode ser considerada como representativa de uma pessoa que estivesse, por exemplo, deprimida (estado cognitivo negativo). Esta situação seria representada pelo valor "1" (ou ainda um valor próximo de "1", considerando-se uma faixa de tolerância) enquanto que a situação emocional inversa, ou seja, a imagem ou estado emocional de um indivíduo motivado pode ser representado pelo valor zero "0" (ou próximo de "0"). Neste caso, o valor médio igual a 0.5 indica o estado emocional em que nenhum destes dois extremos predomina.

\subsection{Por que utilizar Redes Neurais Artificiais?}

Há algumas aplicações industriais e comerciais que empregam algoritmos determinísticos para se obter um comportamento desejado ou uma solução apropriada para algum problema. No entanto, em outras aplicações, a complexidade desses algoritmos tradicionais é muito alta, ou o algoritmo não pode ser completamente especificado. Este é o caso que ocorre com várias aplicações relacionadas com problemas de raciocínio e associatividade, como muitas vezes acontece em sistemas de identificação, controle, predição, robótica, processamento de sinal, filtragem, processamento de imagem e classificação de padrões. Para estes casos, as redes neurais se mostram capazes de fornecer soluções razoáveis para tais problemas aplicando estratégias parecidas ao raciocínio humano, tais como classificação, analogia, aprendizagem e generalização.

A capacidade de aprender por meio de exemplos e de generalizar a informação aprendida são os principais atrativos que as RNAs oferecem. A fase de aprendizagem consiste em extrair as principais características dos dados de entrada (representativos da informação fornecida) para que sejam utilizadas posteriormente na geração de respostas para o problema 
proposto. A generalização está associada à capacidade da rede em aprender fazendo-se uso de um conjunto reduzido de exemplos, e posteriormente, apresentar resultados coerentes a qualquer entrada que não foi submetida à rede durante a etapa de treinamento. Portanto as redes neurais são capazes de extrair informações não apresentadas de forma explícita através dos exemplos de treinamento utilizados.

Outro aspecto relevante é a capacidade de processamento temporal que, aliada à vantagem descrita no parágrafo anterior, fazem das RNAs uma ferramenta extremamente poderosa e atrativa para a solução de problemas com grande complexidade (BRAGA; PONCE; LUDERMIR, 2000).

\subsection{Aplicações de Redes Neurais Artificiais}

Atualmente, inúmeras aplicações empregam as redes neurais. $\mathrm{Na}$ área financeira, por exemplo, existem empresas de investimentos que utilizam redes neurais para obter e analisar prognósticos de comportamentos de ações no mercado financeiro. Outro exemplo de aplicação dessa ferramenta pode ser encontrado no diagnóstico médico. Durante o aprendizado da rede, submete-se uma série de diagnósticos de pacientes com várias características (idade, sexo, dentre outros) e sintomas e os respectivos resultados de seus testes. Além disso, são fornecidos os diagnósticos médicos para cada doença. Portanto, ao serem apresentados os dados de um novo paciente, com seus respectivos sintomas, a rede fornecerá um diagnóstico para cada novo caso. Entre outras aplicações destacam-se: controle de processos, reconhecimento de imagens, reconhecimento de sinais de voz, reconhecimento e análise de aromas e odores (BARATTO, 1997). 
CAPÍTULO 4

\section{METODOLOGIA EXPERIMENTAL}

Uma modelagem matemática do fenômeno da dor é descrita em (PELAÉZ; FIALHO; PIQUEIRA, 2005). Aquela modelagem mostrou como o balanço de atividades entre as fibras de largo e pequeno diâmetro influencia no processo de percepção de dor. Mostrou-se ainda que a dor é percebida quando há atividade na fibra nervosa nociceptiva e ausência de estímulos nervosos na fibra mecano-receptora. A partir deste resultado, que de certa forma é consistente com a Teoria de Controle da Comporta, é possível construir modelos de redes neurais com aprendizado supervisionado, considerando-se uma determinada arquitetura e outros fatores envolvidos no fenômeno da dor além dos sinais conduzidos pelas fibras nociceptivas e mecano-receptoras. 
Em (BARNHILL et al., 1996) verificou-se que experimentos com pessoas mostraram que a inibição ou percepção da dor pode apresentar comportamentos diversos, variando de indivíduo para indivíduo. Em (NATHAN; RUDGE, 1974) mostrou-se que a resposta à dor não é uniforme entre as pessoas: em alguns casos o Mecanismo de Controle de Comporta pode ser aplicado enquanto que em outros casos não. Constatou-se ainda, que poderia existir uma relação entre a temperatura inicial da pele e o limiar de dor no caso de haver uma lesão por queimadura (estímulo de calor). Portanto, o processo de percepção de dor está vinculado a diversos fatores: biológicos, fisiológicos, situacionais, químicos, emocionais, dentre outros. Daí a importância de se caracterizar a contribuição de cada um desses fatores no fenômeno da dor.

Este trabalho propõe dois modelos de redes considerando-se os principais fatores envolvidos no processo de percepção de dor. Será demonstrado que, conforme novos fatores são adicionados ao modelo para descrever os processos de dor, maior o número de casos que podem ser englobados por aquele modelo. O algoritmo de treinamento utilizado nos dois modelos propostos é o algoritmo de retroprogação, que é um dos algoritmos mais empregados em redes neurais. As redes treinadas com este algoritmo apresentam certa robustez, ou seja, mesmo que os dados de testes utilizados na rede após o treinamento apresentem alguma variação, a rede neural fornecerá respostas de forma satisfatória, dentro de uma faixa de tolerância. 


\subsection{Procedimento para ajustes dos parâmetros da rede neural}

Neste item são descritos os mecanismos neurais regulatórios utilizados na implementação dos modelos estudados. São considerados três aspectos: alteração dos pesos sinápticos, o ajuste do deslocamento da função de ativação e o ajuste da inclinação da curva da função de ativação. Cada um destes mecanismos regulatórios é discutido em detalhe adiante.

\subsubsection{Algoritmo de Treinamento}

O treinamento da rede é realizado utilizando-se o algoritmo de retropropagação (backpropagation) que consiste basicamente da apresentação de um padrão à entrada da rede, causando uma resposta na saída. Na camada de saída há uma resposta real que será comparada com a resposta esperada, produzindo um erro. Este erro é minimizado da saída para a entrada recalculando os pesos sinápticos por meio do algoritmo do gradiente descendente. Em outras palavras, é apresentado inicialmente à rede um padrão X de entrada, que produzirá uma saída Y. De posse da saída obtida para cada padrão, é calculado o erro (consistindo da diferença entre o valor desejado e a saída fornecida pela rede). O próximo passo é determinar o erro propagado no sentido inverso, através da rede, associada à derivada do erro quadrático de cada elemento em relação aos pesos e, finalmente, é realizada o ajuste dos pesos de cada elemento. O algoritmo prossegue com a apresentação de um novo padrão, sendo o processo repetido para todos os padrões até que ocorra a convergência. Esta convergência é alcançada quando o erro for menor que um valor mínimo aceitável préestabelecido. 
O algoritmo backpropagation consiste na adaptação dos pesos da rede com o propósito de minimizar o erro quadrático da rede. Sendo a saída do neurônio dada por:

$$
y_{i}=g\left(\sum_{j=1}^{n} w_{i j} \cdot x_{j}\right)
$$

E o erro é dado por:

$$
E(w)=\sum_{l=1}^{L}\left(g\left(w^{t} x_{l}^{d}\right)-y_{l}^{d}\right)^{2}
$$

O gradiente desta função de erro resulta:

$$
\frac{d E(w)}{d w}=2 \cdot \sum_{l=1}^{L}\left(g\left(w^{t} x_{l}^{d}\right)-y_{l}^{d}\right) \frac{d g\left(w^{t} x_{l}^{d}\right)}{d w}=2 \cdot \sum_{l=1}^{L}\left(g\left(w^{t} x_{l}^{d}\right)-y_{l}^{d}\right) \cdot \frac{d g(v)}{d v} \cdot \frac{d\left(w^{t} \cdot x_{l}^{d}\right)}{d w}
$$

$$
\Leftrightarrow 2 \cdot \sum_{l=1}^{L}\left(y_{l}-y_{l}^{d}\right) \cdot \frac{d g(v)}{v} \cdot x_{l}^{d}=-2 \cdot \sum_{l=1}^{L} \delta_{l} \cdot x_{l}^{d}
$$

Onde $v=w^{t} \cdot x$

$\mathrm{E} \delta_{l}=\left(y_{l}^{d}-y_{l}\right) \cdot \frac{d g(v)}{d v}$

Portanto, considerando-se o neurônio de índice $i$ de uma rede neural, e utilizando-se o método do gradiente descendente, o ajuste dos pesos sinápticos pode ser formulado como (KÓVACS, 1996):

$$
w(k+1)=w(k)+\Delta w(k)
$$


Onde $\Delta w(k)=\eta \cdot \frac{d E(w)}{d w}$ e com $\Delta w(k)$ sempre na direção oposta ao gradiente.

Há dois tipos de treinamento que podem ser empregados: o chamado modo de treinamento seqüencial e o modo de treinamento por lote. O modo seqüencial é aquele em que o ajuste dos pesos é efetuado após cada padrão, enquanto que no lote, os pesos são ajustados somente após a apresentação de todos os padrões simultaneamente, nos quais é realizado o treinamento da rede. Neste trabalho, a forma de treinamento utilizado foi o modo de treinamento seqüencial.

\subsubsection{Função de ativação}

Os neurônios empregados nos modelos propostos neste trabalho possuem a função sigmóide como função de ativação. A função sigmóide, normalmente utilizada para decisões em que a saída limite é disparada quando há uma saturação muito alta do valor de ativação, é dada por:

$$
y(x)=\frac{1}{\left(1+e^{-\lambda \cdot(x-\rho)}\right)}
$$

onde $\rho$ e $\lambda$ correspondem respectivamente à translação e inclinação da curva sigmoidal. $\mathrm{O}$ gráfico dessa função, com um formato de "s", é mostrado na figura 4.1. 


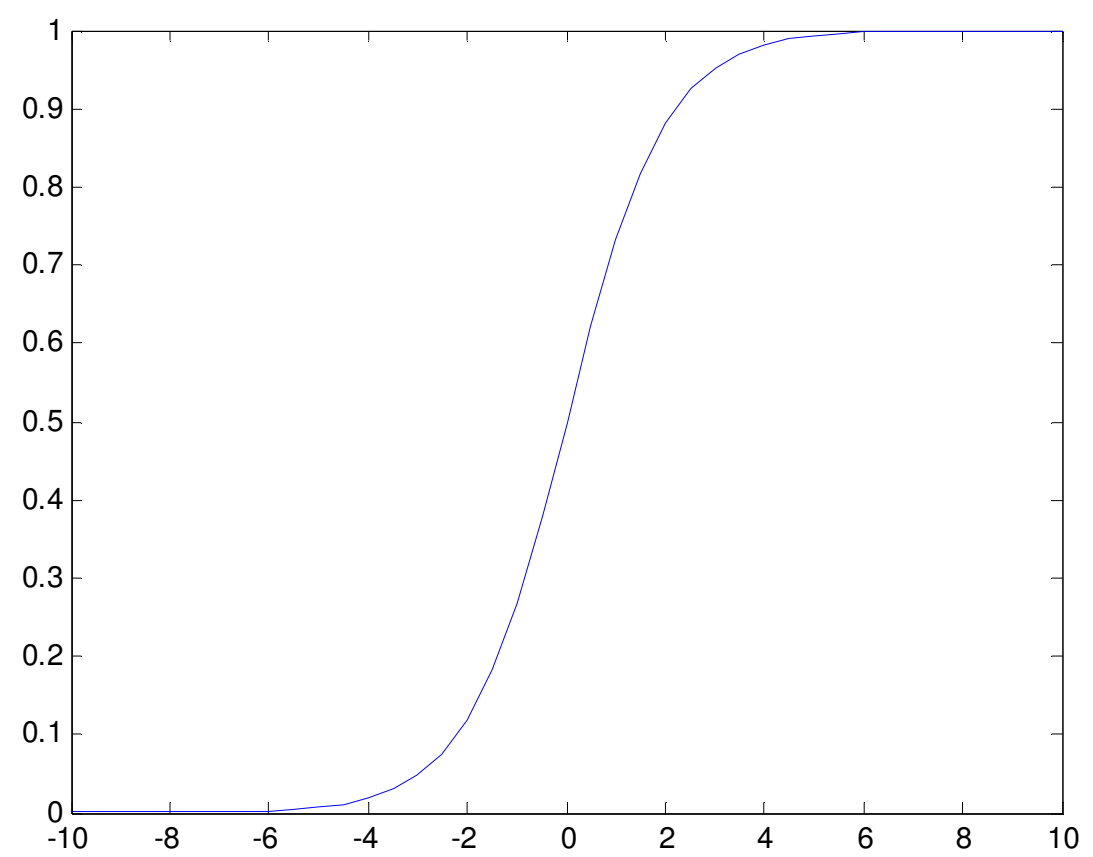

Figura 4. 1 - Curva sigmoidal para função de transferência.

A função sigmoidal produz um sinal nulo de saída somente quando a ativação tiver um grande valor negativo, e produz o valor de saída unitário quando a ativação tiver um grande valor positivo. Essa é a função de ativação mais utilizada na construção de redes neurais, devido a sua propriedade de diferenciabilidade, que permite o emprego do algoritmo de retropropagação (backpropagation) no processo de aprendizagem (HAYKIN, 1999). Uma propriedade que justifica o emprego da função sigmóide é que a saída produzida pela função situa-se entre 0 e 1 , ou seja, com valores representativos de presença ou não de estímulos nervosos, sendo estes valores sempre positivos.

\subsubsection{Ajuste da inclinação e do deslocamento da sigmóide}

A translação da função sigmóide já foi empregada em diversas aplicações (LOTUFO, 2004) com o objetivo de melhorar a capacidade da obtenção de uma solução, ampliando o 
espaço de busca da mesma. O uso desta metodologia permite uma modificação eficiente dos parâmetros da rede neural, resultando em convergência no treinamento e resultados mais precisos em comparação com a formulação convencional do algoritmo de retropropagação.

A adaptação do limiar de disparo é um mecanismo regulador da atividade neural que faz com que neurônios pouco estimulados se tornem ativos por meio da redução gradual do limiar de disparo (threshold). O mecanismo age de modo análogo para neurônios que são intensamente estimulados, produzindo uma elevação do limiar de disparo. Desse modo, é possível controlar a sensibilidade de um determinado neurônio a entradas com valores muito baixos ou altos. Algumas células nervosas biológicas usufruem deste mecanismo de adaptação para manter uma certa sensibilidade a diferentes níveis de entrada sináptica (DESAI; RUTHERFORD; TURRIGIANO, 1999).

O processo adaptativo da função de ativação, como um todo, consiste na realização do ajuste, de forma sistemática, da inclinação (parâmetro $\lambda$ ) e da translação (parâmetro $\rho$ ) da função sigmóide como proposto em (STAMATIS; PARTHIMOS; GRIFFITH, 1999). É um procedimento em que os parâmetros $\lambda$ e $\rho$ são adaptados de forma análoga ao que é realizado com relação aos pesos sinápticos, sendo a regra de adaptação utilizada, a retropropagação. As figuras 4.2 e 4.3 apresentam o comportamento da função sigmóide como função das variações de translação (parâmetro $\rho$ ) e inclinação (parâmetro $\lambda$ ), respectivamente. 


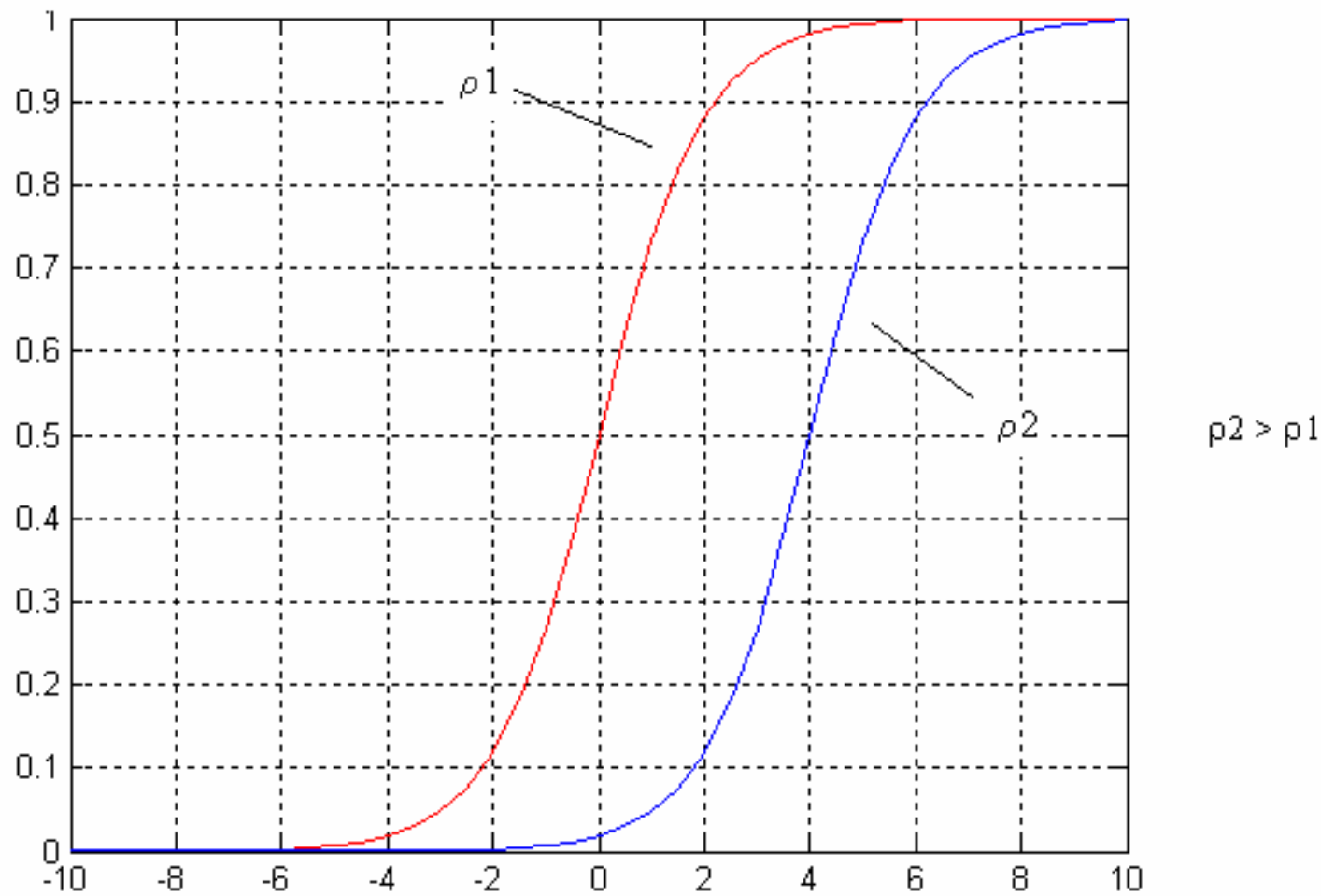

Figura 4. 2 - Ajuste do parâmetro de deslocamento da função sigmoidal.

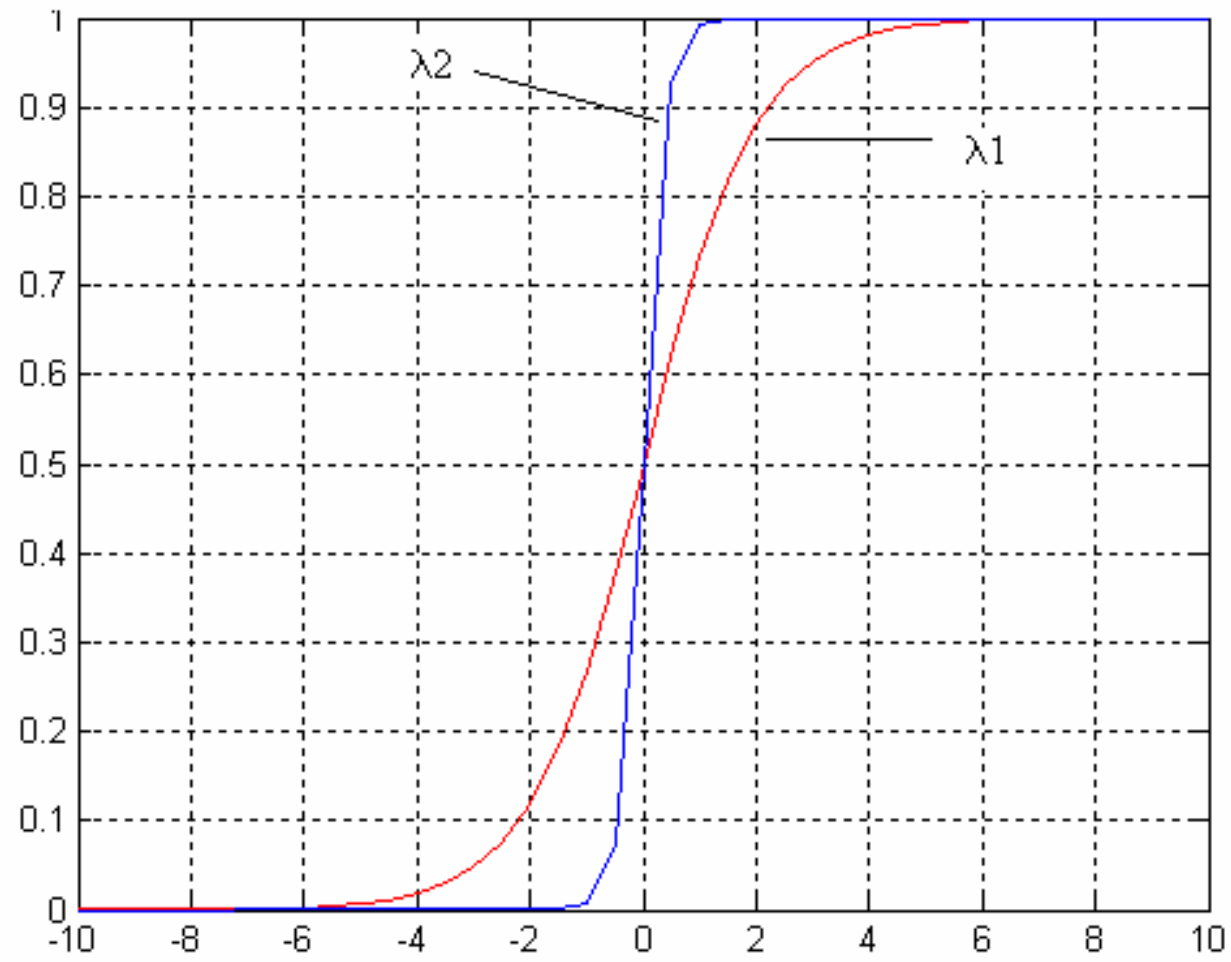

$\lambda 2>\lambda 1$

Figura 4. 3 - Ajuste do parâmetro de inclinação da função sigmoidal. 
A função de ativação é da forma geral $g(\lambda ; \rho ; s)$, onde $\lambda$ e $\rho$ representam respectivamente as propriedades de deslocamento e translação (STAMATIS; PARTHIMOS; GRIFFITH, 1999), enquanto $s$ representa a soma ponderada das entradas, ou seja, a soma de todas as entradas do neurônio multiplicadas pelos respectivos pesos.

As saídas resultantes de cada um dos neurônios que formam a rede podem ser escritas como:

Camada de entrada/escondida:

$$
s_{i}=\sum_{j} w_{i j} \cdot x_{j} \quad z_{j}=g\left(\lambda_{i} ; \rho_{i} ; s_{i}\right)
$$

Camada de saída:

$$
s_{k}=\sum_{i} w_{k j} \cdot z_{i} \quad y_{k}=g\left(\lambda_{k} ; \rho_{k i} ; s_{k}\right)
$$

Os parâmetros de inclinação e translação contêm taxas de aprendizagem correspondentes denotadas por $\eta_{\lambda}$ e $\eta_{\rho}$, respectivamente. $O$ ajuste do parâmetro de inclinação é dado por:

$$
\lambda_{i}(k+1)=\lambda_{i}(k)+\Delta \lambda_{i}(k)
$$

Onde: $\Delta \lambda_{i}(k)=-\gamma^{\lambda}\left[\nabla_{i}^{\lambda}(k)\right](4.12)$

$\nabla_{i}^{\lambda}(k)$ : gradiente do erro quadrático relacionado à inclinação do neurônio i; 
$\lambda_{\mathrm{i}}=\left[\begin{array}{lllll}\lambda_{o i} & \lambda_{1 i} & \lambda_{2 i} & \ldots & \lambda_{n i}\end{array}\right]^{T}:$ vetor contendo as inclinações do neurônio i

$\gamma^{\lambda}$ : taxa de treinamento relacionada à $\lambda$.

O gradiente $\nabla_{i}^{\lambda}$ é representado por:

$\nabla_{i}^{\lambda}(k)=\frac{\partial \varepsilon_{i}^{2}}{\partial \lambda_{i}(k)}=2 \varepsilon_{i} \frac{\partial \varepsilon_{i}}{\partial \lambda_{i}}=-2 \varepsilon_{i} \frac{\partial y_{i}}{\partial \lambda_{i}}=-2 \varepsilon_{i} \sigma_{i}^{\lambda}$

Em que $\sigma_{i}^{\lambda}$ é a derivada da função sigmóide relacionada à $\lambda_{\mathrm{i}}$.

A regra geral que define a adaptação do parâmetro de inclinação da função sigmoidal é dada pela equação abaixo (LOPES; LOTUFO, 2003):

$$
\lambda_{i}(k+1)=\lambda_{i}(k)+2 \cdot \gamma^{\lambda} \cdot \delta_{i}^{\lambda}
$$

Regra que define o cálculo de $\delta_{i}^{\lambda}$ :

- última camada: $\delta_{i}^{\lambda}=\sigma_{i}^{\lambda} \cdot \varepsilon_{i}$

- demais camadas: $\delta_{i}^{\lambda}=\sigma_{i}^{\lambda} \cdot \sum_{j} w_{i j} \cdot \delta_{j}^{\lambda}$

Similar ao procedimento descrito anteriormente, o ajuste do parâmetro de translação é dado por (LOPES; LOTUFO, 2003):

$$
\rho_{i}(k+1)=\rho_{i}(k)+\Delta \rho_{i}(k)
$$

Onde: $\Delta \rho_{i}(k)=-\gamma^{\rho}\left[\nabla_{i}^{\rho}(k)\right]$ 
$\nabla_{i}^{\rho}(k)$ : gradiente do erro quadrático relacionado ao deslocamento da função do neurônio $i$;

$\rho_{i}=\left[\begin{array}{lllll}\rho_{o i} & \rho_{1 i} & \rho_{2 i} & \ldots & \rho_{n i}\end{array}\right]^{T}$ : vetor contendo os deslocamentos do neurônio i

O gradiente $\nabla_{i}^{\rho}$ é representado por:

$\nabla_{i}^{\rho}(k)=\frac{\partial \varepsilon_{i}^{2}}{\partial \rho_{i}(k)}=2 \varepsilon_{i} \frac{\partial \varepsilon_{i}}{\partial \rho_{i}}=-2 \varepsilon_{i} \frac{\partial y_{i}}{\partial \rho_{i}}=-2 \varepsilon_{i} \sigma_{i}^{\rho}$

Em que $\sigma_{i}^{\lambda}$ é a derivada da função sigmóide relacionada a $\rho_{i}$.

A regra geral que define a adaptação do parâmetro de translação da função sigmoidal é dada pela equação abaixo:

$$
\rho_{i}(k+1)=\rho_{i}(k)+2 \cdot \gamma^{\rho} \cdot \delta_{i}^{\rho}
$$

Regra que define o cálculo de $\delta_{i}^{\rho}$ :

- última camada: $\delta_{i}^{\rho}=\sigma_{i}^{\rho} \cdot \varepsilon_{i}$

- demais camadas: $\delta_{i}^{\rho}=\sigma_{i}^{\rho} \cdot \sum_{j} w_{i j} \cdot \delta_{j}^{\rho}$ 


\subsection{Uso do MatLab para o desenvolvimento de RNA}

O MatLab (Matrix Laboratory) é um pacote de softwares desenvolvido pela Mathworks Incorporation para computação numérica científica e de engenharia (DEMUTH; BEALE, 1994). Há mais de uma década, os aplicativos de Redes Neurais no MatLab vem sendo usados em diversas áreas, desde a engenharia até a medicina. Como exemplo, pode-se citar a implementação de uma rede neural utilizando-se o algoritmo de retropropagação no Reconhecimento de Doenças do Coração (SANTOS; ROMERO, 2004).

As implementações dos modelos neurais propostos neste trabalho foram realizadas a partir de expressões matemáticas e matrizes implementadas no MatLab, apesar da disponibilidade de uma ferramenta específica para a aplicação em questão, o Toolbox Neural Network do MatLab. Esta escolha se justifica pelo fato de permitir mostrar todo o processo envolvido na confecção de uma rede neural, ao invés de simplesmente realizar um treinamento e teste de uma "caixa preta" como seria feito caso fosse utilizado o Toolbox. Apesar da possibilidade de se implementar esta rede em outras linguagens de programação (C, C++, Java), a escolha pela utilização do MatLab se justifica pela interface gráfica oferecida, que permite facilmente imprimir gráficos para o acompanhamento do processo de convergência dos pesos sinápticos, pela facilidade em se trabalhar com expressões matemáticas (como a função sigmoidal e sua respectiva derivada), assim como operações envolvendo matrizes numéricas. 


\subsection{Modelo Neural com duas entradas}

O modelo inicialmente adotado nos experimentos, apresentado na figura 4.1, considera alguns dos principais fatores envolvidos no processo de dor e é constituído por três camadas de neurônios. A camada de entrada representa os dois tipos de fatores que podem interferir no processo de percepção de dor: o sinal das fibras de pequeno diâmetro relacionado à dor e o sinal das fibras de largo diâmetro relacionado, por exemplo, à ação de massagear o local lesionado para aliviar a dor.

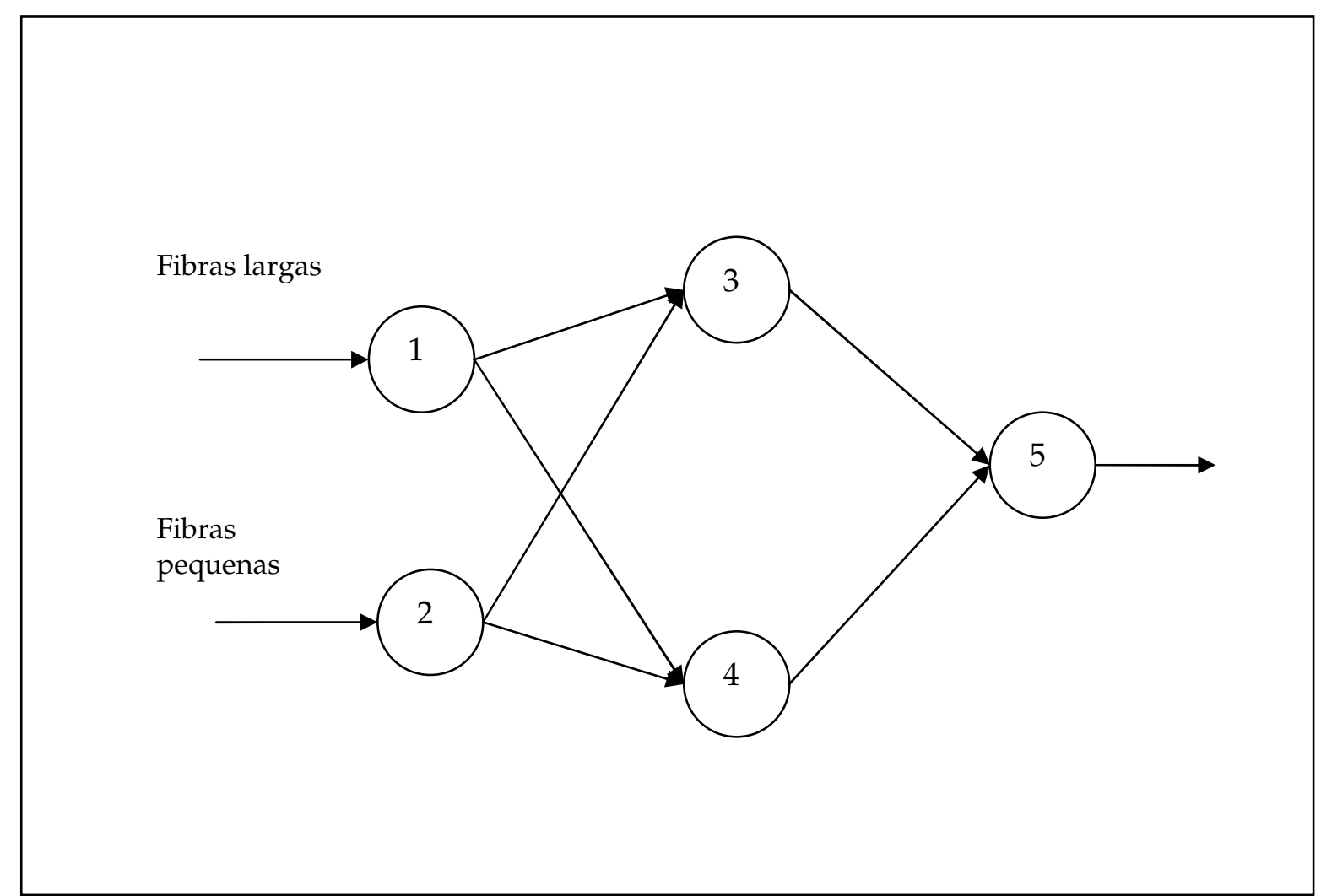

Figura 4. 4 - Modelo Neural para o Mecanismo da porta com duas entradas.

Este modelo é composto por uma rede neural feedforward, totalmente interconectada, constituída por cinco neurônios. O emprego de uma rede totalmente interconectada pode ser visto como uma representação funcional ao Trato de Lissauer presente no sistema biológico, onde o processamento realizado em uma determinada célula da substância gelatinosa pode ser 
influenciado pela contribuição dos sinais de outros neurônios de entrada. No sistema biológico, estas células estão interligadas pelo feixe de fibras do Trato de Lissauer. Assim um sinal de entrada que é enviado a uma determinada célula na substância gelatinosa pode interferir na resposta de outra célula.

O número de neurônios na camada escondida foi escolhido baseando-se na quantidade de elementos de entrada. Neste caso, adotou-se que o número de neurônios na camada escondida deve ser maior ou igual ao número de neurônios na camada de entrada, ou seja:

$$
n_{i+1} \geq n_{i}
$$

onde $n_{i+1}$ representa o número de neurônios na camada escondida e $n_{i}$, o número de neurônios na camada de entrada.

A escolha desse critério se deve ao fato de que inicialmente são necessários pelo menos dois elementos de processamento na camada oculta, um responsável pelo papel de facilitador e outro pela função de inibidor do sinal de dor. Isto leva ainda em conta que sempre haverá no mínimo duas entradas na rede, uma entrada relacionada ao sinal propagado pela fibra sensorial e outra entrada referente à fibra que conduz o sinal de dor. Adicionalmente, um aumento no número de elementos de entrada requer também um aumento no número de elementos na camada intermediária, de tal forma a garantir a convergência da rede. Por outro lado, deve-se garantir ainda que o número de elementos na camada intermediária não seja muito alto, evitando assim o fenômeno de overfitting da rede. Em resumo, o dimensionamento da camada escondida pode ser feito baseando-se no menor 
número de neurônios $n_{i+1}$ que satisfaça a equação 4.23, assegurando convergência e evitando que a rede memorize os padrões de treinamento.

A camada de saída é constituída por um único neurônio correspondente à célula nervosa de transmissão do sinal de dor. Este modelo inicial considera apenas a informação propagada pelas vias nervosas como fator de influência no processo de dor. Em outras palavras, tal modelo tem como objetivo representar o processo de percepção de dor considerando-se apenas o balanço de atividades entre as fibras de largo e pequeno diâmetro. Desta forma, dependendo do valor das entradas (se há ou não entrada de dor e/ou estímulo sensorial) o neurônio de número cinco (neurônio de saída) pode transmitir ou não um impulso nervoso. O modelo de duas entradas apresenta um comportamento que pode ser representado por uma tabela contendo os seguintes elementos exemplificando algumas das entradas que podem ser submetidas à rede:

\begin{tabular}{|l|l|l|l|}
\hline Caso & $\begin{array}{l}\text { Fibras Largas } \\
(\text { Large })\end{array}$ & $\begin{array}{l}\text { Fibras Finas } \\
(\text { Small })\end{array}$ & Saída rede \\
\hline 1 & 0.00 & 0.00 & 0.00 \\
\hline 2 & 0.00 & 0.50 & 1.00 \\
\hline 3 & 0.00 & 1.00 & 1.00 \\
\hline 4 & 0.50 & 0.00 & 0.00 \\
\hline 5 & 0.50 & 0.50 & 0.00 \\
\hline 6 & 0.50 & 1.00 & 1.00 \\
\hline 7 & 1.00 & 0.00 & 0.00 \\
\hline 8 & 1.00 & 0.50 & 0.00 \\
\hline 9 & 1.00 & 1.00 & 0.00 \\
\hline
\end{tabular}

Tabela 4. 1 - Tabela da verdade para o modelo de duas entradas.

Em (KOVÁCS, 1997) descreve-se que a intensidade do estímulo nervoso é, em alguns casos, uma função direta e praticamente linear da taxa ou freqüência de disparo dos pulsos nervosos. Considerando-se entradas normalizadas para a rede, tem-se que o valor " 1 " indica 
fibras nervosas transmitindo sinais com freqüência máxima enquanto o valor " 0 ” indica a ausência ou baixa atividade presente na fibra. Desta forma, uma fibra nociceptiva transmitindo pulsos elétricos com freqüência máxima pode representar uma situação onde o estímulo doloroso é extremamente intenso. E nenhuma atividade na fibra indica o caso em que não há a presença de dor. Valores situados dentro desta faixa (entre 0 e 1) representariam situações intermediárias.

Na tabela 4.1, o número "1" (um) pode corresponder a um trem de pulsos que provoca a sensação de dor (conduzido pelas fibras de pequeno diâmetro), ou a percepção de uma massagem para aliviar a dor (para o sinal conduzido pelas fibras de largo diâmetro). Pela tabela anterior, pode-se perceber que:

- Na ausência de dor e estímulo sensorial (massagem), não há nenhum sinal de dor sendo transmitido (caso 1);

- Sem dor, com estímulo sensorial também não haverá a transmissão de sinal de dor (casos 4 e 7);

- Ao se ter dor e sem nenhum estímulo sensorial, é enviado ao cérebro um sinal de que uma lesão ocorreu (casos 2 e 3);

- Haverá a transmissão a transmissão de dor no caso do sinal propagado pela fibra fina seja maior que aquele presente na fibra larga (casos 6 e 8);

- A presença de dor e estímulo sensorial com mesma intensidade fará com que não seja enviado nenhum sinal ao cérebro (casos 5 e 9).

Os dados da tabela 4.1 exemplificam um conjunto de informações que pode ser adotado durante o processo de treinamento da rede. Neste caso, consideram-se as seguintes 
situações: nenhuma atividade, sinal de intensidade média e máxima intensidade presente em cada fibra nervosa.

\subsubsection{Implementação da rede com duas entradas}

Considerando-se a premissa de que a tabela 4.1 representa com alguma fidelidade o processo de percepção de dor típica em um ser humano, uma rede neural pode ser utilizada de forma que desempenhe a mesma função de um sistema nervoso biológico. O modelo neural mostrado na figura 4.4 é treinado pelo algoritmo de retropropagação (backpropagation) sofrendo um ajuste dos pesos sinápticos, da translação e da inclinação da função de ativação de todos os neurônios que compõem a rede. Conforme descrito nos próximos itens, o teste da rede fornece resultados consistentes, demonstrando o que eventualmente ocorre em uma pessoa ao se deparar com algumas das situações descritas pela tabela de dados 4.1.

Após determinar a dimensão das saídas que são esperadas para cada padrão na entrada, o aprendizado da rede pode ser escolhido como supervisionado. A rede neural mostrada na figura 4.1 pode ser vista em detalhes na figura 4.5 , que evidencia os pesos sinápticos. 


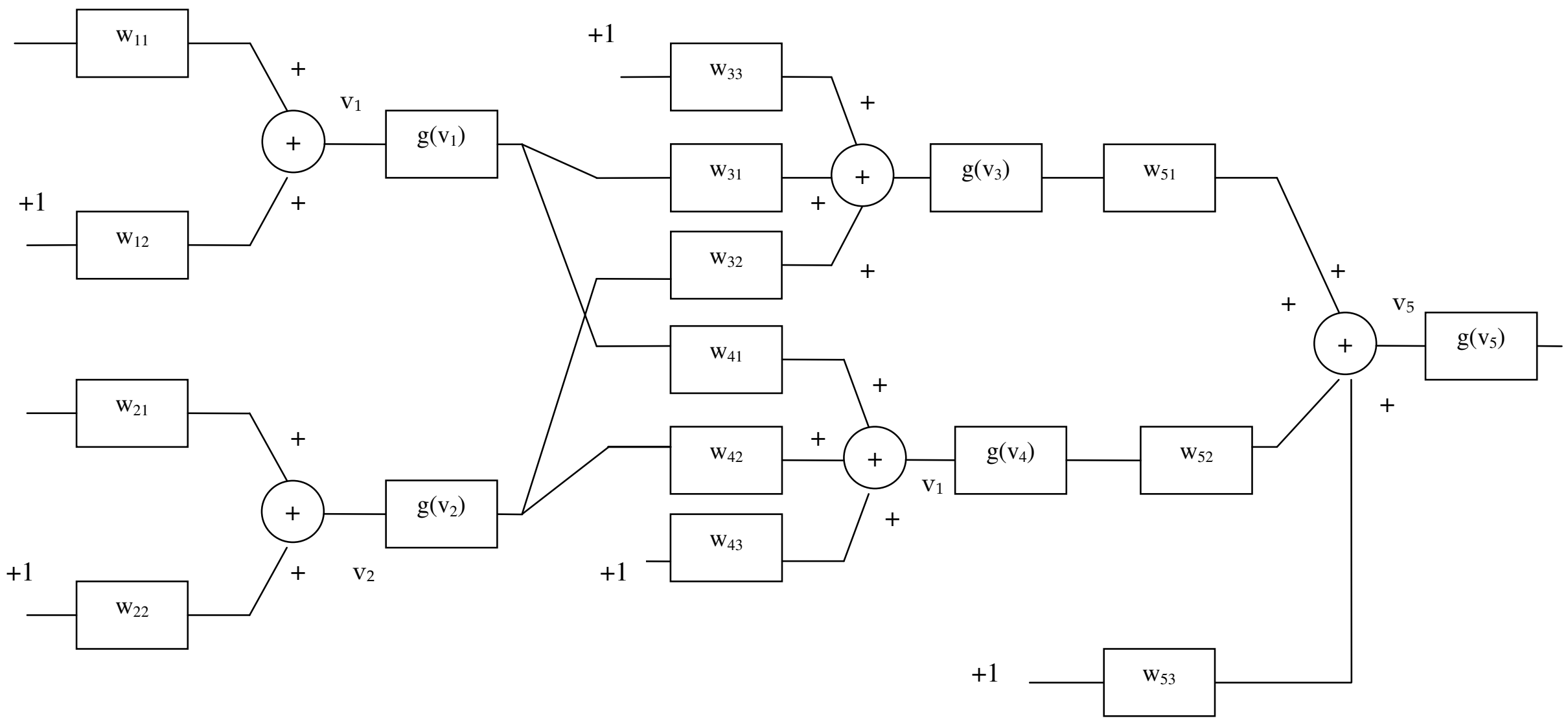

Figura 4. 5- Modelo Neural com duas entradas vista em detalhes. 


\subsubsection{Treinamento da rede com duas entradas}

O treinamento da rede inicialmente utilizou, como critério de saída do processo de convergência, o instante em que o número de iterações fosse maior que um valor $k_{\max }$ préfixado (igual a 1000) ou quando o erro quadrático médio fosse menor que 0.1. Neste caso, o valor do erro quadrático encontrado durante o treinamento da rede foi igual a 0.1575 , após 1000 iterações. Os valores obtidos para os pesos sinápticos da rede são mostrados na tabela 4.2

\begin{tabular}{|l|l|}
\hline Pesos & Valor \\
\hline $\mathrm{w}_{11}$ & 4.8966 \\
\hline $\mathrm{w}_{12}$ & -4.8133 \\
\hline $\mathrm{w}_{21}$ & -0.6934 \\
\hline $\mathrm{w}_{22}$ & -0.0726 \\
\hline $\mathrm{w}_{31}$ & 8.4614 \\
\hline $\mathrm{w}_{32}$ & -10.0320 \\
\hline $\mathrm{w}_{33}$ & -1.7572 \\
\hline $\mathrm{w}_{41}$ & -6.2889 \\
\hline
\end{tabular}

\begin{tabular}{|l|l|}
\hline Pesos & Valor \\
\hline $\mathrm{w}_{42}$ & -3.1809 \\
\hline $\mathrm{w}_{43}$ & 2.4984 \\
\hline $\mathrm{w}_{51}$ & -1.9385 \\
\hline $\mathrm{w}_{52}$ & 2.0792 \\
\hline $\mathrm{w}_{53}$ & -0.3793 \\
\hline
\end{tabular}

Tabela 4. 2 - Valores obtidos para os pesos sinápticos da rede.

De acordo com a tabela, observa-se pelo menos uma sinapse inibitória (com peso sináptico negativo) que vai da camada escondida (representando a substância gelatinosa) para a camada de saída (células T). Esta sinapse é responsável pela resposta de inibição à dor que ocorre nos casos em que não haveria transmissão de sinal de dor conforme a tabela 4.1. 


\begin{tabular}{|l|l|}
\hline $\begin{array}{l}\text { Inclinação da } \\
\text { função }\end{array}$ & Valor \\
\hline$\lambda_{1}$ & 3.0000 \\
\hline$\lambda_{2}$ & 3.0002 \\
\hline$\lambda_{3}$ & 2.9841 \\
\hline$\lambda_{4}$ & 3.0171 \\
\hline$\lambda_{5}$ & 6.0333 \\
\hline
\end{tabular}

Tabela 4. 3 - Valores obtidos para a inclinação

de cada função de transferência da rede.

Os valores convergidos para a inclinação são mostrados na tabela 4.3. De acordo com os valores da tabela, observa-se que a inclinação da função de ativação não é alterada significativamente durante o processo de treinamento da rede com relação aos valores inicialmente adotados. Consequientemente, este parâmetro desempenha um papel minoritário no processo de treinamento da rede neural, quando comparado com outros fatores.

\begin{tabular}{|l|l|}
\hline $\begin{array}{l}\text { Translação } \\
\text { da função }\end{array}$ & Valor \\
\hline$\rho_{1}$ & -1.3603 \\
\hline$\rho_{2}$ & -1.0612 \\
\hline$\rho_{3}$ & 0.8594 \\
\hline$\rho_{4}$ & -0.3492 \\
\hline$\rho_{5}$ & 0.5943 \\
\hline
\end{tabular}

Tabela 4. 4 - Valores obtidos para o deslocamento de cada função de transferência da rede.

Os valores convergidos para os deslocamentos são mostrados na tabela 4.4. Observase que os parâmetros de translação da função de transferência são ajustados de forma que cada neurônio apresente uma maior sensibilidade em um determinado valor. Desta forma, valores de entradas muito altos forçam um deslocamento negativo, de maneira análoga ocorrendo para entradas muito baixas. 


\subsection{Modelo Neural com três entradas}

A rede neural com três entradas apresentada na figura 4.6 considera, além do balanço de atividades entre fibras de largo e pequeno diâmetro, outros fatores ligados à atividade cerebral dentre os quais se destacam os fatores cognitivos ou emocionais. Esta rede também é constituída por três camadas de neurônios. A camada de entrada representa os três tipos de fatores que podem interferir no processo de percepção de dor: o sinal das fibras de pequeno diâmetro relacionado à dor, o sinal das fibras de largo diâmetro (cuja estimulação promove o alívio da dor), e por último o sinal proveniente do cérebro relacionado aos fatores cognitivos ou emocionais.

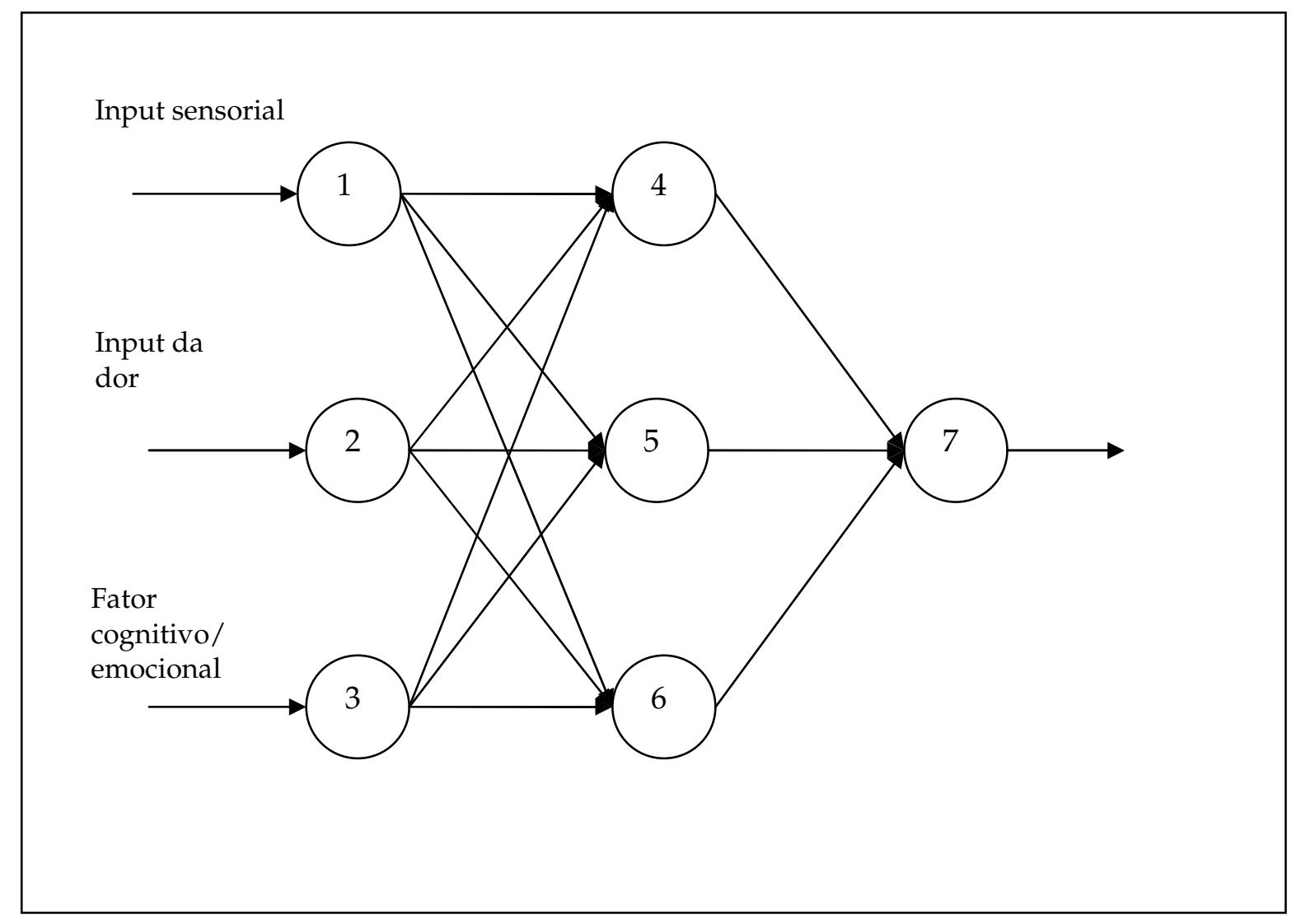

Figura 4. 6 - Modelo Neural para o Mecanismo da porta com três entradas. 
Este modelo é composto por uma rede neural feedforward, interconectada, constituída por sete neurônios. Aqui a substância gelatinosa é representada pela camada escondida de três neurônios, conforme critério descrito pela equação 4.23. Conforme será mostrado mais adiante, a presença de três neurônios na camada escondida é suficiente para garantir a convergência da rede. A camada de saída é constituída por um único neurônio correspondendo à célula nervosa de transmissão do sinal de dor. Conforme será visto, este modelo apresenta resultados que são coerentes com os modelos biológicos, uma vez que sinais de dor são bloqueados no seu trajeto ao cérebro toda vez que há um estímulo sensorial ou táctil no local onde a dor se manifesta (para o caso em que fatores cognitivos e emocionais também contribuam para este resultado).

De acordo com a Teoria de Controle da Comporta, pode-se concluir que dependendo do valor das entradas (se há ou não entrada de dor, estímulo sensorial e/ou fatores cognitivos ou emocionais envolvidos) o neurônio de saída pode transmitir ou não um impulso nervoso. $\mathrm{O}$ comportamento deste modelo é descrito na tabela 4.5. 


\begin{tabular}{|c|c|c|c|c|}
\hline Caso & Fibras largas & Fibras finas & Fator cognitivo & Saída rede \\
\hline 1 & 0.00 & 0.00 & 0.00 & 0.00 \\
\hline 2 & 0.00 & 0.00 & 0.40 & 0.00 \\
\hline 3 & 0.00 & 0.00 & 0.95 & 0.70 \\
\hline 4 & 0.00 & 0.50 & 0.00 & 0.00 \\
\hline 5 & 0.00 & 0.85 & 0.00 & 0.00 \\
\hline 6 & 0.00 & 0.75 & 0.50 & 0.75 \\
\hline 7 & 0.00 & 1.00 & 0.50 & 1.00 \\
\hline 8 & 0.00 & 0.50 & 1.00 & 0.70 \\
\hline 9 & 0.00 & 1.00 & 1.00 & 1.00 \\
\hline 10 & 0.50 & 0.00 & 0.00 & 0.00 \\
\hline 11 & 1.00 & 0.00 & 0.00 & 0.00 \\
\hline 12 & 0.50 & 0.00 & 0.50 & 0.00 \\
\hline 13 & 1.00 & 0.00 & 0.50 & 0.00 \\
\hline 14 & 0.50 & 0.00 & 1.00 & 0.70 \\
\hline 15 & 1.00 & 0.00 & 1.00 & 0.70 \\
\hline 16 & 0.50 & 0.50 & 0.00 & 0.00 \\
\hline 17 & 0.50 & 1.00 & 0.00 & 0.05 \\
\hline 18 & 1.00 & 1.00 & 0.00 & 0.00 \\
\hline 19 & 0.50 & 0.50 & 0.50 & 0.00 \\
\hline 20 & 0.50 & 1.00 & 0.50 & 0.50 \\
\hline 21 & 1.00 & 0.50 & 0.50 & 0.00 \\
\hline 22 & 1.00 & 1.00 & 0.50 & 0.00 \\
\hline 23 & 0.50 & 0.50 & 1.00 & 0.65 \\
\hline 24 & 0.50 & 1.00 & 1.00 & 0.70 \\
\hline 25 & 1.00 & 0.50 & 1.00 & 0.70 \\
\hline 26 & 1.00 & 0.25 & 0.00 & 0.00 \\
\hline 27 & 1.00 & 1.00 & 1.00 & 0.70 \\
\hline
\end{tabular}

Tabela 4. 5 - Tabela para ilustrar o Mecanismo da porta para a rede com três entradas.

Similarmente à tabela do modelo de duas entradas, aqui o número “1” (um) pode corresponder a um trem de pulsos que provoca a sensação de dor (conduzidos pelas fibras de pequeno diâmetro), ou a percepção de uma massagem para aliviar a dor (fibras de largo diâmetro). Assim uma fibra nociceptiva transmitindo pulsos elétricos com freqüência máxima pode representar uma situação onde o estímulo doloroso transmitido é extremamente intenso. E nenhuma atividade na fibra indica o caso em que não há a presença de dor. Valores situados dentro desta faixa, entre 0 e 1 , representariam situações intermediárias. 
Na tabela, a entrada referente ao fator cognitivo pode assumir os seguintes valores:

- Valores iguais ou próximos a zero representam um estado emocional positivo: por exemplo, alegria, distração, motivação, dentre outros;

- Valores iguais ou próximos a 0.5 representam uma situação normal, ou seja, um estado emocional que está distante dos pólos eufórico e depressivo;

- Valores iguais ou próximos a um representam um estado emocional negativo: por exemplo, tristeza, ansiedade, preocupação, depressão, dentre outros.

Da mesma forma que para as outras entradas, o fator cognitivo poderá também assumir valores intermediários. Estes valores podem vir a serem determinados, num futuro próximo, com o auxílio de algumas técnicas de mapeamento cerebral conforme discutido no capítulo anterior, ou ainda, a partir de questionários clínicos conforme será discutido no próximo capítulo.

No caso do efeito cognitivo, além da ansiedade e preocupação, experimentos realizados com pacientes mostraram que a percepção de dor estaria essencialmente relacionada com o estado de atenção e distração do indivíduo (NATHAN; RUDGE, 1974). Pessoas focadas na dor possuíam a tendência de senti-las com maior frequiência e/ou maior intensidade, enquanto aquelas que estivessem distraídas tinham maior tolerância à dor.

Há algumas estratégias cognitivas que visam amenizar a sensação dolorosa durante o tratamento de pacientes. Entre elas estão a distração e a hipnose. A distração, por exemplo, busca desviar a atenção da pessoa das sensações ou reações emocionais produzidas pelo estímulo doloroso, consumindo um grau de energia cognitiva que de outra forma seria 
devotada à percepção de dor (McCAUL; MALLOT, 1984). Deste modo, o indivíduo tende a perceber a dor com maior intensidade e experimentar maiores níveis de estresse quando focaliza sua atenção sobre experiências potencialmente dolorosas, principalmente quando cria expectativas sobre a ocorrência de dor (VESSEY; CARLSON; McGILL, 1994).

De acordo com a tabela anterior, os casos de percepção da dor podem ser descritos por:

- Caso 1: Na ausência de dor e estímulo sensorial e tendo efeito cognitivo positivo (por exemplo, relaxamento, distração), não há nenhum sinal de dor sendo transmitido.

- Caso 2: Na ausência de dor e estímulo sensorial e quase nenhuma influência cognitiva, não há nenhum sinal de dor sendo transmitido.

- Caso 3: Sem dor, sem estímulo sensorial, mas com fator cognitivo negativo há transmissão de dor. Esta situação ilustra o que poderia eventualmente ocorrer com pacientes que sofrem com a dor do membro fantasma. Nessa situação, um indivíduo amputado continua a sentir a dor de um membro que já não faz mais parte do seu corpo.

- Casos 4 e 5: Ao se ter dor e sem nenhum estímulo sensorial, mas com fator cognitivo positivo, é enviado ao cérebro um "falso" sinal de que não há lesão. Esta condição poderia ilustrar diversas situações observadas no dia-a-dia, como o caso de um jogador que sofre uma lesão durante uma partida, mas por estar focado no jogo inibe a percepção da lesão.

- Casos 6 e 7: Ao se ter dor e sem nenhum estímulo sensorial e nenhuma influência cognitiva, um sinal de que uma lesão ocorreu é enviado ao cérebro. Nestas situações, considera-se que a intensidade de dor possa estar diretamente relacionada à 
intensidade de atividade presente na fibra fina. Estes casos indicam que a mesma lesão pode ter efeitos distintos em diferentes pessoas, ou até mesmo na mesma pessoa em diferentes situações. Variáveis psicológicas podem intervir entre estímulo e percepção e produzir um alto grau de variabilidade entre os dois. Na maioria das vezes, é certo que uma relação simples será válida: quanto maior a extensão do ferimento, maior será a percepção da dor. A não interferência de fatores cognitivos e/ou emocionais simplifica a relação entre estímulo e sensação a uma relação de um para um.

- Casos 8 e 9: Ao se ter dor e sem nenhum estímulo sensorial, e ainda na presença de fatores cognitivos negativos, é enviado ao cérebro um sinal de que uma lesão ocorreu. Neste caso, se um indivíduo está potencialmente focado na experiência dolorosa, a tendência é que a dor seja percebida mais intensamente que o normal. Em (HALL; STRIDE, 1954) foi descoberto que a simples ocorrência da palavra "dor", em um conjunto de instruções para a avaliação da dor, aumentava a ansiedade nos pacientes, que forneciam respostas extremamente dolorosas quando submetidos a um pequeno choque elétrico, o que não ocorria quando tal palavra estava ausente nas instruções. Nestes casos, a influência negativa da parte emocional contribui para que a dor seja sentida com maior intensidade. Como estes dois casos possuem o mesmo valor de entrada referente ao fator cognitivo, a intensidade de dor será proporcional à intensidade na fibra nociceptiva.

- Casos 10 e 11: Sem dor, com estímulo sensorial e com fator cognitivo positivo também não haverá a transmissão de sinal de dor.

- Casos 12 e 13: Na ausência de dor, com estímulo sensorial e nenhuma influência cognitiva, não há transmissão de dor. 
- Casos 14 e 15: Na ausência de dor, com estímulo sensorial e com fator cognitivo negativo, há transmissão de dor. Aqui a intensidade de dor independe da atividade presente na fibra larga, sendo que apenas o fator cognitivo é aquele que participará do processo de percepção de dor. Nesta situação, quando um tecido é lesionado, pode ocorrer uma inflamação, acompanhada de sintomas como febre, mal-estar generalizado, dores musculares, além de uma hipersensibilidade à dor em partes do corpo perfeitamente sadias, localizadas próximas ao local da inflamação. Por muito tempo, se considerou que tudo isto ocorria por um mecanismo coordenado pelo cérebro e envolvendo a transmissão de impulsos nervosos da região lesionada, através da medula espinhal, para o cérebro. Por outro lado, uma recente pesquisa (BARTFAI, 2001) mostrou que devido à presença de algumas substâncias químicas no cérebro, o mesmo pode experimentar a sensação da dor mesmo que não existam impulsos nervosos nociceptivos envolvidos. Isto poderia justificar a situação em que não há uma lesão aparente que provoque a dor, mas há a percepção de uma dor "psicológica” devido aos sinais provenientes do próprio cérebro, decorrentes desse processo químico.

- Casos 16, 17 e 18: A presença de dor, estímulo sensorial e fator cognitivo positivo farão com que não seja enviado nenhum sinal ao cérebro ou um sinal de pequena intensidade.

- Casos 19 a 22: A presença de dor, estímulo sensorial e nenhuma influência cognitiva produzirão respostas que dependam do balanço de atividades nas fibras nervosas. $\mathrm{O}$ caso de número 20 pode ilustrar a situação particular em que o sinal presente na fibra larga não é suficiente para estimular a inibição da dor fazendo com que seja percebido uma dor de pequena intensidade. 
- Casos 23 a 25 e 27: Ao se ter simultaneamente dor e estímulo sensorial e efeito cognitivo negativo (preocupação, ansiedade com a lesão), será enviado um sinal ao cérebro relatando uma sensação de dor. Nestes casos, a influência cognitiva negativa contribuirá para a transmissão da dor, sendo que o balanço de atividades entre fibras finas e largas é que irá determinar a intensidade da dor transmitida.

- Caso 26: Ao se ter estímulo sensorial, fibra nociceptiva com atividade de intensidade média e influência cognitiva positiva, não haverá sinal de dor sendo transmitido.

Diferente do que foi adotado no treinamento para a rede de duas entradas, aqui a saída da rede de três entradas terá valores contínuos a exemplo do que ocorre com os valores de suas entradas.

Em alguns dos casos citados anteriormente, quando fatores psicológicos aparentam ter uma contribuição predominante na dor de uma pessoa, esta dor pode ser rotulada como "psicogênica", ou seja, a pessoa é presumida de sentir dor porque ela precisa ou deseja isto (MELZACK; WALL, 1982).

As entradas acima são usadas como referências no treinamento da rede e representam as principais situações relacionadas à percepção de dor. Desta forma, a rede neural irá generalizar para outras situações, considerando-se nesses casos, outras faixas de valores para as entradas das fibras nervosas. 


\subsubsection{Implementação da rede com três entradas}

Considerando-se que a tabela 4.5 representa com fidelidade o processo de percepção de dor, pode-se afirmar que este modelo de rede neural com três entradas é mais realista (ou geral) que o modelo anterior. O modelo neural de três entradas é treinado pelo algoritmo de backpropagation ajustando-se os parâmetros mencionados anteriormente. O resultado do teste desta rede visa demonstrar o que eventualmente ocorre em uma pessoa ao se deparar com as situações descritas pela tabela 4.5 .

Da mesma forma que se conhecem quais as saídas que são esperadas para cada padrão na entrada, o aprendizado da rede utilizado é do tipo supervisionado. A rede neural mostrada na figura 4.6 pode ser vista com mais detalhes na figura 4.7 , em que estão evidenciados os pesos sinápticos. 


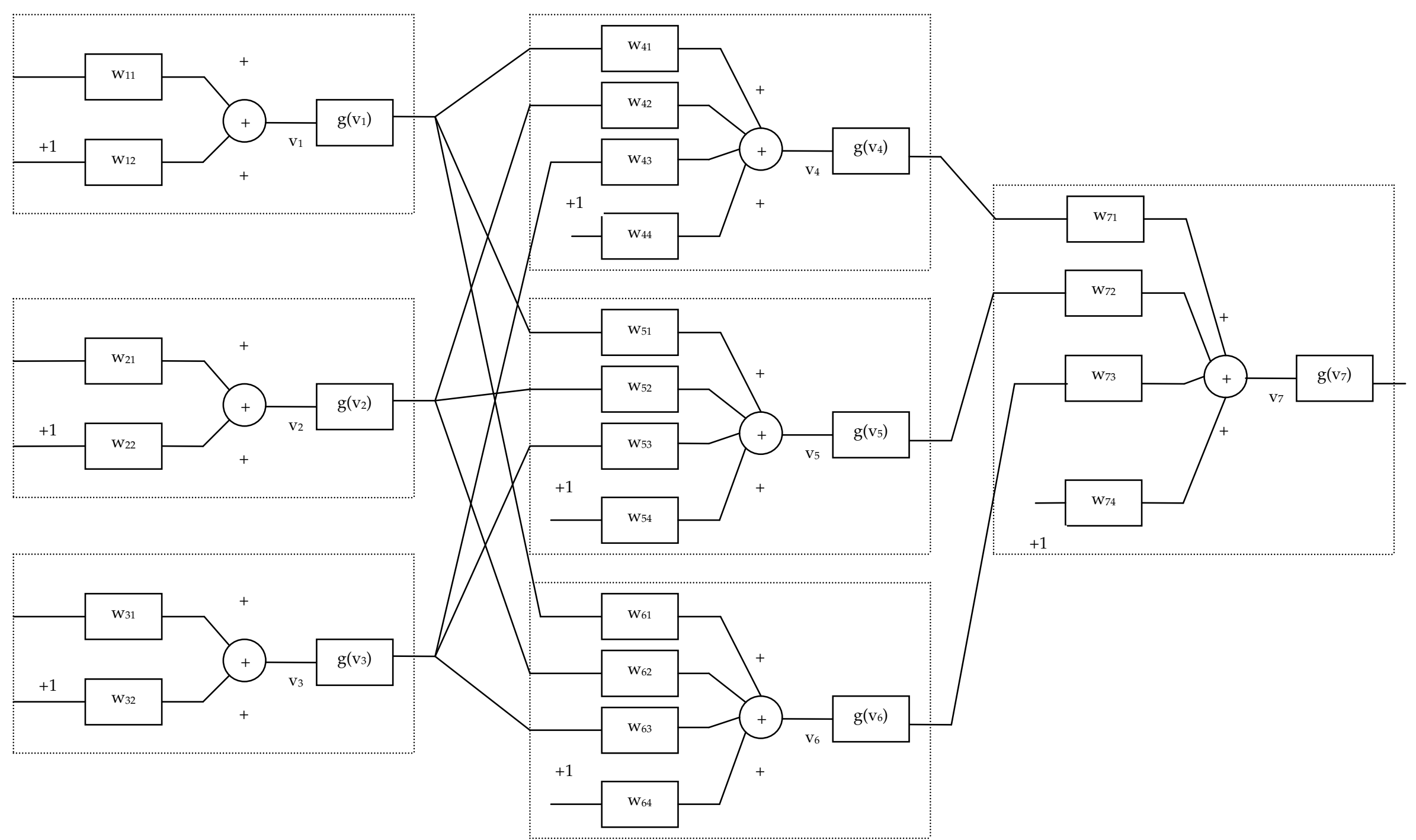

Figura 4. 7 - Modelo Neural com três entradas. 


\subsubsection{Treinamento da rede com três entradas}

Para o treinamento da rede, similarmente ao que foi realizado para a rede de duas entradas, utilizou-se como critério de parada quando o número de épocas (número de iterações) fosse maior que um valor $k_{\max }$ pré-fixado (igual a 1000), ou quando o erro quadrático médio fosse menor que 0.1 . O erro quadrático obtido foi igual a 0.2454 (após 1000 iterações). Os valores obtidos para os pesos sinápticos da rede são mostrados na tabela a seguir:

\begin{tabular}{|c|c|c|c|c|c|}
\hline Pesos & Valor & Pesos & Valor & Pesos & Valor \\
\hline $\mathrm{w}_{11}$ & 14.5646 & $\mathrm{~W}_{43}$ & 6.6910 & $\mathrm{w}_{63}$ & 5.3237 \\
\hline $\mathrm{w}_{12}$ & -9.1146 & $\mathrm{~W}_{44}$ & -0.2471 & $\mathrm{w}_{64}$ & -0.4225 \\
\hline $\mathrm{w}_{21}$ & 14.8013 & $\mathrm{~W}_{51}$ & 6.4118 & $\mathrm{w}_{71}$ & 1.1109 \\
\hline $\mathrm{w}_{22}$ & -17.3566 & $\mathrm{~W}_{52}$ & -9.7489 & $\mathrm{~W}_{72}$ & -1.6676 \\
\hline $\mathrm{w}_{31}$ & 17.0337 & $W_{53}$ & -8.3673 & $\mathrm{w}_{73}$ & 0.9461 \\
\hline$w_{32}$ & -10.4600 & $\mathrm{~W}_{54}$ & 2.1893 & $\mathrm{~W}_{74}$ & -0.4730 \\
\hline $\mathrm{w}_{41}$ & 1.1380 & $\mathrm{~W}_{61}$ & -1.0740 & & \\
\hline$w_{42}$ & 4.2520 & $\mathrm{~W}_{62}$ & 8.1535 & & \\
\hline
\end{tabular}

Tabela 4. 6 - Valores obtidos para os pesos sinápticos da rede.

De acordo com a tabela anterior, observa-se a presença de pelo menos uma sinapse inibitória que vai da camada escondida (representando a substância gelatinosa) para a camada de saída (células T). Da mesma forma que no modelo de duas entradas, as sinapses inibitórias deste modelo são responsáveis pela resposta de inibição à dor que ocorre em alguns casos conforme a tabela 4.6. Para o caso em que não houver a transmissão de dor, a influência do 
sinal a ser propagado por esta sinapse é maior do que a de outras sinapses, de forma que a célula de transmissão se mantenha inativa para esta situação.

A tabela 4.7 mostra os valores convergidos para a inclinação da função de transferência. De acordo com os resultados, observa-se que a inclinação da função de ativação não é alterada significativamente durante o processo de treinamento da rede com relação aos valores inicialmente adotados.

\begin{tabular}{|l|l|}
\hline $\begin{array}{l}\text { Inclinação da } \\
\text { função }\end{array}$ & valor \\
\hline$\lambda_{1}$ & 2.0010 \\
\hline$\lambda_{2}$ & 2.0013 \\
\hline$\lambda_{3}$ & 1.9992 \\
\hline$\lambda_{4}$ & 2.0021 \\
\hline$\lambda_{5}$ & 1.9966 \\
\hline$\lambda_{6}$ & 2.0018 \\
\hline$\lambda_{7}$ & 2.0096 \\
\hline
\end{tabular}

Tabela 4. 7 - Valores obtidos para a inclinação de cada função de transferência da rede.

A tabela 4.8 apresenta os valores convergidos para os deslocamentos da função de transferência. Observa-se que os valores de translação da função de transferência obtidos situam-se em faixas bem distintas mostrando que os neurônios da rede devem se adaptar de forma que alguns deles devem ser sensíveis a um estímulo pequeno na entrada, enquanto que outros, a um estímulo mais intenso.

\begin{tabular}{|l|l|}
\hline $\begin{array}{l}\text { Translação } \\
\text { da função }\end{array}$ & Valor \\
\hline$\rho_{1}$ & -1.6072 \\
\hline$\rho_{2}$ & -1.7590 \\
\hline$\rho_{3}$ & -1.7151 \\
\hline$\rho_{4}$ & 1.0261 \\
\hline$\rho_{5}$ & 0.9650 \\
\hline$\rho_{6}$ & 1.0219 \\
\hline$\rho_{7}$ & 0.9958 \\
\hline
\end{tabular}

Tabela 4. 8 - Valores obtidos para o deslocamento de cada função de transferência da rede. 


\section{CAPÍTULO 5}

\section{DISCUSSÃO DOS RESULTADOS E CONCLUSÃO}

Este capítulo discute os resultados obtidos a partir dos experimentos computacionais realizados, comparando-se as entradas fornecidas com aquelas esperadas em cada modelo. A análise permitiu checar a consistência de cada modelo frente ao universo de casos de dor relatados. Por último, são listadas algumas sugestões e idéias com o objetivo de melhorar a modelagem proposta neste trabalho. 


\subsection{Resultados obtidos: rede neural com duas entradas}

Substituindo-se os valores de pesos, deslocamentos e inclinações encontrados na rede mostrada na figura 4.5, a realização de testes permitiu observar que, ao se propagar cada padrão de entrada na rede, o resultado obtido foi próximo ao que era esperado, demonstrando que a arquitetura de rede empregada apresenta convergência para a aplicação em questão.

\begin{tabular}{|c|c|c|c|}
\hline Caso & $\begin{array}{c}\text { Fibras Largas } \\
\text { (Large) }\end{array}$ & $\begin{array}{c}\text { Fibras Finas } \\
\text { (Small) }\end{array}$ & Saída rede \\
\hline 1 & 0.00 & 0.00 & 0.2238 \\
\hline 2 & 0.00 & 0.50 & 0.7443 \\
\hline 3 & 0.00 & 1.00 & 0.9925 \\
\hline 4 & 0.50 & 0.00 & 0.0311 \\
\hline 5 & 0.50 & 0.50 & 0.1631 \\
\hline 6 & 0.50 & 1.00 & 0.9555 \\
\hline 7 & 1.00 & 0.00 & 0.0028 \\
\hline 8 & 1.00 & 0.50 & 0.0028 \\
\hline 9 & 1.00 & 1.00 & 0.0023 \\
\hline
\end{tabular}

Tabela 5. 1 - Tabela comparativa das saídas fornecidas pela rede (duas entradas) com as esperadas.

A tabela 5.1 compara as saídas obtidas pela rede com aquelas esperadas, de onde se observa que os valores obtidos pela rede estão bem próximos daqueles esperados. Desta forma, o modelo de duas entradas ilustra consistentemente o processo fisiológico envolvido. Por outro lado, este modelo neural necessita ser aprimorado, pois de acordo com a própria Teoria de Controle da Comporta, além do balanço de atividades entre as vias nervosas, é relevante considerar outros fatores que contribuam para o fenômeno da dor, como por exemplo, os fatores cognitivos ou emocionais, que estão ausentes nesse modelo. 


\subsubsection{Teste geral da rede de duas entradas}

Neste item realizaram-se alguns testes com a rede neural de duas entradas considerando-se outros valores de entradas. Alguns dados dos testes realizados vistos na tabela 5.2 mostram, que ao se propagar cada padrão de entrada na rede, o resultado obtido foi próximo ao que era esperado.

\begin{tabular}{|c|c|c|c|c|}
\hline Caso & $\begin{array}{c}\text { Fibras Largas } \\
\text { (Large) }\end{array}$ & $\begin{array}{c}\text { Fibras Finas } \\
\text { (Small) }\end{array}$ & Saída esperada & Saída rede \\
\hline 1 & 0.01 & 0.01 & $\sim 0.0$ & 0.2285 \\
\hline 2 & 0.00 & 0.75 & $\sim 1.0$ & 0.9526 \\
\hline 3 & 0.65 & 0.65 & $\sim 0.0$ & 0.0030 \\
\hline 4 & 0.10 & 1.00 & $\sim 1.0$ & 0.9925 \\
\hline 5 & 0.90 & 0.00 & $\sim 0.0$ & 0.0028 \\
\hline 6 & 0.98 & 0.30 & $\sim 0.0$ & 0.0028 \\
\hline 7 & 0.95 & 0.95 & $\sim 0.0$ & 0.0026 \\
\hline 8 & 0.01 & 0.99 & $\sim 1.0$ & 0.9920 \\
\hline 9 & 0.95 & 0.01 & $\sim 0.0$ & 0.0026 \\
\hline
\end{tabular}

Tabela 5. 2 - Tabela comparativa das saídas fornecidas pela rede (duas entradas) com as esperadas (teste geral).

Pode-se notar aqui uma das principais vantagens da utilização da rede neural neste tipo aplicação: a generalização. Apesar da utilização de um conjunto de entrada restrito, a rede conseguiu convergir e apresentar uma boa resposta para outros valores contínuos de entradas.

\subsection{Resultados obtidos: rede neural com três entradas}

Substituindo-se os valores dos pesos, deslocamentos e inclinações convergidos, na rede mostrada na figura 4.7 e realizando simulações computacionais de cada padrão de entrada na rede, observa-se que a rede fornece resultados consistentes. Isto demonstra que a arquitetura de rede empregada também apresenta convergência para a aplicação em questão. 


\begin{tabular}{|c|c|c|c|c|c|}
\hline Caso & Fibras largas & Fibras finas & $\begin{array}{c}\text { Fator } \\
\text { cognitivo }\end{array}$ & $\begin{array}{c}\text { Saída } \\
\text { desejada }\end{array}$ & $\begin{array}{c}\text { Saída rede } \\
\text { obtida }\end{array}$ \\
\hline 1 & 0.00 & 0.00 & 0.00 & 0.00 & 0.003100 \\
\hline 2 & 0.00 & 0.00 & 0.40 & 0.00 & 0.003663 \\
\hline 3 & 0.00 & 0.00 & 0.95 & 0.70 & 0.765154 \\
\hline 4 & 0.00 & 0.50 & 0.00 & 0.00 & 0.003100 \\
\hline 5 & 0.00 & 0.85 & 0.00 & 0.00 & 0.003157 \\
\hline 6 & 0.00 & 0.75 & 0.50 & 0.75 & 0.634526 \\
\hline 7 & 0.00 & 1.00 & 0.50 & 1.00 & 0.751880 \\
\hline 8 & 0.00 & 0.50 & 1.00 & 0.70 & 0.765154 \\
\hline 9 & 0.00 & 1.00 & 1.00 & 1.00 & 0.765296 \\
\hline 10 & 0.50 & 0.00 & 0.00 & 0.00 & 0.002732 \\
\hline 11 & 1.00 & 0.00 & 0.00 & 0.00 & 0.004847 \\
\hline 12 & 0.50 & 0.00 & 0.50 & 0.00 & 0.113513 \\
\hline 13 & 1.00 & 0.00 & 0.50 & 0.00 & 0.028226 \\
\hline 14 & 0.50 & 0.00 & 1.00 & 0.70 & 0.764914 \\
\hline 15 & 1.00 & 0.00 & 1.00 & 0.70 & 0.632668 \\
\hline 16 & 0.50 & 0.50 & 0.00 & 0.00 & 0.002732 \\
\hline 17 & 0.50 & 1.00 & 0.00 & 0.05 & 0.008687 \\
\hline 18 & 1.00 & 1.00 & 0.00 & 0.00 & 0.011835 \\
\hline 19 & 0.50 & 0.50 & 0.50 & 0.00 & 0.113513 \\
\hline 20 & 0.50 & 1.00 & 0.50 & 0.50 & 0.688931 \\
\hline 21 & 1.00 & 0.50 & 0.50 & 0.00 & 0.028226 \\
\hline 22 & 1.00 & 1.00 & 0.50 & 0.00 & 0.081852 \\
\hline 23 & 0.50 & 0.50 & 1.00 & 0.65 & 0.764914 \\
\hline 24 & 0.50 & 1.00 & 1.00 & 0.70 & 0.765283 \\
\hline 25 & 1.00 & 0.50 & 1.00 & 0.70 & 0.632668 \\
\hline 26 & 1.00 & 0.25 & 0.00 & 0.00 & 0.004847 \\
\hline 27 & 1.00 & 1.00 & 1.00 & 0.70 & 0.760010 \\
\hline
\end{tabular}

Tabela 5. 3 - Tabela comparativa das saídas fornecidas pela rede (três entradas) com aquelas esperadas.

A tabela 5.3 compara as saídas obtidas pela rede convergida com aquelas esperadas, de onde se pode concluir que esta arquitetura de rede neural descreve satisfatoriamente muitas situações clínicas relacionadas com a dor, e, portanto, é um modelo representativo do fenômeno de percepção de dor. Este tipo de representação é mais realista que o modelo anterior, pois considera a importante influência que sinais provenientes do cérebro têm no processo de percepção da dor. De acordo com os resultados da tabela 5.3, a saída da rede pode auxiliar no processo de avaliação e mensuração de dor em pacientes. 


\subsubsection{Teste geral da rede de três entradas}

Neste item realizaram-se alguns testes com a rede neural de três entradas considerando-se outros valores de entradas. Alguns dados dos testes realizados podem ser vistos na tabela 5.4 e mostram que o resultado obtido foi próximo ao que era esperado ao se propagar cada padrão de entrada na rede.

\begin{tabular}{|c|c|c|c|c|c|}
\hline Caso & Fibras largas & Fibras finas & $\begin{array}{c}\text { Fator } \\
\text { cognitivo }\end{array}$ & $\begin{array}{c}\text { Saída } \\
\text { desejada }\end{array}$ & $\begin{array}{c}\text { Saída rede } \\
\text { obtida }\end{array}$ \\
\hline 1 & 0.05 & 0.00 & 0.00 & $\sim 0$ & 0.003100 \\
\hline 2 & 0.82 & 0.95 & 0.00 & $\sim 0.1$ & 0.006041 \\
\hline 3 & 0.10 & 0.15 & 0.25 & $\sim 0$ & 0.003102 \\
\hline 4 & 0.00 & 0.25 & 0.25 & $\sim 0$ & 0.003102 \\
\hline 5 & 0.00 & 0.68 & 0.50 & $\sim 0.6$ & 0.634334 \\
\hline 6 & 0.00 & 0.99 & 0.50 & $\sim 0.7$ & 0.743572 \\
\hline 7 & 0.01 & 0.60 & 0.50 & $\sim 0.6$ & 0.634309 \\
\hline 8 & 0.15 & 0.85 & 0.50 & $>0.6$ & 0.638481 \\
\hline 9 & 0.71 & 0.65 & 0.75 & $>0.6$ & 0.637229 \\
\hline 10 & 0.01 & 0.95 & 0.75 & $>0.7$ & 0.765231 \\
\hline 11 & 0.02 & 0.80 & 1.00 & $>0.7$ & 0.765156 \\
\hline 12 & 0.00 & 0.99 & 1.00 & $>0.7$ & 0.765288 \\
\hline
\end{tabular}

Tabela 5. 4 - Tabela comparativa das saídas fornecidas pela rede (três entradas) com aquelas esperadas (teste geral).

Nos testes realizados, considerou-se além dos dois pólos emocionais (depressivo e eufórico) o paciente em um estado normal e variações entre este estado e seus extremos.

De acordo com a tabela 5.4, observa-se que se o estado emocional do paciente é positivo, é transmitido um sinal de pequena intensidade. Com o aumento da atividade na fibra fina há um pequeno aumento no sinal de saída. Quando o paciente se encontra num estado emocional distante dos pólos eufórico e depressivo, o sinal na saída da rede é proporcional ao balanço de atividade nas fibras nervosas. Com um nível de atividade baixo na fibra larga, 
observa-se (casos 5, 6 e 7) que quanto maior a atividade na fibra fina, maior a intensidade de dor na saída.

\subsection{Importância da mensuração da dor}

Cada área das ciências usa algum tipo de método de mensuração das propriedades e atributos inerentes ao objeto de estudo, tendo o seu próprio conjunto de instrumentos de mensuração e unidades de medidas. Por exemplo, algumas unidades são bastante conhecidas: o metro, a hora, o quilo, o hectare, a temperatura. No caso da mensuração da dor, o objetivo é assinalar um valor à dor vivenciada por um dado indivíduo num dado momento e em certas condições (SILVA; RIBEIRO FILHO, 2006). Isto representa um grande desafio, uma vez que quando um indivíduo tenta descrever a ocorrência, ficam evidentes os elementos subjetivos da percepção da dor. Por outro lado, a quantificação da percepção da dor deve ser baseada em elementos científicos, e, portanto mensuráveis e reproduzíveis. Por exemplo, o efeito de uma determinada droga analgésica só pode ser analisado se for possível de se quantificar o seu resultado sobre a percepção da dor (MELZACK; WALL, 1982).

A ausência de uma medida quantitativa da dor torna difícil uma decisão determinística sobre a necessidade, eficácia, ou duração de um determinado tratamento. Por outro lado, uma mensuração apropriada da dor permite determinar se os riscos de um dado tratamento superam os danos causados pelo problema clínico e, também, permite escolher qual é o melhor e o mais seguro entre diferentes tipos de procedimentos terapêuticos. Adicionalmente, pode-se fazer um melhor acompanhamento e análise dos mecanismos de ação de diferentes drogas farmacológicas otimizando o processo na sua escolha. 
Uma outra aplicação para o modelo da RNA com três entradas é auxiliar neste processo de avaliação e mensuração da dor. Os itens que se seguem descrevem dois instrumentos comumente empregados para avaliação e mensuração da dor. Cada um tem suas particularidades, assim como suas vantagens e desvantagens. Por último, é discutido o contexto em que o modelo proposto possa ser útil na mensuração da dor.

\subsubsection{Escala de Categoria Numérica}

Um método bastante utilizado é a Escala de Categoria Numérica (Numeric Rating Scale - NRS). O paciente é apresentado a uma escala numerada de 0 a 10 . A faixa de 0 a 1 indica nenhuma dor presente, de 1 a 3 representa uma dor branda, de 4 a 6 ilustra uma dor de intensidade moderada e de 7 a 10 uma dor intensa. O paciente é orientado a fazer uma marca em um ponto da linha dessa escala que representaria a intensidade de sua dor. Embora esse método proporciona um diagnóstico rápido, ele não fornece informações mais detalhadas a respeito da qualidade, freqüência e localização da sensação dolorosa.

\subsubsection{Questionário de McGill}

Uma outra técnica de mensuração da dor bastante difundida é o Questionário de McGill (MELZACK; TORGERSON, 1971) mostrado na figura 5.1. Este questionário é baseado em palavras que os pacientes selecionam para descrever sua própria dor, avaliando-a em três dimensões descritas a seguir:

- Dimensão sensorial: inclui palavras que descrevem a qualidade da experiência de dor em termos de propriedades temporais, térmicas, espaciais, de pressão e outras similares. 
- Dimensão afetiva: inclui palavras que descrevem a qualidade da experiência de dor em termos de tensão, medo, temor, receio e outros sentimentos.

- Dimensão avaliativa: inclui palavras que descrevem a intensidade subjetiva global da intensidade de dor.

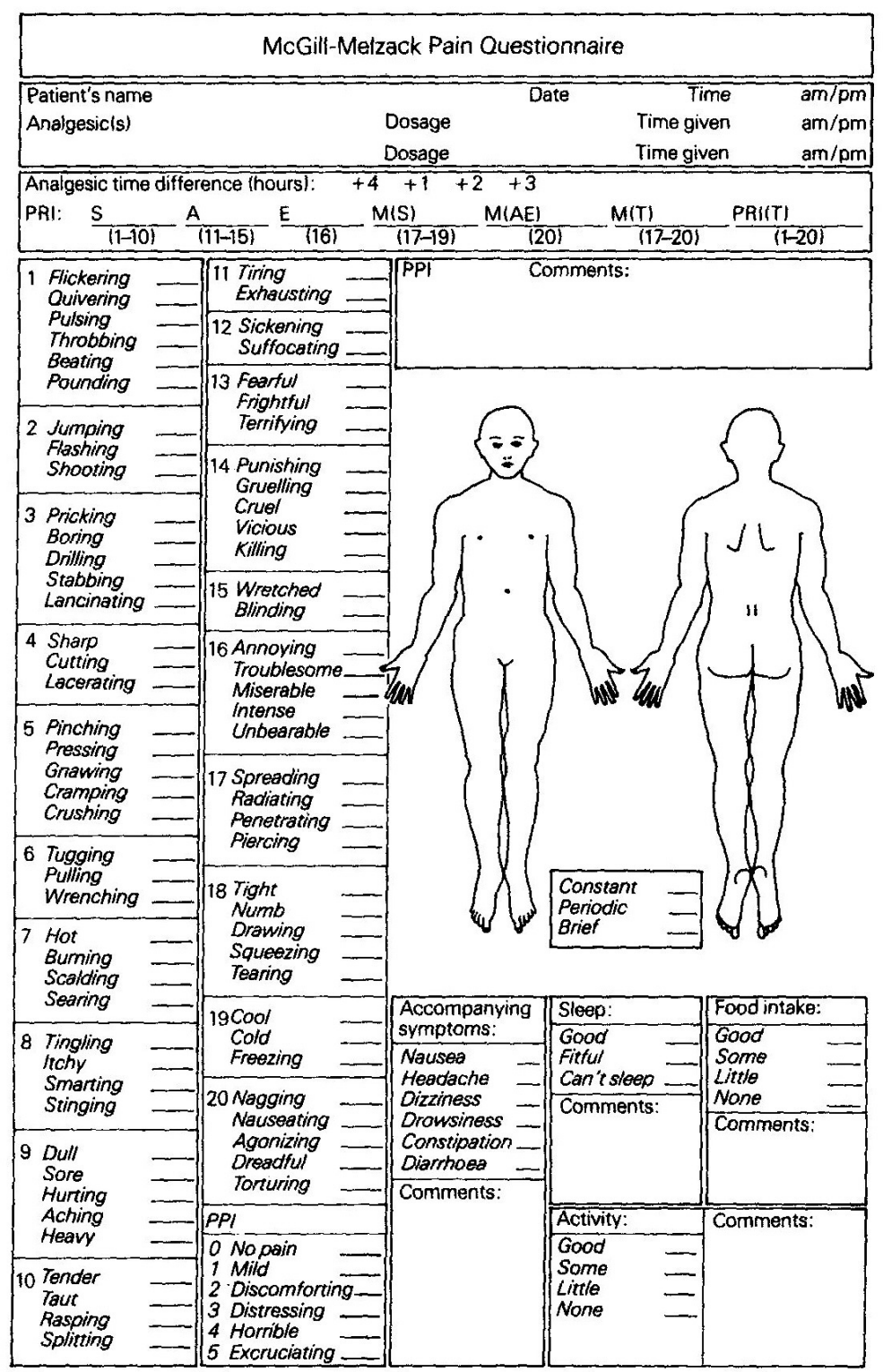

Figura 5. 1 - Questionário de McGill da dor.

Extraído de (MELZACK; WALL, 1982). 
Este instrumento inclui várias subclasses de descritores ou adjetivos, um diagrama corporal em que o paciente possa indicar a localização e a distribuição espacial da dor, além de alguns descritores relacionados às propriedades temporais da dor. O questionário consiste de 78 palavras (ou descritores), organizadas em 4 grupos e 20 subgrupos. Os grupos referemse aos seguintes componentes da dor: sensorial (subgrupos de 1 a 10), afetivo (subgrupos de 11 a 15) e avaliativo (subgrupo 16). Os subgrupos de 17 a 20 compreendem itens de miscelânea. Cada subgrupo é composto por um conjunto de palavras qualitativamente similares, mas com nuances que as tornam diferentes em termos de magnitude. Assim, para cada descritor corresponde um número que indica a sua intensidade. Neste caso, à palavra em cada subclasse implicando a mínima dor é dado um valor de um “1”, à palavra seguinte é dado o valor de dois " 2 " e assim por diante.

A partir desse questionário, pode-se chegar ao número de descritores escolhidos e ao índice de dor. O número de descritores escolhidos corresponde às palavras que o paciente selecionou para explicar a sua dor. O maior valor possível é 20, pois o doente só pode escolher, no máximo, uma palavra por subgrupo. O índice de dor é obtido pela soma dos valores de intensidade dos descritores escolhidos. O valor máximo possível é 78 . Desta forma, a lista de palavras descritivas do questionário é lida a um paciente com a instrução explícita que ele escolha apenas aquelas palavras que descrevam seus sentimentos e sensações naquele momento. Dois índices são obtidos. O primeiro é o índice de avaliação da dor (Pain Rating Index - PRI), que é a soma dos valores das palavras escolhidas, baseada nas posições destas em cada categoria ou subclasse. A pontuação PRI pode ser computada separadamente para cada classe (sensorial, afetiva, avaliativa e miscelânea), além de fornecer uma pontuação total considerando-se todas as classes. O segundo índice é a intensidade de dor presente (PPI - Present Pain Intensity) que mede a intensidade de dor global em uma escala de 0 a 5 onde 
cada número é associado a uma palavra: 0 - nenhuma dor, 1 - branda, 2 - desconfortável, 3 aflitiva, 4 - horrível, 5 - martirizante.

Esse questionário fornece informação sobre a intensidade da dor, assim como as qualidades da mesma. Uma vez que o PRI fornece um índice da intensidade global da dor, é possível comparar a intensidade (ou severidade) relativa de dor com base nessa medida. Sabese que qualquer que seja a precisão de uma escala de medida empregada para mensurar a dor, duas mensurações efetuadas sobre um fenômeno de dor raramente darão resultados idênticos. Desta forma, o questionário é executado diversas vezes sobre o mesmo paciente, considerando-se a média das respostas (SILVA; RIBEIRO FILHO, 2006).

\subsection{Uso do modelo neural de três entradas na mensuração da dor}

Apesar do uso do MPQ ser uma prática comum, este e outros instrumentos de avaliação e mensuração da dor podem apresentar algumas incertezas uma vez que um paciente possa estar amenizando ou até dramatizando o seu sofrimento. Além disso, alguns pacientes ficam confusos com o vocabulário empregado, pois há a chance de se desconhecer o real significado das palavras presentes neste questionário, ou seja, pessoas com dificuldades cognitivas e comunicação limitada farão o preenchimento incompleto ou impreciso desse questionário (SILVA; RIBEIRO-FILHO, 2006).

Apesar destes pontos, o MPQ continua sendo uma referência na avaliação e mensuração de dor. O modelo proposto neste trabalho pode ser utilizado em conjunto com este instrumento a fim de preencher as lacunas existentes ou até ajudar a fornecer um diagnóstico mais preciso da dor presente. 
O uso de um modelo representativo da dor pode auxiliar em uma eventual caracterização do fenômeno estudado. Com a mensuração apropriada da dor, o médico clínico pode extrair informações que podem auxiliá-lo a escolher o melhor tratamento, a verificar e checar a eficácia de um analgésico e a acompanhar a interferência da dor nas atividades cotidianas do paciente. Assim, uma avaliação compreensiva e fiel da dor é peça fundamental de qualquer programa de tratamento e manejo da dor.

\subsubsection{Modelo Neural de três entradas e Questionário de McGill de Dor}

Nas primeiras seções deste capítulo procurou-se mostrar com dados hipotéticos qual seria o comportamento desejado da rede neural a partir de uma combinação de dados na entrada. Esta seção mostrará uma outra forma de definir os dados de treinamento da rede com o auxílio do Questionário de McGill. Para isto, os dados fornecidos por pacientes que sofrem de um determinado tipo de dor podem ser utilizados para refinar o processo de treinamento da rede, uma vez que o desempenho e eficácia da rede no que se refere em classificar ou fornecer um sinal de dor está ligado ao que é submetido à mesma durante a fase de aprendizado.

Desta forma, os dados de treinamento da rede neural podem ser definidos a partir das informações coletadas pelo Questionário de McGill. Estas mesmas informações podem também vir a serem obtidas utilizando-se o Questionário de McGill na sua forma reduzida. Apesar do menor tempo gasto para se levantar os dados necessários com o uso do Questionário de McGill na forma reduzida, a principal desvantagem em se adotar tal formato nas avaliações é a de perder algumas informações relevantes tais como localização, duração 
da dor, sensibilidade, o que não ocorreria quando do uso do questionário no seu formato integral.

Uma forma de aproximar a saída da rede com valores que realmente possam ocorrer na prática, é utilizar como base, amostras de um grupo de pacientes que sofrem de um determinado tipo de dor, e que registraram tal relato, através do Questionário de McGill.

Em (MELZACK, 1975) foi realizado um estudo baseado nos dados do Questionário de McGill de 297 pacientes sofrendo de diferentes tipos de dor (artrite, câncer, dor de origem dermatológica, dor nas costas etc). A tabela 5.5 mostra resumidamente alguns dos resultados obtidos a partir deste estudo e que serão úteis na presente análise. Nesta tabela são mostrados os valores e as médias obtidas para os índices de mensuração e avaliação da dor para algumas síndromes examinadas. Os valores do Índice de Estimativa de Dor (PRI) para as quatro categorias - sensorial, afetiva, avaliativa e mista - revelam algumas diferenças interessantes entre as síndromes. Por exemplo, a dor devido ao câncer tem um valor alto na dimensão sensorial; além disso, seu efeito (que poderia ser alto por causa das sérias implicações da doença) não é maior que aquela referente à dor menstrual que não possui nenhuma implicação para a sobrevivência. 


\begin{tabular}{|c|c|c|c|c|}
\hline \multirow{2}{*}{$\begin{array}{c}\text { Síndrome de } \\
\text { dor }\end{array}$} & \multirow{2}{*}{$\begin{array}{c}\mathrm{N} \\
\text { (Número de } \\
\text { respostas) }\end{array}$} & \multirow{2}{*}{$\begin{array}{l}\text { Média } \\
\text { PPI }\end{array}$} & \multicolumn{2}{|c|}{ Média PRI (R) } \\
\hline & & & $\begin{array}{c}\mathrm{S} \\
\text { (Sensorial) }\end{array}$ & $\begin{array}{c}\text { A } \\
\text { (Afetivo) }\end{array}$ \\
\hline Menstrual & 25 & 2.4 & 12.6 & 2.4 \\
\hline Artrite & 19 & 1.9 & 10.3 & 2.5 \\
\hline Câncer & 16 & 2.8 & 17.3 & 2.3 \\
\hline Dental & 15 & 2.3 & 11.8 & 1.7 \\
\hline $\begin{array}{c}\text { Dor nas } \\
\text { costas }\end{array}$ & 14 & 2.6 & 14.0 & 3.5 \\
\hline
\end{tabular}

Tabela 5. 5 - Tabela contendo de forma resumida alguns resultados obtidos a partir de estudo utilizando o Questionário de McGill.

Fonte: (MELZACK, 1975).

No item de Índice de Estimativa de Dor (PRI), dois dos descritores utilizados são de dois tipos: (i) palavras que descrevem as qualidades sensoriais da experiência em termos de propriedades temporais, espaciais, térmicas e outras e (ii) palavras que descrevem qualidades afetivas como medo, tensão e propriedades individuais que são parte da experiência dolorosa (MELZACK, 1975).

Neste caso, todas as palavras que descrevem as qualidades sensoriais estão representadas no sinal transmitido pela fibra nociceptiva conforme a Teoria de Controle da Comporta (TURK; RUDY; SALOVEY, 1985). Desta forma, pode-se pressupor de que o máximo sinal transmitido pela fibra nervosa de pequeno diâmetro ocorrerá quando em cada subclasse for escolhido o descritor que represente a pior dor possível. De forma análoga, ocorre para a entrada cognitiva da rede, onde uma escolha no descritor que represente a pior dor possível espelha o indivíduo com um estado emocional bem debilitado. Além disso, considera-se que cada descritor tem o mesmo peso na somatória total na contribuição do resultado final, sendo o PPI uma estimativa da saída esperada da rede neural.

Esta análise inicial considera a entrada de dor e a entrada cognitiva da rede neural sendo que a participação da fibra larga, quando ela existe, pode ser considerada a partir dos 
conceitos empregados pela Teoria de Controle da Comporta de dor conforme visto anteriormente. Assim, usando como exemplo a artrite, tem-se que o valor representativo da classe sensorial é igual a 10.3 sendo que a maior pontuação possível para esta classe é 42 (considerando-se o peso de cada descritor). Como a rede neural aceita apenas valores entre $0 \mathrm{e}$ 1 é preciso normalizá-los. Uma simples regra que pode ser adotada é a de dividir o valor obtido pelo máximo. No caso da classe afetiva, o valor a ser considerado é igual a 2.5 sendo a maior pontuação possível igual a 14. Pode-se adotar uma simples equação para o tratamento deste tipo de dado:

$$
\text { valor_normalizado }=\frac{\text { valor_questionario }}{\text { maior_ } \text { pontuacao }_{\text {por }}} * 0.5+0.5
$$

Para a relação "valor_questionario/maior_pontuacao", o menor valor possível de ser obtido é 0 e o máximo, é 1 . Como no Questionário de McGill há apenas palavras que descrevem qualidades emocionais negativas é preciso utilizar a equação 5.1 anterior para que o valor de treinamento da rede se situe entre 0.5 e 1.0. Nesta aplicação em particular se adotará a premissa que o indivíduo irá variar apenas de um estado emocional normal para um estado emocional negativo.

\begin{tabular}{|l|l|l|l|}
\hline Informação & $\begin{array}{l}\text { Pontuação } \\
\text { Total } \\
\text { Questionário }\end{array}$ & $\begin{array}{l}\text { Dado de entrada da rede neural (valor } \\
\text { obtido/maior pontuação possível) }\end{array}$ \\
\hline Classe sensorial & 10.3 & $\sim 0.25$ \\
\hline Classe afetiva & 2.5 & $0.59(=0.18 * 0.5+0.5)$ \\
\hline
\end{tabular}

Tabela 5. 6 - Tabela normalização dados de entrada da rede.

Quanto ao dado de treinamento referente à saída da rede neural, pode-se utilizar o PPI de dor obtida, realizando-se apenas uma normalização conforme exemplificado na tabela 5.7. 
Neste caso, o valor esperado como saída da rede, segundo o exemplo acima, é aproximadamente igual a 0.4. Este é o valor esperado da saída da rede que pode ser utilizado como referência durante o processo de treinamento.

\begin{tabular}{|l|l|}
\hline $\begin{array}{l}\text { PPI } \\
\text { (Questionário) }\end{array}$ & $\begin{array}{l}\text { Saída esperada da rede (valores } \\
\text { aproximados) normalizada }\end{array}$ \\
\hline $0-1$ & $\sim 0.2$ \\
\hline $1-2$ & $\sim 0.4$ \\
\hline $2-3$ & $\sim 0.6$ \\
\hline $3-4$ & $\sim 0.8$ \\
\hline $4-5$ & $\sim 1.0$ \\
\hline
\end{tabular}

Tabela 5. 7 - Tabela de normalização dos dados de saída da rede.

Com os valores anteriores, criou-se um pequeno conjunto de treinamento e submeteuse à rede. Verificou-se que a rede convergiu (erro igual 0.0039) e apresentou resultados consistentes após um teste com os mesmos dados conforme mostrado na tabela 5.8 (os outros dados que fizeram parte deste conjunto foram deduzidos a partir dos conceitos já discutidos anteriormente).

\begin{tabular}{|c|c|c|c|c|c|}
\hline Caso & Fibras largas & Fibras finas & $\begin{array}{c}\text { Fator } \\
\text { cognitivo }\end{array}$ & $\begin{array}{c}\text { Saída } \\
\text { desejada }\end{array}$ & $\begin{array}{c}\text { Saída rede } \\
\text { obtida }\end{array}$ \\
\hline 1 & 0.00 & 0.25 & 0.59 & 0.40 & 0.4007 \\
\hline 2 & 0.00 & 0.00 & 0.00 & 0.00 & 0.0016 \\
\hline 3 & 0.00 & 0.00 & 0.50 & 0.00 & 0.0623 \\
\hline 4 & 1.00 & 0.00 & 0.50 & 0.00 & 0.0072 \\
\hline
\end{tabular}

Tabela 5. 8 - Resultados obtidos com dados do Questionário.

Assim, realizando-se um tratamento adequado dos dados submetidos à rede, pode-se conseqüentemente melhorar sua eficácia uma vez que as referências utilizadas no processo de aprendizado serão muito próximas do que ocorre na prática. Além disso, percebe-se que 
quanto maior o número de dados e amostras obtidas com o Questionário de McGill, maior a riqueza de informações que pode ser atribuída ao conjunto de dados de treinamento da rede.

\subsection{Conclusão e Perspectivas Futuras}

Os experimentos computacionais mostraram a viabilidade de se implementar um sistema neural artificial para simular a percepção humana do fenômeno da dor. Por outro lado, como a dor é uma experiência que contém elementos subjetivos, ou seja, pode variar de pessoa para pessoa, assim como os fatores que contribuem para a sua percepção (fatores emocionais, situacionais entre outros), há ainda outros elementos que precisam ser incorporados no modelo de forma a estender a sua descrição. Desta forma, uma possível melhoria a ser estudada e analisada com relação aos modelos apresentados aqui é considerar entradas adicionais na rede neural, que incorporariam outros componentes de controle dos mecanismos da dor. Neste sentido, poderiam ser incorporadas entradas referentes a outros elementos (além daqueles já mencionados no texto) como fatores químicos, uma vez que já foi identificado que a percepção e intensidade da dor é influenciada pela liberação de substâncias químicas no organismo. Além disso, é importante que seja dada uma atenção especial à tarefa de especificar e detalhar a entrada referente a influências cognitivas e/ou emocionais, de forma a analisar melhor a sua contribuição e facilitar o seu mapeamento para a coleta de dados para a rede. $\mathrm{O}$ aumento no número de entradas na rede potencialmente aumenta o número de casos de dor relatados que podem ser explicados pela modelagem de redes neurais artificiais. Por outro lado, aumentar o número de entradas na rede pode eventualmente prejudicar um discernimento dos fenômenos da dor, uma vez que cada entrada é considerada como um elemento independente das outras entradas. Porém, considerando 
ainda o caráter subjetivo do fenômeno da dor abordado, muitos elementos de influência (considerados como entradas da rede) podem estar inter-correlacionados.

Uma descrição completa do fenômeno da dor, através de um modelo teórico, ainda representa um desafio instransponível, principalmente pelo fato de não se conhecer esse fenômeno em sua plenitude devido a seu caráter fortemente subjetivo e variável. Por outro lado, novas pesquisas sobre os mecanismos fisiológicos, cerebrais envolvidos no processo de percepção de dor e sobre as técnicas utilizadas para sua avaliação e manejo serão úteis para o ajuste de conhecimentos para o mapeamento do fenômeno da dor, conforme o aspecto individual de cada pessoa e dos aspectos situacionais.

A evidência psicológica apóia fortemente a visão da dor como uma experiência perceptual cuja qualidade e intensidade são influenciados por um passado histórico do indivíduo, pelo significado que ele dá a situação de dor vivenciada e pelo seu estado mental no momento em questão. Esses três aspectos foram incorporados numa única entrada da rede, relacionada a fatores cognitivos. No entanto, essas três características podem ser tratadas de forma individual o que poderia fornecer uma topologia de rede diferente com mais entradas podendo ainda mais detalhar e ampliar o universo trabalhado.

Ao se conferir se a escala relacionada com a saída da rede do modelo de três entradas está realmente mensurando a intensidade da dor, não se pode comparar diretamente o escore de um paciente na escala com a sua dor real ou verdadeira, uma vez que há muitos outros fatores que possam estar envolvidos no processo de percepção de dor. No entanto, de imediato, pode-se utilizar as saídas da rede para verificar como os escores das escalas diferenciam indivíduos que têm dor daqueles que não a possuem. 
Por fim, um modelo que seja capaz de simular também cada uma das técnicas existentes para o alívio da dor, como a estimulação nervosa transcutânea elétrica (TENS) ou a acupuntura, poderia ter implicações significantes na maneira como a dor é tratada. Neste caso, podem-se desenvolver novos modelos ou até mesmo adaptar os modelos apresentados neste trabalho para o estudo de possíveis métodos de anestesia natural, ou seja, um tipo de anestesia que não envolveria o uso de drogas anestésicas, evitando que determinados pacientes tenham reações alérgicas ou colaterais quando houvesse a necessidade de amenizar intensas dores. 


\section{BIBLIOGRAFIA}

BALlONE, G. J. Eletroencefalograma, PET e SPECT, Tomografia Computadorizada, Ressonância Nuclear Magnética - in. PsiqWeb, Internet, disponível em www.psiqweb.med.br, revisto em 2005.

BARATTO, G. Classificador de Aromas com Redes Neurais Artificiais para um Nariz Eletrônico. 1997. 199 f. Tese de Doutorado - Engenharia Elétrica - Universidade de São Paulo, São Paulo, 1997.

BARTFAI, T. Telling the brain about pain. Nature, Califórnia-EUA, $\mathrm{n}^{\circ} 410,2001$, p. $425-$ 426.

BARNHILL, B. J.; HOLBERT, M. D.; JACKSON, N. M; ERICKSON, R. S. Using pressure to decrease the pain of intramuscular injections. Journal of Pain and Symptom Management, Portland-Oregon, Volume 12, Issue 1, Julho 1996, p. 52-58.

BRAGA, A. P.; PONCE, A. L. F. C; LUDERMIR, T. B. R. Redes Neurais Artificiais Teoria e Aplicações. Rio de Janeiro: Editora LTC, 2000. 262p.

BRITTON, N. F.; SKEVINGTON, S. M. A mathematical model of the gate control theory of pain. Journal of the Theoretical Biology, Bath, $\mathrm{n}^{\circ}$ 137, 1989, p. 91-105.

CARVAlHO, M. M. M. J; LODUCA, A.; PORTNOI, A. G.; PIMENTA C. A. M.; FIGUEIRÓ, J. A. B.; BORGES, L. M.; YENG, L. T.; TEIXEIRA, M. J.; KÓVACS, M. J.; MURTA, S. G.; LORDELlO, S. R. M; GUIMARÃES, S. S. DOR: Um estudo multidisciplinar. São Paulo: Summus Editorial, $2^{a}$ Edição 1999, 344p.

DEMUTH, H.; BEALE, M. Neural Network Toolbox for use with MATLAB - User's Guide. The Math Works Inc, 1994.

DESAI, N. S.; RUTHERFORD, L. C.; TURRIGIANO, G. G. Plasticity in the intrinsic excitability of cortical pyramidal neurons. Nature Neuroscience, Massachusetts, $\mathrm{n}^{\circ} 2,1999$, p. $515-520$.

ENCICLOPÉDIA MIRADOR INTERNACIONAL. São Paulo: Encyclopaedia Britannica do Brasil Publicações Ltda, 1987. 
HAERI, M.; ASEMANI, D.; GHARIBZADEH, SH. Modeling of Pain Using Artificial Neural Networks. Journal of Theoretical Biology, Tehran, $n^{\circ} 220,2003$, p. 277-284.

HALL, K. R. L.; STRIDE, E. The varying response to pain in psychiatric disorders: a study in abnormal psychology. British Journal Med. Psychol, nº 27, 1954, p.48-60.

HAYKIN, S. Redes Neurais - Princípios e Prática, Porto Alegre: Editora Bookman, $2^{\text {a }}$ Edição 1999, 900p.

HEATH, B.; AMARTEY, R. Pain Survey. British Pain Society, 2005, p.1-3.

IASP. Disponível em: <http://www.iasp-pain.org/>. Acesso em 09 de Janeiro de 2006.

KOVÁCS, Z. L. Redes Neurais Artificiais: Fundamentos e Aplicações. São Paulo: Editora Livraria da Física 2a Edição, 1996, 164 p.

KOVÁCS, Z. L. O Cérebro e a sua Mente: Uma Introdução à Neurociência Computacional. São Paulo: Edição Acadêmica, 1997. 214 p.

LOESCH, C.; SARI, S. T. Redes Neurais Artificiais: fundamentos e modelos. Blumenau: Editora da FURB, 1996, 166p.

LOPES, M. L. M.; LOTUFO, A. D. P.; MINUSSI, C. R. A Fast Electric Load Forecasting Using Adaptive Neural Networks. IEEE Bologna PowerTech Conference, Bologna, Junho 2003.

LOTUFO, A. D. P. Análise de sensibilidade por redes neurais para estudos da estabilidade transitória de sistemas elétricos de potência. 2004. 133 p. Tese de Doutorado - Engenharia Elétrica - UNESP, Ilha Solteira, agosto 2004.

MÁRQUEZ, J. O. Bases de Anatomia e Fisiopatologia. Dor Diagnóstico e Tratamento. São Paulo, V. 1, nº 01, Abril/Maio/Junho 2004, p. 1-10.

McCAUl, K. D.; MALOTT, J. M. Distraction and Coping With Pain. Psychological Bulletin. North Dakota, Vol. 95, n³ 3, 1984, p. 516-533. 
MELZACK, R. The McGill Pain Questionnaire: Major Properties and Scoring Methods. Pain. Amsterdam, 1, 1975, p. 277-299.

MELZACK, R. Pain: Past, Present and Future. Canadian Journal of Experimental Psychology. Montreal, 47:4, 1993, 47:4, p. 615-629.

MELZACK, R.; TORGERSON, W. S. On the language of pain. Anesthesiology. $\mathrm{N}^{\circ} 34.1971$. pp. $50-59$.

MELZACK, R.; WALL, P. D. Pain Mechanisms: A New Theory. Science. MIT, V. 150, $\mathrm{n}^{\circ}$ 3699, 1965, p. 971-979.

MELZACK, R.; WALL, P. D. The Challenge of Pain. Harmondsworth, Middlesex: Penguin Books, $2^{a}$ Edição 1982, 339p.

NATHAN, P. W.; RUDGE, P. Testing the gate-control theory of pain in man. Journal of Neurology, Neurosurgery and Psychiatry. Londres, V. 1, Issue 4, 1974, p. 1366-1372.

POSNER, M. I.; RAICHLE, M. E. Images of Mind. Nova York: Scientific American Library, 1994, p. 257.

RANG, H. P.; DALE, M. M.; RITTER, J. M.; MOORE, P. K. Farmacologia. São Paulo: Editora Elsevier, 2004, seção 4.

PELAÉZ, J. R.; FIALHO, A. R. S; PIQUEIRA, J. R. C. Plasticity in the Gate Mechanism of Pain: a computational model. EPUSP. São Paulo, 2005

PRINCE, K.; CAMPBELL, J.; PICTON, P.; TURNER, S. A Computational Model of Acute Pain. I. J. Of Simulation. Vol. 6, n 9, 2005, 10p.

SANTOS, V. P.; ROMERO, R. A. F. Utilização do Matlab para o desenvolvimento de Redes Neurais. São Carlos, Universidade de São Paulo - Instituto de Ciências Matemáticas de São Carlos e Departamento de Ciência da Computação e Estatística, Junho/2004.

SILVA, J. A.; RIBEIRO-FILHO, N. P. Avaliação e Mensuração de dor: Pesquisa, Teoria e Prática. Ribeirão Preto: FUNPEC Editora, $1^{\text {a }}$ Edição, 2006, 467p. 
STAMATIS, N.; PARTHIMOS, D.; GRIFFITH, T. M. Forecasting Chaotic Cardiovascular Time Series with an Adaptive Slope Multilayer Perceptron Neural Network. IEEE Transactions on Biomedical Engineering. Vol. 46, n 12 , 1999, p. 1441 - 1453.

TAFNER, M. A; XEREZ, M.; RODRIGUES FILHO, I.W. Redes Neurais Artificiais Introdução e Princípios de Neurocomputação. Blumenau: Editora EKO, 1995, 199 p.

TRIBIOLI, R. A. Análise Crítica Atual sobre a TENS envolvendo parâmetros de estimulação para o controle da dor. Ribeirão Preto, 2003. 61p. Dissertação (Mestrado) Escola de Engenharia de São Carlos/Faculdade de Medicina de Ribeirão Preto/Instituto de Química de São Carlos, Universidade de São Paulo.

TURK, D.C.; RUDY, T.E.; SALOVEY, P. The McGill Pain Questionnaire reconsidered: confirming the factor structure and examining appropriate uses. Pain. 21(4), 1985, p. $385-$ 397.

VESSEY, J. A.; CARLSON, K. L.; McGILL, J. Use of Distraction with Children During an Acute Pain Experience. Nursing Research. Vol. 43, n 6 , 1994, p. 369 - 372.

WALL, P. D. The Gate Control Theory of Pain Mechanisms - A re-examination and restatement. Brain. $\mathrm{n}^{\circ}$ 101. 1978, p. 1-18. 